RICARDO AUGUSTO DIAS

\title{
Caracterização Espacial da Brucelose Bovina no Estado de São Paulo
}

São Paulo 
RICARDO AUGUSTO DIAS

\section{Caracterização Espacial da Brucelose Bovina no Estado de São Paulo}

Tese apresentada ao Programa de Pós-graduação em Epidemiologia Experimental e Aplicada às Zoonoses da Faculdade de Medicina Veterinária e Zootecnia da Universidade de São Paulo para obtenção do título de Doutor em Medicina Veterinária

Departamento:

Medicina Veterinária Preventiva e Saúde Animal

Área de Concentração:

Epidemiologia Experimental e Aplicada às Zoonoses

Orientador:

Prof. Dr. Fernando Ferreira

São Paulo 
Autorizo a reprodução parcial ou total desta obra, para fins acadêmicos, desde que citada a fonte.

DADOS INTERNACIONAIS DE CATALOGAÇÃO NA PUBLICAÇÃO

(Biblioteca da Faculdade de Medicina Veterinária e Zootecnia da Universidade de São Paulo)

T-1401 Dias, Ricardo Augusto

FMVZ Caracterização espacial da brucelose bovina no Estado de São Paulo / Ricardo Augusto Dias. - São Paulo : R. A. Dias, 2004 $112 \mathrm{f}$. : il.

Tese (doutorado) - Universidade de São Paulo. Faculdade de Medicina Veterinária e Zootecnia. Departamento de Medicina Veterinária Preventiva e Saúde Animal, São Paulo, 2004.

Programa de Pós-graduação: Epidemiologia Experimental e Aplicada às Zoonoses.

Área de concentração: Epidemiologia Experimental e Aplicada às Zoonoses.

Orientador: Prof. Dr. Fernando Ferreira

1. Brucelose animal. 2. Epidemiologia (controle). 3. Bovinos. I. Título. 


\title{
PARECER DA COMISSÃO DE BIOÉTICA
}

\author{
UNIVERSIDADE DE SÃO PAULO \\ Faculdade de Medicina Veterinária e Zootecnia \\ Cidade Universitária "Armando de Salles Oliveira" \\ Comissão Bioética \\ CERTIFICADO
}

Certificamos que o Projeto intitulado "Caracterização espacial da brucelose bovina no Estado de São Paulo", protocolo n ${ }^{\circ} 321 / 2003$, sem utilização de animais, sob a responsabilidade do Prof. Dr. Fernando Ferreira, está de acordo com os princípios éticos de experimentação animal da Comissão de Bioética da Faculdade de Medicina Veterinária e Zootecnia da Universidade de São Paulo e foi aprovado "ad referendun".

(We certify that the Research "Spatial characterization of bovine brucelosis in São Paulo State, Brazil" protocol number 321/2003, under the responsibility of Prof. Dr. Fernando Ferreira, agree with Ethical Principles in Animal Research adopted by Biotic Commission of the Faculty of Veterinary Medicine and Zootechny of University of São Paulo and was approved "ad referendun").

São Paulo, 12 de junho de 2003

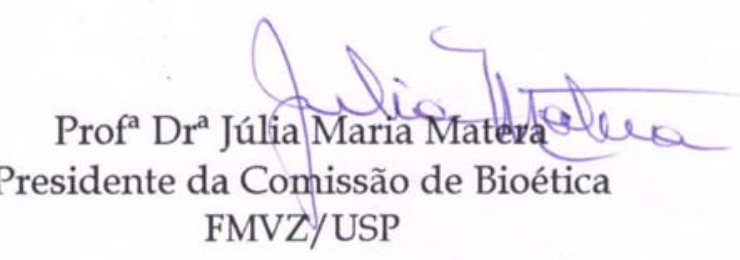




\section{FOLHA DE AVALIAÇÃo}

Nome do Autor: DIAS, Ricardo Augusto

Título: Caracterização Espacial da Brucelose Bovina no Estado de São Paulo

Tese apresentada ao Programa de Pós-graduação em Epidemiologia Experimental e Aplicada às Zoonoses da Faculdade de Medicina Veterinária e Zootecnia da Universidade de São Paulo para obtenção do título de Doutor em Medicina Veterinária

Data:

Banca Examinadora:

Prof. Dr.

Instituição:

Assinatura:

Julgamento:

Prof. Dr.

Instituição:

Assinatura:

Julgamento:

Prof. Dr.

Instituição:

Assinatura:

Julgamento:

Prof. Dr.

Instituição:

Assinatura:

Julgamento:

Prof. Dr.

Instituição:

Assinatura:

Julgamento: 
Dedico este trabalho àqueles que importam mais, momoi, papae, basito e nats. 


\section{AGRADECIMENTOS}

Ao Professor Doutor Fernando Ferreira, por sua paciência e disposição para acompanhar minha trajetória no LEB nestes cinco anos.

Ao Professor Doutor José Soares Ferreira Neto, por me ajudar na fase mais crítica do trabalho, que foi sua concepção, e também durante todo 0 seu desenvolvimento.

Ao Professor Doutor Marcos Amaku, por sua amizade e disposição em ajudar sempre que necessário.

Ao Professor Doutor Vitor Salvador Picão Gonçalves, por compartilhar seu conhecimento durante as oportunidades em que pudemos trabalhar juntos, 0 que foi de suma importância para 0 desenvolvimento deste trabalho.

Ao Professor Sílvio Arruda Vasconcellos, pelo auxílio prestado frente à Pós-graduação, por sua preocupação e incentivo.

À equipe do MAPA, especialmente à Vera Figueiredo, ao José Ricardo e ao Jorge Caetano, pela grata oportunidade de trabalharmos em conjunto e também pela amizade que pudemos formar.

À equipe da CDA, que foram os responsáveis pela principal fase deste projeto, a coleta dos dados. É impossível enumerar todos aqueles que colaboraram com 0 trabalho, porém algumas pessoas foram responsáveis diretas pela articulação desta parceria e acabaram tornando-se muito próximas, Zélia, Mônica Fagundes, Vera Bonafé e o Doutor Otto.

Aos amigos do LEB: Patrícia, Rodrigo, Juliana, Jucélia, Lorena, Suzana, Rita, Wilson, Cátia, Rísia, Cristiene, Cecília e a Alessandra.

Aos amigos do VPS, funcionários e docentes, principalmente àqueles que trabalharam em conjunto, tanto neste como em outros projetos: César (Pancho), Eugênia, Sérgio, Adriano, Simone Miyashiro, Maurício, Daniel, Sílvio, Paula Spinha, Paula (Larica), Flávia, Esther, e todos os outros.

Aos meus amigos Valéria Homem, Fábio Gregori, Marcos Bryan, Adriana Cortez, Jean Carlos e Fernanda Marvulo, que foram grandes incentivadores deste trabalho, de forma decisiva.

Ao pessoal do $C A B$, por me ajudarem nas horas em que eu precisei esfriar a cabeça, fazendo algo pelo qual acabei me apaixonando: 0 ciclismo.

À FAPESP, pelo apoio financeiro imprescindível. 


\section{RESUMO}

DIAS, R. A. Caracterização espacial da brucelose bovina no Estado de São Paulo. [Spatial characterization of bovine brucelosis in São Paulo State, Brazil]. 2004. $112 \mathrm{f}$. Tese (Doutorado em Medicina Veterinária) - Faculdade de Medicina Veterinária e Zootecnia, Universidade de São Paulo, São Paulo, 2004.

0 presente trabalho é resultante de uma parceria estabelecida entre o Ministério da Agricultura, Pecuária e Abastecimento (MAPA), a Coordenadoria de Defesa Agropecuária do Estado de São Paulo (CDA) e o Departamento de Medicina Veterinária Preventiva e Saúde Animal da Faculdade de Medicina Veterinária e Zootecnia da Universidade de São Paulo (VPS-FMVZ-USP). 0 Estado de São Paulo foi estratificado em sete circuitos produtores de bovinos e 150 rebanhos com atividade reprodutiva foram aleatóriamente selecionados em cada um deles. Em cada rebanho foi aplicado um questionário epidemiológico, foram aletoriamente coletadas amostras de soro de 10 ou 15 fêmeas com idade maior ou igual a 24 meses (em rebanhos com $<100$ fêmeas, e rebanhos $\geq 100$ fêmeas, respectivamente) e as coordenadas geográficas foram obtidas com um aparelho GPS. Os soros foram submetidos a um protocolo de testes em série, tendo 0 Rosa Bengala como método de triagem e a fixação de complemento como método confirmatório. A prevalência estimada de rebanhos com, ao menos, um animal soropositivo foi de $9,7 \%[7,8 \% ; 11,6 \%]$, enquanto que a prevalência estimada de animais soropositivos foi 3,8\% [0,7\%; 6,9\%], no Estado de São Paulo. Foi elaborado um mapa temático georreferenciado do Estado de São Paulo, no qual evidenciou-se a ausência de agrupamentos espaciais de rebanhos infectados. A análise também procurou medir o grau de associação das características de criação com a presença da doença, sendo que propriedades com 87 ou mais bovinos $(O R=2,25)$ e compra de reprodutores $(O R=1,56)$ foram as mais associadas. 0 modelo matemático proposto nesse trabalho mostrou que deverá ser intensificado o esforço para a vacinação de fêmeas e que, mesmo assim, os benefícios advindos da adoção desta medida, em termos de queda da 
prevalência da doença e diminuição do número de abortos, só se darão em prazos que podem alcançar décadas.

Palavras-chave: Brucelose animal. Epidemiologia (Controle). Bovinos. 


\begin{abstract}
DIAS, R. A. Spatial characterization of bovine brucelosis in São Paulo State, Brazil. [Caracterização espacial da brucelose bovina no Estado de São Paulo]. 2004. 112 f. Tese (Doutorado em Medicina Veterinária) - Faculdade de Medicina Veterinária e Zootecnia, Universidade de São Paulo, São Paulo, 2004.
\end{abstract}

The present work is the result of a partnership established by the Ministry of Agriculture, Livestock and Food Supply (MAPA), the Animal and Plant Health Service of the State of São Paulo (CDA) and the Department of Preventive Veterinary Medicine and Animal Health of the University of São Paulo (VPS-FMVZ-USP). The State of São Paulo was stratified in seven cattle production regions and 150 herds with reproductive activity were randomly sampled within each one. In each herd was applied an epidemiological questionnaire, 10 or 15 cows over 24 months of age (on herds with $<100$ cows, and herds $\geq 100$ cows, respectively) were bled at random and the geographical coordinates were recorded with a GPS. Sera were tested using a serial testing procedure with the Rose Bengal Test as the screening method and the Complement Fixation as the confirmatory method. The estimated prevalence of herds with at least one test-positive animal was $9.7 \%$ $[7.8 \% ; 11.6 \%]$, whereas the estimated prevalence of test-positive cattle was $3.8 \%[0.7 \% ; 6.9 \%]$. It was developed a georeferenced thematic map of the state of São Paulo, which revealed the absence of spatial clusters of infected herds. The analysis looked into the likely association of herd characteristics with the presence of the infection. The most associated characteristics were farms with more than 87 bovines (OR $=$ $2.25)$ and reproduction animals reposition $(O R=1.56)$. A mathematical model was proposed in the present work, in wich the female vaccination effort was proposed to be intensificated, but according to the same model, the benefits of this measure will only be noticed, in terms of brucellosis prevalence and number of abortions decrease, in a matter of decades.

Key words: Animal brucellosis. Epidemiology (Control). Bovine. 


\section{LISTA DE QUADROS}

Quadro 1 - Distribuição do número de propridades com atividade reprodutiva e fêmeas bovinas com idade igual ou superior a 24 meses amostradas, e respectivos tamanhos de amostra, por circuito produtor e para a totalidade do Estado de São Paulo - São Paulo - 2004 


\section{LISTA DE TABELAS}

Tabela 1 - Prevalência aparente de focos de brucelose bovina no Estado de São Paulo - São Paulo - 2004

Tabela 2 - Prevalência aparente de fêmeas com idade superior a 24 meses soropositivas para brucelose bovina no Estado de São Paulo - São Paulo - 2004

Tabela 3 - Prevalência aparente de focos de brucelose bovina estratificada por tipo de exploração - São Paulo - 2004

Tabela 4 - Distribuição dos tipos de exploração nas propriedades, por circuitos produtores e no Estado de

São Paulo - São Paulo - 2004

Tabela 5 - Distribuição dos tipos de criação nas propriedades, por circuitos produtores e no Estado de São

Paulo - São Paulo - 2004 .46

Tabela 6 - Distribuição da frequiência de ordenha nas propriedades, por circuitos produtores e no Estado de

São Paulo - São Paulo - 2004 .46

Tabela 7 - Distribuição dos tipos de ordenha nas propriedades, por circuitos produtores e no Estado de São

Paulo - São Paulo - 2004 .46

Tabela 8 - Distribuição dos tipos de protocolo reprodutivo nas propriedades, por circuitos produtores e no

Estado de São Paulo - São Paulo - 2004

Tabela 9 - Distribuição das raças de bovinos nas propriedades, por circuitos produtores e no Estado de São

Paulo - São Paulo - 2004

Tabela 10 - Distribuição da ocorrência de abortos (sem causa comprovada) de outubro de 2000 a dezembro de 2001 nas propriedades, por circuitos produtores e no Estado de São Paulo - São Paulo 2004 .

Tabela 11 - Distribuição dos tipos de manejo de material abortado nas propriedades, por circuitos produtores e no Estado de São Paulo - São Paulo - 2004

Tabela 12 - Distribuição da utilização de testes diagnósticos para detecção de brucelose nas propriedades, por circuitos produtores e no Estado de São Paulo - São Paulo - 2004

Tabela 13 - Distribuição dos tipos de reposição de bovinos nas propriedades, por circuitos produtores e no Estado de São Paulo - São Paulo - 2004

Tabela 14 - Distribuição da ocorrência de venda de reprodutores nas propriedades, por circuitos produtores e no Estado de São Paulo - São Paulo - 2004. 
Tabela 15 - Distribuição da prática de vacinação contra brucelose nas propriedades, por circuitos

produtores e no Estado de São Paulo - São Paulo - 2004.

Tabela 16 - Distribuição da prática de aluguel de pastos nas propriedades, por circuitos produtores e no

Estado de São Paulo - São Paulo - 2004

Tabela 17 - Distribuição da presença de pastos comuns com outras propriedades, por circuitos produtores e

no Estado de São Paulo - São Paulo - 2004

Tabela 18 - Distribuição da ocorrência de áreas alagadiças nas propriedades, por circuitos produtores e no

Estado de São Paulo - São Paulo - 2004

Tabela 19 - Distribuição da presença de piquete de parição nas propriedades, por circuitos produtores e no

Estado de São Paulo - São Paulo - 2004 57

Tabela 20 - Distribuição da presença de assistência veterinária nas propriedades, por circuitos produtores e no Estado de São Paulo - São Paulo - 2004

Tabela 21 - Fatores de risco para brucelose bovina nas propriedades com atividade reprodutiva no Estado de São Paulo - São Paulo - 2004

Tabela 22 - Fator protetor para brucelose bovina nas propriedades com atividade reprodutiva no Circuito

Produtor 1 - São Paulo - 2004

Tabela 23 - Fator de risco para brucelose bovina nas propriedades com atividade reprodutiva no Circuito

Produtor 4-São Paulo - 2004

Tabela 24 - Fatores de risco para brucelose bovina nas propriedades com atividade reprodutiva no Circuito

Produtor 5 - São Paulo - 2004 81

Tabela 25 - Fatores de risco para brucelose bovina nas propriedades com atividade reprodutiva no Circuito

Produtor 6 - São Paulo - 2004

Tabela 26 - Fator de risco para brucelose bovina nas propriedades com atividade reprodutiva no Circuito

Produtor 7 - São Paulo - 2004

Tabela 27 - Fator protetor para brucelose bovina nas propriedades especializadas na exploração pecuária de corte no Estado de São Paulo - São Paulo - 2004

Tabela 28 - Fator protetor para brucelose bovina nas propriedades especializadas na exploração pecuária de corte no Circuito Produtor 1 - São Paulo - 2004

Tabela 29 - Fator protetor para brucelose bovina nas propriedades especializadas na exploração pecuária de corte no Circuito Produtor 5 - São Paulo - 2004 
Tabela 30 - Fator de risco para brucelose bovina nas propriedades especializadas na exploração pecuária mista no Estado de São Paulo - São Paulo - 2004

Tabela 31 - Fator de risco para brucelose bovina nas propriedades especializadas na exploração pecuária mista no Circuito Produtor 1 - São Paulo - 2004 .86

Tabela 32 - Fator protetor para brucelose bovina nas propriedades especializadas na exploração pecuária mista no Circuito Produtor 2 - São Paulo - 2004

Tabela 33 - Fator de risco para brucelose bovina nas propriedades especializadas na exploração pecuária de leite no Estado de São Paulo - São Paulo - 2004.

Tabela 34 - Fator de risco para brucelose bovina nas propriedades especializadas na exploração pecuária de leite no Circuito Produtor 3 - São Paulo - 2004

Tabela 35 - Fator de risco para brucelose bovina nas propriedades especializadas na exploração pecuária de leite no Circuito Produtor 5 - São Paulo - 2004

Tabela 36 - Fator protetor para brucelose bovina nas propriedades especializadas na exploração pecuária de leite no Circuito Produtor 7 - São Paulo - 2004 


\section{LISTA DE MAPAS}

Mapa 1 - Distribuição dos tipos de exploração nas propriedades amostradas .........................................62

Mapa 2 - Distribuição dos tipos de criação nas propriedades amostradas .................................................63

Mapa 3 - Distribuição dos protocolos reprodutivos nas propriedades amostradas .....................................64

Mapa 4 - Número de vacas em lactação nas propriedades amostradas ....................................................65

Mapa 5 - Produção de leite (em litros) nas propriedades amostradas ........................................................66

Mapa 6 - Número de vacas com idade superior a 24 meses nas propriedades amostradas .........................67

Mapa 7 - Tamanho total do rebanho bovino nas propriedades amostradas ...............................................68

Mapa 8 - Distribuição dos destinos de material de aborto nas propriedades amostradas ..........................69

Mapa 9 - Compra de reprodutores nas propriedades amostradas...........................................................70

Mapa 10 - Vacinação contra brucelose bovina nas propriedades amostradas ...........................................71

Mapa 11 - Aluguel de pastos nas propriedades amostradas .....................................................................72

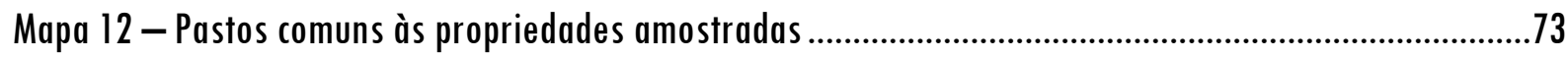

Mapa 13 - Piquete de parição nas propriedades amostradas ...................................................................74

Mapa 14 - Assistência veterinária nas propriedades amostradas ..........................................................75

Mapa 15 - Brucelose bovina nas propriedades amostradas .....................................................................76 


\section{LISTA DE FIGURAS}

Figura 1 - Diagrama de blocos mostrando a dinâmica da brucelose em populações bovinas de exploração leiteira.

Figura 2 - Número de vacas em lactação nas propriedades, por circuito produtor. Os símbolos sobre os diagramas de blocos representam valores aberrantes.

Figura 3 - Produção de leite (em litros) nas propriedades, por circuito produtor. Os símbolos sobre os diagramas de blocos representam valores aberrantes.

Figura 4 - Produtividade de leite (em litros/vaca em lactação) das propriedades, por circuito produtor. Os símbolos sobre os diagramas de blocos representam valores aberrantes

Figura 5 - Estudo das faixas etárias de machos bovinos nas propriedades, por circuito produtor. Os símbolos sobre os diagramas de blocos representam valores aberrantes

Figura 6 - Estudo das faixas etárias de fêmeas bovinas nas propriedades, por circuito produtor. Os símbolos sobre os diagramas de blocos representam valores aberrantes

Figura 7 - Número total de bovinos nas propriedades, por circuito produtor. Os símbolos sobre os diagramas de blocos representam valores aberrantes.

Figura 8 - Frequiência de ocorrência de outras espécies domésticas, que não a bovina, nas propriedades, por circuito produtor. As linhas representam os intervalos de confiança.

Figura 9 - Frequiência de ocorrência de espécies silvestres nas propriedades, por circuito produtor. As linhas representam os intervalos de confiança.

Figura 10 - Distribuição de destino de reprodutores para abate nas propriedades, por circuito produtor. As linhas representam os intervalos de confiança.

Figura 11 - Distribuição do tipo de entrega de leite das propriedades, por circuito produtor. As linhas representam os intervalos de confiança....

Figura 12 - Distribuição dos fatores relacionados à tecnificação da produção leiteira nas propriedades, por circuito produtor. As linhas representam os intervalos de confiança.

Figura 13 - Distribuição das fêmeas bovinas com idade superior a 24 meses segundo 0 tipo de exploração, por circuito produtor. Os símbolos sobre os diagramas de blocos representam valores aberrantes. 
Figura 14 - Distribuição do total de bovinos segundo o tipo de exploração, por circuito produtor. Os símbolos sobre os diagramas de blocos representam valores aberrantes.

Figura 15 - Distribuição das fêmeas com idade superior a 24 meses segundo 0 tipo de criação, por circuito produtor. 0 s símbolos sobre os diagramas de blocos representam valores aberrantes.

Figura 16 - Diferença entre os valores da função Kpara propriedades foco e não foco em função da distância em metros.

Figura 17 - Proporção de fêmeas positivas para brucelose, segundo coberturas vacinais de 95\%,90\%, $80 \%, 70 \%, 60 \%, 50 \%, 40 \%, 30 \%$ e $3 \%$, da esquerda para a direita.

Figura 18 - Proporção de abortos por brucelose, segundo coberturas vacinais de 95\%, 90\%, 80\%, 70\%, $60 \%, 50 \%, 40 \%, 30 \%$ e $3 \%$, da esquerda para a direita. 


\section{LISTA DE ABREVIATURAS E SIGLAS}

\begin{tabular}{|c|c|}
\hline$\%$ & Proporção em porcentagem \\
\hline CDA & Coordenadoria de Defesa Agropecuária do Estado de São Paulo \\
\hline$C D C$ & Center for Diseases Control and Prevention \\
\hline EDA & Escritório de Defesa Agropecuária (unidade de atenção da (DA) \\
\hline FMVZ-USP & Faculdade de Medicina Veterinária e Zootecnia da Universidade de São Paulo \\
\hline GPS & Sistema de Posicionamento Global, do inglês Global Positioning System \\
\hline GTA & Guia de trânsito animal \\
\hline IB & Instituto Biológico de São Paulo \\
\hline IC & Intervalo de confiança ( $95 \%$ de confiança) \\
\hline LUPA & Levantamento de Unidades de Produção Agrícola \\
\hline MAPA & Ministério da Agricultura, Pecuária e Abastecimento \\
\hline ME & Teste do mecaptoetanol \\
\hline $\mathrm{n}$ & Número de ocorrências \\
\hline OIE & Office International de Epizooties \\
\hline OR & Odds ratio \\
\hline PNCETB & Programa Nacional de Controle e Erradicação da Tuberculose e Brucelose Bovina \\
\hline RFC & Reação de fixação do complemento \\
\hline SP & Estado de São Paulo \\
\hline TRB & Teste Rosa Bengala (ou teste do antígeno acidificado tamponado) \\
\hline VPS & Departamento de Medicina Veterinária Preventiva e Saúde Animal \\
\hline
\end{tabular}




\section{SUMÁRIO}

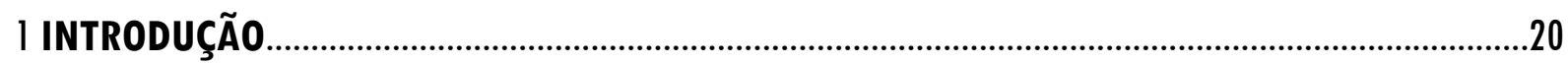

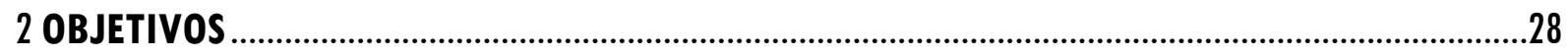

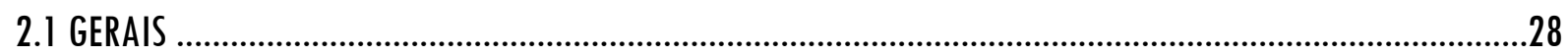

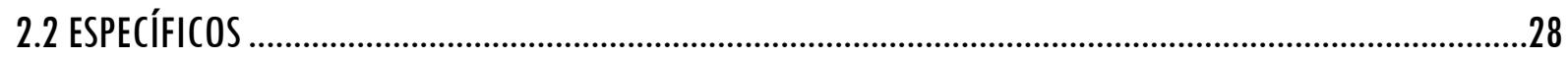

3 MATERIAL E MÉTODO ………………………………………………………………………29

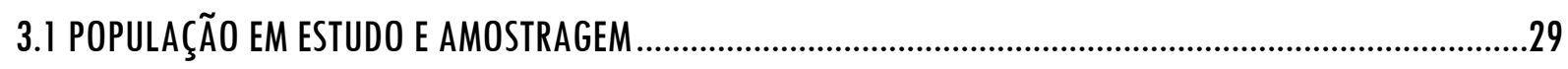

3.2 CONSTRUÇÃO DE MAPAS GEORREFERENCIADOS ............................................................................3

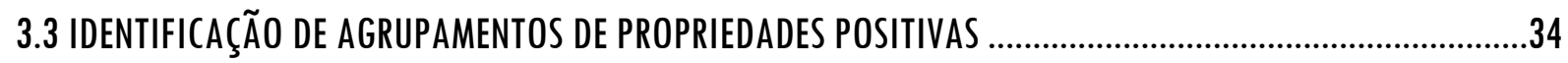

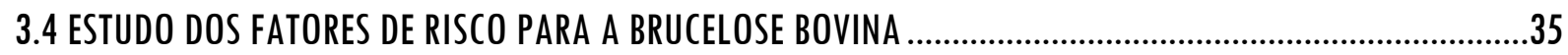

3.5 SIMULAÇÃO DE MEDIDAS DE CONTROLE DA BRUCELOSE BOVINA PROPOSTAS NO PNCETB ATRAVÉS DE

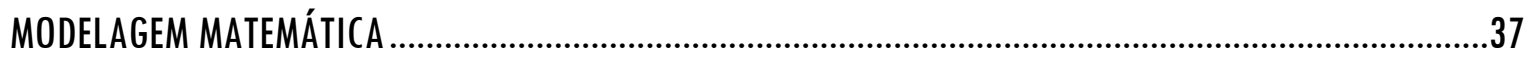

4 RESULTADOS

4.1 ESTUDO DE PREVALÊNCIAS ............................................................................................................

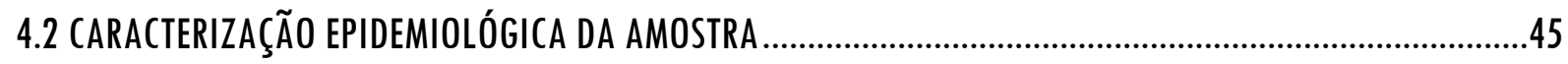

4.3 LOCALIZAÇÃO ESPACIAL DAS PROPRIEDADES VISITADAS E IDENTIFICAÇÃO DOS AGRUPAMENTOS DE

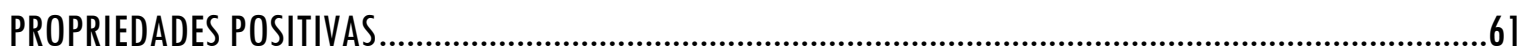

4.4 ESTUDO DOS FATORES DE RISCO PARA A BRUCELOSE BOVINA ..............................................................7

4.4.1 Estudo dos fatores de risco no âmbito estadual.................................................................................79

4.4.2 Estudo dos fatores de risco em propriedades com exploração pecuária de corte ..................................82

4.4.3 Estudo dos fatores de risco em propriedades com exploração pecuária mista .......................................85

4.4.4 Estudo dos fatores de risco em propriedades com exploração pecuária de leite ....................................87

4.5 SIMULAÇÃO DE MEDIDAS DE CONTROLE DA BRUCELOSE BOVINA PROPOSTAS NO PNCETB ATRAVÉS DE

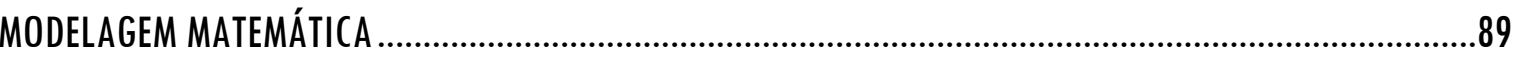

5 DISCUSSÃ 0

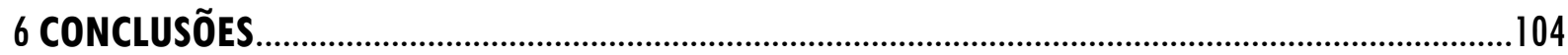

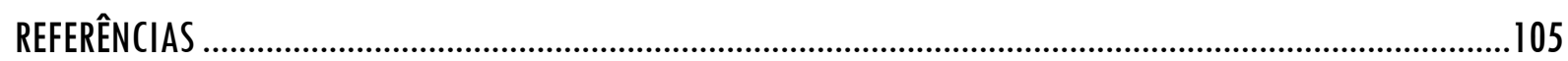

ANEXO A — QUESTIONÁRIO EPIDEMIOLÓGICO APLICADO NAS PROPRIEDADES AMOSTRADAS ........................111 


\section{INTRODUÇão}

A descrição documentada mais antiga da brucelose data de 1859, feita por Martson (VASSALO, 1992' apud NICOLETTI, 2002). Anteriormente, Hipócrates já havia citado a existência de uma febre endêmica do mediterrâneo semelhante à brucelose (BEER, 1988). Outros registros são hoje creditados à doença, principalmente aqueles ligados à afecção que acometeu os soldados e marinheiros durante a Guerra da Criméia, entre 1853 e 1856. A brucelose era chamada de febre mediterrânea, e suas complicações, principalmente o reumatismo, invalidaram muitos marinheiros da Marinha Real Britânica (WYATT, 1999² apud NICOLETTI, 2002). Por esse motivo, o capitão David Bruce foi enviado à ilha de Malta, para pesquisar a doença, em 1884, tendo isolado um microorganismo, descrito como Micrococus melitensis, em 1887, em seres humanos. 0 pesquisador percebeu que os pacientes do hospital local recebiam leite de cabra cru como tratamento para diversas doenças. Acreditava-se que estes animais não adoreciam, mesmo tendo sido inoculadas com culturas do microorganismo estudado. Um colaborador de Bruce, Themistocles Zammit, um médico maltês, testou o sangue das cabras e concluiu que $50 \%$ continham aglutininas, o que gerou muita polêmica sobre seu papel na disseminação da doença, pois acreditava-se que transmissão era dada por vetores (NICOLETTI, 2002). Em 1895, o professor Benhard Bang, um patologista veterinário dinamarquês, descreveu um novo agente em bovinos, chamando-o de Bacillus abortus (NICOLETTI, 2002). Em 1920, este microorganismo foi nomeado Brucella abortus, em homenagem ao capitão Bruce, quando Mayer e Shaw propuseram a criação do gênero Brucella (BEER, 1988). Finalmente em 1905, a comissão da febre mediterrânea sugeriu que as cabras tinham papel importante na transmissão. Assim, em 1906, o leite de cabra foi banido na Marinha Real Britânica, acabando com o problema, porém a controvérsia persistiu até a

\footnotetext{
' VASSALO, D. J. The corps disease: brucellosis and its historical association with the Royal Army Medical Corps. J. R. Army Med. Corps, v. 138, p. 148-150, 1992.

${ }^{2}$ WYATT, H. V. Royal Navy surgeons and the transmition of brucellosis by goats' milk. R. Naval Med. Serv., v. 85, p. 112 $117,1999$.
} 
década de 1930, quando o papel zoonótico foi elucidado e alguns países começaram programas de controle. Em 1914, um microorganismo que causava aborto em suínos foi isolado e nomeado Brucella suis, por Taum (NICOLETTI, 2002). 0 primeiro caso de brucelose no Brasil foi detectado em 1913, por Gonçalves Carneiro, em humano (VERONEZI, 1976).

A brucelose bovina é uma zoonose bacteriana de caráter crônico, que causa perdas econômicas à exploração pecuária de corte e leite. 0 principal agente etiológico é a Brucella abortus, sendo o biotipo 10 mais comum (ACHA; SZYFRES, 1986). A infecção de bovinos por Brucella melitensis é menos freqüente e, raramente é dada pela Brucella suis(PAULIN; FERREIRA NETO, 2003).

É uma doença que consta da lista $B$ da OIE, ou seja, uma doença transmissível que pode ser considerada de importância sócio-econômica e de saúde pública e que pode ter impacto significativo no comércio de animais e subprodutos (0IE, 2003). A brucelose bovina está amplamente distribuída mundialmente, mas concentra-se especialmente nos países subdesenvolvidos (PAULIN; FERREIRA NETO, 2003). É frequiente a forma endêmica, com aparecimento estacionário e simultâneo em zonas amplas, ligadas por relações econômicas (BEER, 1988).

Nos bovinos, o principal sinal clínico é o aborto ou expulsão prematura dos fetos. Em geral, o aborto ocorre na segunda metade da gestação, podendo haver retenção placentária seguida de metrite, podendo causar infertilidade permanente. Pode haver também o nascimento a termo de bezerros fracos ou mortos. Tanto machos como fêmeas são susceptíveis à doença, porém as fêmeas gestantes são mais sensíveis e permanecem cronicamente infectadas devido à permanência das brucelas nos linfonodos e no útero (PAULIN e FERREIRA NETO, 2003). Esta fêmea tem papel central na disseminação da doença, através dos produtos do abortamento. Fêmeas não gestantes e infetadas também podem tornar-se portadoras assintomáticas e disseminar a doença através do leite. Os bezerros que ingerem este leite podem albergar a brucela nos linfonodos do trato gastro-intestinal e excretá-las nas fezes. Contudo, de seis a oito semanas após 0 
desmame, tornam-se livres, pois bezerros até seis meses de idade são pouco susceptíveis à infecção. Na maturidade sexual, tornam-se novamente susceptíveis (ACHA; SZYFRES, 1986). Touros também podem disseminar a brucelose através do sêmem, o que não ocorre com animais castrados (PAULIN; FERREIRA NETO, 2003). A inseminação artificial, utilizando sêmem de touros infectados, constitui um eficiente modo de transmissão da brucelose, pois através deste protocolo reprodutivo, o sêmem é depositado no interior do útero da vaca receptora, não sofrendo a ação de mecanismos de defesa natural existentes na vagina (VASCONCELLOS; ITO; CÔRTES, 1987). Por este motivo, a monta natural não constitui uma via eficiente de transmissão da doença (PAULIN; FERREIRA NETO, 2003). Machos jovens ou castrados não são fontes de infeç̧ão para bovinos adultos, porém são importantes na transmissão da doença para 0 homem durante 0 abate (BEER, 1988).

0 produto do aborto é o principal fator de contaminação ambiental por brucelas. Em menor grau, pode contribuir para a contaminação do campo o material fecal de bezerros que se alimentam de leite contaminado, uma vez que nem todas as brucelas são destruídas no trato digestivo. A porta de entrada mais freqüente é o trato gastro-intestinal, pela ingestão de pasto, forragens e água contaminados. Além disso, as vacas costumam lamber membranas fetais, fetos e bezerros recém-nascidos, que constituem uma importante fonte de infecção. 0 hábito das vacas lamberem os órgãos genitais de suas companheiras também contribui para a transmissão da doença. Além disso, pode ocorrer também a transmissão congênita (ACHA; SZYFRES, 1986), sendo que a soroconversão do animal que é infectado na fase de vida intrauterina ocorre na metade da primeira gestação. De 2,5 a $9 \%$ desses animais se tornam portadores latentes (BISHOP; BOSMAN; HERR, 1994). Nestes animais, a vacinação é ineficaz (TIMONEY et al., 1988), o que constitui um dos principais problemas no controle da doença quando a prevalência do rebanho é baixa.

É difícil estimar 0 período de incubação, mesmo em infecções experimentais, por ser difícil a determinação do momento da infecção. No entanto, determinou-se que o período de incubação é variável e 
inversamente proporcional ao desenvolvimento do feto. A aparição dos anticorpos específicos ocorre em duas semanas, podendo levar meses (ACHA; SZYFRES, 1986).

Apesar da Brucella abortus ter como hospedeiro preferencial o bovino, outros animais podem se infectar por este patógeno, podendo transmití-lo novamente para os bovinos. Os eqüinos, apesar de serem susceptíveis, são considerados hospedeiros terminais (LYRA, 1984; PAULIN; FERREIRA NETO, 2003; VASCONCELLOS; ITO; CÔRTES, 1987). Os suínos são peferencialmente acometidos pela Brucella suis, porém podem ser acometidos pela Brucella abortus (VASCONCELLOS; ITO; CÔRTES, 1987). Nestes, a infecção por Brucella abortus é transitória, mas pode constituir uma importante fonte de infecção para os bovinos. Os bovinos, por sua vez, raramente se infectam com a Brucella suis, sendo que essa possibilidade está ligada ao hábito de compartilhar pastagens e instalações com os suínos (PAULIN; FEREIRA NETO, 2003). Os cães não são acometidos pela Brucella abortus, porém são importantes carreadores dos restos de aborto, até mesmo entre propriedades (VASCONCELLOS; ITO; CÔRTES, 1987).

0 contato entre rebanhos, na forma de pastos comuns e existência de rios e charcos entre as propriedades pode aumentar significantemente a ocorrência da brucelose (SALMAN; MEYER; HIRD, 1984). Além disso, a introdução de animais, principalmente aqueles provenientes de descarte, também aumenta 0 risco de introdução da doença nos rebanhos (CRAWFORD; HUBER; ADAMS, 1990). Por outro lado, a existência de um local específico para parição e para o período pós-parto é uma prática importante nas propriedades criadoras, para a redução da ocorrência de brucelose, uma vez que, após o início da adoção desta medida, os níveis de contaminação das pastagens e das instalações caem após um ano (BEER, 1988).

Os reservatórios naturais, principalmente ungulados silvestres, atuam como mantenedores da Brucella sp. no ambiente não modificado pelo homem (PAULIN; FERREIRA NETO, 2003). No Brasil, o agente foi isolado em capivaras (Hidrochoerus hydrochaeris) e queixadas (Tayassu tajacu) no pantanal matogrossense (ITO et al., 1998). Em outros países, o agente foi isolado em uma grande variedade de espécies de 
mamíferos, inclusive marinhos (GODFROID, 2002). Nos países onde foram implantados programas de controle e erradicação da brucelose, foi dada atenção aos reservatórios silvestres somente quando a erradicação da doença nos animais domésticos estava próxima de ser alcançada (GODFROID, 2002).

Antes da adoção da pasteurização do leite, a principal via de transmissão da brucelose para o homem era dada pelo consumo de leite in natura e derivados, provenientes de animais doentes. 0 processo perpetuava-se pelo fato de não haver alteração nas glândulas mamárias e no leite de vacas doentes (CORRÊA, 1975).

No homem, o período de incubação dura de uma a três semanas, podendo prolongar-se por meses. Trata-se de uma doença septicêmica de início repentino ou insidioso, com febre contínua, intermitente ou irregular. A forma aguda consiste de calafrios, suores profusos e febre. São sintomas comuns: insônia, impotência sexual, constipação, anorexia, cefaléia, artralgias e dores generalizadas. Os impactos sobre 0 sistema nervoso se traduzem em irritação, nervosismo e depressão. As brucelas localizam-se intracelularmente nos tecidos do sistema reticulo-endotelial e as reações tissulares são do tipo granulomatosa. Existe terapêutica satisfatória, porém podem ocorrer complicações tais como encefalite, meningite, neurite, espondilite, artrite supurativa e endocardite. A forma crônica tem difícil diagnóstico. Em áreas onde a brucelose é enzooótica, em especial a bovina, há muitas infecções que transcorrem de modo assintomático (ACHA; SZYFRES, 1986). Atualmente, a transmissão da brucelose para o homem se dá principalmente através de contato direto com animais infectados. Verifica-se também a transmissão por aerossóis. Porém, a importância do modo de transmissão e das portas de entrada do agente etiológico varia com a área geográfica, os reservatórios animais e com os grupos ocupacionais expostos ao risco, tais como veterinários, trabalhadores de fazendas e magarefes (ACHA; SZYFRES, 1986). 0 homem também é considerado um hospedeiro terminal da doença, sendo que as transmissões homem-homem e homemanimal são raras e contestáveis (LYRA, 1984). 
Os prejuízos ocasionados pela brucelose estão relacionados à diminuição da produção de leite e carne no rebanho acometido, além da diminuição do valor dos animais e dos subprodutos provenientes de zonas endêmicas, da perda de mercados potenciais e dos custos provenientes dos serviços médicos e do afastamento de humanos da função produtiva (GARCIA-CARRILO, 1987). Estes custos são sempre superiores ao custo do controle da doença em si. No Canadá, estimou-se um ganho de 5 dólares para cada dólar invesido no programa de controle, em 10 anos (GARCIA-CARRIL0, 1987). Estima-se que a infecção ocasione perdas de 20 a 25\% na produção de leite, devido à interrupção da lactação pelo abortamento. Em vacas inseminadas artificialmente com sêmen infectado, pode haver repetição de cio (ACHA; SZYFRES, 1986). Além disso, observa-se perdas de 10 a 15\% na produção de carne, 15\% de perda de bezerros devido a abortamentos, aumento de $30 \%$ da necessidade de reposição de animais, aumento de intervalo de partos de 11,5 para 20 meses e perda de uma em cada cinco vacas que abortam por esterilidade (FARIA, 1984).

Não há estimativas atualizadas das perdas devidas à brucelose bovina no Brasil, porém em 1982, num estudo da Secretaria de Defesa Animal do MAPA, estimou que o país havia perdido, no mínimo, 30 milhões de dólares americanos (OIE, 1987). Na mesma época, Faria (1984) estimou perdas na América Latina da ordem de 600 a 700 milhões de dólares americanos.

A brucelose bovina grassa em todo o território nacional, porém sua prevalência e distribuição regional não estão caracterizadas. Sabe-se que a brucelose atinge tanto rebanhos destinados a corte quanto à exploração leiteira de bovinos ou bubalinos. 0 último levantamento da situação da brucelose bovina em nível nacional foi realizado em 1975, sendo que a estimativa da porcentagem de animais soropositivos foi de 4,0\% na região Sul; 7,5\% na região Sudeste; $6,8 \%$ na região Centro-0este; $2,5 \%$ na região Nordeste e 4,1\% na região Norte. No Estado de São Paulo, a prevalência da brucelose foi estimada em 6,8\% (MAPA, 2001 a). Posteriormente, outros estudos foram realizados nos Estados de Santa Catarina, Rio Grande do Sul, Paraná, Mato Grosso do Sul e Minas Gerais (MAPA, 2001a). Em 1997, data do último boletim oficial 
brasileiro, a frequiência da doença foi estimada em 1,66\%, em bovinos do Estado de São Paulo (MAPA, 2000a). No Brasil, estimou-se esta frequiência em 3,47\% em 1997, não observando-se tendência de queda desde 1987 (MAPA, 2000a). Não há estudos de prevalência de propriedades positivas (focos), em âmbito estadual ou nacional até o momento.

Os prejuízos causados pela brucelose e a possibilidade desta ser controlada ou até mesmo erradicada justificou a adoção de programas nacionais ao redor do mundo. Alguns programas nacionais bem estruturados proporcionaram a erradicação da brucelose, como é o caso do Canadá, Austrália e Nova Zelândia (PAULIN; FERREIRA NETO, 2003).

No Brasil, o controle da brucelose era regulamentado pela Portaria 23 de 1976, porém sem atingir a eficácia desejada, pela ausência de um programa estruturado. Apesar da desarticulação nacional, alguns Estados, como o Rio Grande do Sul e Minas Gerais iniciaram programas massais de vacinação do rebanho bovino, em 1965 e 1994, respectivamente (POESTER; GONÇALVES; LAGE, 2002).

Em janeiro de 2001, com a publicação da Instrução Normativa número 2 (MAPA, 2001b), foi instituído 0 Programa Nacional de Controle e Erradicação da Brucelose e Tuberculose (PNCETB), através da aprovação do Regulamento Técnico do PNCETB (MAPA, 200lb). Os objetivos do programa são: baixar a prevalência e a incidência da brucelose e da tuberculose bovina e criar um número significativo de propriedades certificadas que oferecem produtos que proporcionem baixo risco sanitário (MAPA, 2001b). Além da certificação de propriedades livres e monitoradas, de adesão voluntária, também serão aplicadas medidas compulsórias, como a vacinação de bezerras de três a oito meses de idade com a vacina B19 e controle de trânsito de reprodutores (MAPA, 2001b).

Deve-se levar em consideração que os custos da implantação de um programa no Brasil são elevados. Assim, o conhecimento da situação epidemiológica da doença é de extrema importância quando se pretende implementar medidas de controle e erradicação, por duas razões principais: (1) permite escolher as 
melhores estratégias, pois estas podem diferir dependendo da frequiência e do padrão de distribuição da doença; (2) o conhecimento da situação inicial permite acompanhar o andamento do programa e julgar, racionalmente, a necessidade de promover correções, evitando o desperdício de tempo e recursos.

A prevalência da brucelose bovina no Estado de São Paulo foi determinada através de um estudo amostral de propriedades rurais com atividade reprodutiva, dirigido a detectar focos da doença. Esta foi uma das atividades integrantes do Programa Nacional de Controle e Erradicação de Brucelose e Tuberculose (PNCEBT), implementada, no Estado de São Paulo, pela Coordenadoria de Defesa Agropecuária (CDA). Em 2001, houve 0 estabelecimento de uma parceria entre 0 Departamento de Medicina Veterinária Preventiva e Saúde Animal (VPS) e o Ministério da Agricultura, Pecuária e Abastecimento (MAPA), com a finalidade de estabelecer uma colaboração na análise dos resultados do PNCEBT. As atribuições de cada parceiro foram as seguintes: (a) a coordenação e o desenho amostral ficaram a cargo do MAPA; (b) as atividades de campo e a realização dos testes diagnósticos, a cargo da CDA e (c) 0 tratamento dos dados, a cargo do VPS. As atividades de campo, no Estado de São Paulo, se deram entre outubro e dezembro de 2001.

Nas demais unidades federativas, o programa foi implementado, e encontra-se em diferentes fases de execução. Até maio de 2004, os Estados de Santa Catarina (SIKUSAWA, 2004), Paraná (DIAS, 2003), São Paulo, Minas Gerais, Goiás, Tocantins, Mato Grosso e Espírito Santo, além do Distrito Federal, haviam finalizado as atividades de campo e os estudos de prevalência. Nos Estados da Bahia e Sergipe, somente as atividades de campo foram concluídas. Nos Estados da Rondônia, Rio Grande do Sul e Rio de Janeiro as atividades de campo estão em fase de execução. No Estados do Acre, Maranhão e no sul do Estado do Pará, a amostra foi delineada, e os preparativos para o início das atividades de campo foram feitos. Nos outros 10 Estados, ainda não foram iniciadas as atividades do PNCETB. 


\section{OBJETIVOS}

\subsection{GERAIS}

Caracterizar espacialmente a brucelose em bovinos no Estado de São Paulo, em termos de prevalência de focos e animais soropositivos, fatores de criação mais associados com 0 aparecimento da doença nas propriedades com atividade reprodutiva e comparar medidas de controle propostas no PNCETB.

\subsection{ESPECÍFICOS}

Definir a prevalência de fêmeas bovinas com idade superior a 24 meses, soropositivas para brucelose, nos circuitos produtores e no Estado de São Paulo.

Identificar a prevalência de propriedades com um ou mais fêmeas soropositivas para brucelose, nos circuitos produtores e no Estado de São Paulo.

Identificar os fatores de risco para a brucelose bovina nas criações paulistas.

Verificar a existência de agrupamentos espaciais de focos de brucelose no Estado de São Paulo.

Propor um modelo matemático que represente a dinâmica da doença na população, de modo a permitir a avaliação das medidas de controle propostas no Programa Nacional. 


\section{MATERIAL E MÉTODO}

\subsection{POPULAÇÃO EM ESTUDO E AMOSTRAGEM}

Os parâmetros epidemiológicos da brucelose bovina variam quando se compara diferentes sistemas de produção, práticas de manejo, finalidades de exploração, tamanho médio de rebanhos e sistemas de comercialização. Portanto, para se conhecer estas diferenças regionais, estratificou-se o Estado de São Paulo em circuitos produtores de bovinos, levando-se em consideração os fatores acima citados. 0 conceito de regionalização foi extrapolado do Programa Nacional de Erradicação da Febre Aftosa (MAPA, 2000c), adaptado à realidade estadual. Este conceito baseia-se nas relações entre os sistemas de produção predominantes nas diferentes áreas geográficas e a interdependência destes em relação ao comércio de animais, seus produtos e sub-produtos. Cada um destes grupos de produção e sistemas comerciais (por exemplo, cria, recria e engorda), configura um circuito produtor praticamente independente. São considerados "ecossistemas de produção", com alto grau de independência nos vários estágios da cadeia produtiva, sendo que a probabilidade de um animal passar por todos os estágios de produção dentro do circuito é elevada. No entanto, os circuitos produtores mantêm relações de dependência, principalmente movimentos de comércio (MAPA, 2000c). A divisão do Estado em circuitos produtores também levou em conta a capacidade operacional e logística da CDA, baseando-se nas áreas de atuação dos seus quarenta Escritórios de Defesa Agropecuária (EDA). 
Em cada circuito produtor, estimou-se a prevalência de propriedades infectadas pela brucelose bovina e de animais soropositivos através de um estudo amostral em dois estágios, dirigido a detectar focos de brucelose: no primeiro, sorteou-se, de forma aleatória, um número pré-estabelecido de propriedades com atividade reprodutiva (unidades primárias de amostragem) e, no segundo, sorteou-se um número préestabelecido de fêmeas bovinas com idade igual ou superior a 24 meses (unidades secundárias de amostragem).

Nas propriedades rurais com atividade reprodutiva, escolheu-se como alvo do inquérito, o rebanho bovino de maior importância econômica, de principal objetivo de produção (corte, leite ou misto), no qual os animais estavam submetidos às mesmas condições de manejo, ou seja, sob os mesmos fatores de risco. A escolha da unidade primária de amostragem foi aleatória, baseada no cadastro de propriedades rurais paulistas com atividade reprodutiva de bovinos. Se uma propriedade sorteada não pôde, por quaisquer motivos, ser visitada, esta foi substituída por uma outra, nas proximidades e com as mesmas características de produção. 0 tamanho da amostra, por circuito, foi determinado pelo grau de confiança do resultado, pelo nível de precisão desejado e pelo valor da prevalência esperado (NOORDHUIZEN et al., 1997), sendo condizente com a capacidade operacional e financeira da CDA e utilizando-se a fórmula para amostras simples aleatórias, segundo Thrusfied (1995) e Noordhuizen (1997):

$$
n=\frac{Z_{\alpha}^{2} \cdot \sqrt{P(1-P)}}{d^{2}}
$$

Onde:

$n=$ número de propriedades amostradas por circuito produtor;

$Z_{\alpha}=$ valor da distribuição normal para 0 grau de confiança de 95\%;

$P=$ prevalência esperada, fixada em $20 \%$;

$d=$ erro absoluto, fixado em $6 \%$. 
Sabendo-se 0 número de unidades primárias de amostragem por circuito produtor, definiu-se 0 número de unidades secundárias de amostragem, ou seja, o número de fêmeas maiores que 24 meses, nas quais realizou-se testes de brucelose, com 0 objetivo de classificar 0 rebanho como infectado ou livre de brucelose.

0 protocolo de testes foi composto do teste do antígeno acidificado tamponado ou teste Rosa Bengala (TRB) e do teste do mercaptoetanol (ME), utilizados em sequência, de acordo com as diretrizes recomendadas no PNCETB (MAPA, 2000b). Os testes foram realizados no Instituto Biológico de São Paulo (IB). Os animais positivos no teste Rosa Bengala foram submetidos ao teste do mercaptoetanol, para confirmação do resultado. Soros que resultaram inconclusivos no teste do mercaptoetanol foram retestados com a reação de fixação do complemento (RFC). Uma propriedade foi considerada positiva quando, ao menos, um animal positivo foi detectado (ou seja, o ponto de corte de animais sororeatores = I) (DONALD; GARDNER; WIGGINS, 1994). 0 número de animais testados em cada propriedade foi determinado pela sensibilidade e especificidade dos testes combinados, 95\% e 99,5\%, respectivamente (FLETCHER, 1988). Assim como no cálculo das unidades primárias de amostragem, a prevalência esperada utilizada nos cálculos do número de unidades secundárias foi 20\%. 0 programa de computador Herdacc version 3 (University of Guelph, 1995) foi empregado para a realização do cálculo do tamanho das unidades secundárias de amostragem, por meio de simulações da sensiblidade e especificidade de rebanho. Esta decisão foi tomada de modo a aliar uma sensibilidade e especificidade agregadas maior que 90\%, segundo Jordan (1996) e Martin, Shoukri e Thorburn (1992). A escolha das fêmeas dentro das propriedades foi casual sistemática.

0 estudo amostral permitiu determinar as prevalências de focos e de fêmeas maiores que 24 meses soropositivas para brucelose no Estado de São Paulo e nos circuitos produtores, individualmente. Os cálculos de prevalências desta amostra e os respectivos intervalos de confiança foram realizados com o auxílio do programa Epilnfo 6.04d (CDC, 2001). 
Considerando-se que a amostra de unidades primárias em cada circuito produtor foi aleatória sistemática (COCHRAN, 1977), a prevalência aparente de focos de brucelose foi calculada utilizando-se como parâmetros 0 número de focos e 0 número de propriedades amostradas (DEAN, 1994). No Estado de São Paulo, devido à divisão em circuitos produtores, considerou-se que a amostra de unidades primárias foi estratificada sistemática aleatória (COCHRAN, 1977), sendo que os parâmetros utilizados no cálculo da prevalência aparente de focos foram o estatus da propriedade (foco ou livre da brucelose), 0 circuito a que pertence cada propriedade e o peso estatístico de cada propriedade amostrada no circuito, calculado pela razão entre 0 número de propriedades com atividade reprodutiva e o número de propriedades amostradas em cada circuito produtor (DEAN, 1994).

A prevalência aparente de fêmeas maiores que 24 meses soropositivas também foi calculada para os circuitos produtores e para o Estado. Neste caso, a escolha de unidades secundárias foi feita através de uma amostra de agrupamentos estratificada (COCHRAN, 1977). Os parâmetros utilizados neste cálculo foram 0 estatus do animal (positivo ou negativo), o circuito a qual pertence a propriedade da qual foi retirada cada amostra, a identificação da propriedade no estudo e o peso estatístico de cada animal amostrado, calculado através da fórmula abaixo (DEAN, 1994):

$$
\text { peso }=\frac{\text { fêmeas }>24 \text { meses no circuito produtor }}{\text { fêmeas }>24 \text { meses nas propr. amostradas }} * \frac{\text { fêmeas }>24 \text { meses na propr. }}{\text { fêmeas }>24 \text { meses amostradas na propr. }}
$$

0 primeiro fator desta fórmula representa quanto cada animal potencialmente selecionável representa no circuito, e o segundo fator representa quanto cada animal selecionado representa na propriedade.

Também foram calculadas as prevalências estratificadas por tipos de exploração da produção pecuária: carne, leite e misto. As ponderações foram as mesmas do cálculo da prevalência de focos brucelose. 
Em cada propriedade visitada foi aplicado um questionário epidemiológico (Anexo A), que permitiu a caracterização das práticas de manejo empregadas, além do estudo de fatores de risco associados com a presença ou ausência da brucelose. Para isso, foi criado um banco de dados com as informações epidemiológicas, as coordenadas geográficas e as informações dos testes diagnósticos aplicados nas propriedades visitadas. Este banco de dados também foi utilizado para o cálculo das prevalências.

Os médicos veterinários do CDA foram treinados de modo a padronizar-se o procedimento de colheita de material nas propriedades visitadas. 0 sangue foi coletado em tubos tipo vacutainer (sem anticoagulante) de $15 \mathrm{ml}$ (o tubo nunca era cheio até a capacidade total, facilitando a obtenção do soro), dessorado nos EDA, congelados na posição vertical, acondicionados e enviados ao Instituto Biológico para análise laboratorial. 0 transporte foi feito em caixas de isopor com gelo, sendo o formulário epidemiológico envolto em plástico e fixado na tampa. Os frascos foram identificados com um código de 11 dígitos com caneta esferográfica em uma etiqueta de esparadrapo. As atividades de campo se deram, no Estado de São Paulo, entre outubro e dezembro de 2001.

\subsection{CONSTRUÇÃO DE MAPAS GEORREFERENCIADOS}

Os limites geográficos dos circuitos produtores foram delimitados em um mapa temático georreferenciado do Estado de São Paulo, baseado no mapa da malha municipal obtido junto ao Instituto Brasileiro de Geografia e Estística (1999).

Durante a visita às propriedades, com 0 objetivo de coletar amostras de soro e aplicação do questionário epidemiológico, também levantou-se as coodenadas geográficas (latitude e longitude) das mesmas. Para isso, utilizou-se aparelhos de posicionamento global por satélite (GPS, do inglês global 
positioning system), modelo Garmin $12 \mathrm{XL}^{3}$. Estas coordenadas foram adicionadas ao banco de dados criado para dar suporte ao estudo, sendo posteriormente plotadas no mapa georreferenciado dos circuitos produtores, através do programa ArCView 3.1 (ESRI INC., 1996). Procurou-se unificar o sistema de coordenadas na fase de obtenção das coordenadas geográficas, de modo a facilitar sua inclusão no mapa georreferenciado. Nos casos onde houve necessidade de fazer a conversão dos sistemas de coordenadas, utilizou-se o programa GeoBase VB50 (Base Aerofotogrametria e Projetos, 2000).

\subsection{IDENTIFICAÇÃO DE AGRUPAMENTOS DE PROPRIEDADES POSITIVAS}

Uma das possibilidades para verificação de agrupamentos espaciais se dá através da comparação da distribuição obtida com uma distribuição espacial completamente aleatória, entretanto, esta análise tem como pressuposição que o processo é isotrópico ou homogêneo e no caso de doenças, sabe-se que a intensidade do aparecimento de casos deve variar com a densidade populacional que normalmente não é homogênea, assim, este método tem aplicação limitada na investigação de agrupamentos de doenças (BAILEY; GATRELL, 1995; CARPENTER, 2001; ELLIOT et al., 1992; WARD; CARPENTER, 2000).

Uma maneira alternativa para verificar a presença de agrupamento de doenças pode ser utilizada na existência de um grupo ou processo controle que atue como substituto para as variações na população sob risco (BAILEY; GARTELL, 1995). Neste caso, supondo $n_{1}$ o número de casos observados na área de estudo $\mathfrak{R}$ e uma amostra aleatória na região $\mathfrak{R}$ de $n_{2}$ controles da população sob risco, têm-se $n=n_{1}+n_{2}$ eventos. Se não há agrupamento dos casos em relação aos controles isto implica que os casos são uma

\footnotetext{
${ }^{3}$ Garmin GPS 12 XL. Olathe: Garmin Corp., 1988.
} 
amostra aleatória dos padrões de casos e controles. Assim, a hipótese que se quer testar é a de identificação aleatória de casos e controles. Esta hipótese não faz pressuposições sob a forma dos processos envolvidos no aparecimento de casos e controles. Para testar esta hipótese pode-se utilizar a função $K$.

Sob a hipótese de identificação aleatória, os padrões de casos e controles tomados individualmente representam uma redução aleatória do processo espacial combinado. Da definição da função $K$ temos que ela é invariante para reduções aleatórias e desse modo segue-se que $K_{11}(h)=K_{22}(h)=K_{12}(h)$.

Assim, um modo simples de identificar 0 afastamento da identificação aleatória é verificar a significância da diferença entre as estimativas destas funções. Se casos são eventos do tipo l e controles eventos do tipo 2, pode-se utilizar um gráfico de $\hat{K}_{11}(h)-\hat{K}_{22}(h)$ como função de $h$ (distância) para verificar 0 afastamento da pressuposição de identificação aleatória. Neste caso, os picos representam agrupamento de casos independentemente do agrupamento espacial dos controles. Os limites superior e inferior desta curva, utilizados para verificar a significância dos picos, são estimados a partir de valores de $\hat{K}_{11}$ e $\hat{K}_{22}$ calculdados em repetidas simulações utilizando $n_{1}+n_{2}$ localizações fixas porém identificando aleatoriamente como casos $n_{1}$ localidades (BAILEY; GATRELL, 1995).

\subsection{ESTUDO DOS FATORES DE RISCO PARA A BRUCELOSE BOVINA}

As variáveis de caracterização epidemiológica permitiram identificar os fatores de risco para a brucelose bovina nas propriedades criadoras. Das variáveis relacionadas no questionário epidemiológico (ANEXO A), foram estudadas como possíveis fatores de risco: tipo de exploração (ou sistema de produção: carne, leite e misto), tipo de criação (confinado, semi-confinado, extensivo), uso de inseminação artificial, 
raças predominantes, número de vacas com idade superior a 24 meses, número de bovinos na propriedade, presença de outras espécies domésticas, presença de animais silvestres, destino da placenta e do feto abortados, compra e venda de animais, vacinação contra brucelose, abate de animais na propriedade, aluguel de pastos, pastos comuns com outras propriedades, pastos alagados, piquete de parição e assistência veterinária.

As categorias das variáveis foram manipuladas de modo a apresentarem-se em escala crescente de risco, segundo informações da literatura (ACHA; SZYFRES, 1986; BEER, 1998; CRAWFORD; HUBER; ADAMS, 1990; ITO et al., 1998; PAULIN; FERREIRA NETO, 2003; SALMAN; MEYER; HYRO, 1984; VASCONCELLOS; ITO; CÔRTES, 1987). Quando necessário, realizou-se a recategorização destas categorias para atender este critério, de modo a preparar o banco de dados para as análises. A categoria de menor risco foi considerada como base para a comparação das demais categorias. As variáveis quantitativas foram recategorizadas em quartis.

Inicialmente, foi realizada uma análise univariada (utilizando-se os testes qui-quadrado ou Fischer) para verificar-se a associação de cada um dos possíveis fatores de risco com a variável dependente (rebanho livre ou infectado por brucelose) (ZAR, 1996). 0 nível de significância adotado nesta fase foi 20\%. As características mais associadas à variável dependente permitiram a identificação dos fatores de risco propriamente, através de uma análise múltipla (regressão logística múltipla) (HOSMER; LEMESHOW, 1989). 0 nível de significância adotado nesta fase foi $5 \%$.

Tanto a análise univariada, quanto a múltipla, foram estratificadas pelo tipo de exploração (carne, leite ou misto), sendo realizadas também para a totalidade do Estado de São Paulo. As análises foram relizadas no programa SPSS version 9.0 (SPSS INC., 1999b). 


\subsection{SIMULAÇÃO DE MEDIDAS DE CONTROLE DA BRUCELOSE BOVINA PROPOSTAS NO PNCETB ATRAVÉS DE MODELAGEM MATEMÁTICA}

Foi construído um modelo matemático determinístico (MASSAD et al., 2004), adaptado do modelo proposto por González-Guzmán e Naulin (1994), de modo a permitir a representação da dinâmica da brucelose na população bovina, com o objetivo de comparar as medidas de controle propostas no PNCETB, na dependência da situação epidemiológica encontrada no Estado de São Paulo.

0 modelo foi proposto para simular a dinâmica da brucelose no tipo de exploração de leite, assumindo-se que este rebanho era formado inteiramente de fêmeas. Esta população foi dividida em seis compartimentos: fêmeas susceptíveis $(S)$, fêmeas vacinadas $(V)$, portadoras latentes primíparas $\left(L_{1}\right)$, fêmeas infecciosas primíparas $\left(I_{1}\right)$, portadoras latentes multíparas $\left(L_{2}\right)$, fêmeas infecciosas multíparas $\left(I_{2}\right)$.

No Estado de São Paulo, o tamanho do rebanho leiteiro manteve-se constante ao longo do período de 2000 a 2002, em torno de 1.700 .000 animais (AMARAL et al., 2003), sendo este valor adotado no modelo, mantido constante através do ajuste entre a taxa de natalidade e reposição de susceptíveis $(\eta)$ e a taxa de mortalidade natural e descarte $(\mu)$, considerando-se uma vida média das fêmeas leiteiras de 8 anos (Equação 11). Sendo $\beta$ o coeficiente de transmissão, dado pelo número de contatos per capita por unidade de tempo e que leva em conta a probabilidade de um contato resultar em infecção, caso este se dê entre um indivíduo infectado e outro suscetível, tem-se que $\beta \cdot\left(I_{1}+I_{2}\right)$ é a taxa de infecção e, por consequiência, $\beta \cdot S \cdot\left(I_{1}+I_{2}\right)$ fêmeas por unidade de tempo deixam o compartimento $S$ em direção ao compartimento $L_{1} \cdot 0$ coeficiente $\beta$ foi ajustado de forma a determinar uma prevalência da brucelose no patamar estimado pelo estudo de prevalências, sem vacinação. As bezerras nascidas de mães positivas também se tornam portadoras latentes $\left(L_{1}\right)$ a uma proporção $\rho$, fixada em 9\% (PAULIN; FERREIRA NETO, 2003). As fêmeas portadoras latentes (primíparas ou multíparas) tornam-se infecciosas a uma taxa $\gamma$, relacionada ao período de gestação $\left(T_{\gamma}\right)$, ou seja, 20 meses nas fêmeas infectadas (FARIA, 1984). As fêmeas permanecem 
infecciosas (abortivas ou não) durante o puerpério, porém as brucelas eliminadas nos restos do aborto podem permanecer viáveis no ambiente por períodos variáveis, de um a seis dias na pastagem (TIMONEY et al., 1988) até quatro meses em instalações (RUSSEL; YARNICH; KOULIKOVSKII, 1984). Assim, considerou-se 60 dias como período infeccioso $(I \delta)$, sendo que as fêmeas infecciosas $\left(I_{1}\right.$ e $\left.I_{2}\right)$ retornam ao estado latente a uma taxa $\delta$, equivalente ao inverso do período infeccioso. A proporção de abortos $\alpha$ gerados pelas fêmeas infectadas primíparas foi fixada em 80\% (PAULIN; FERREIRA NETO, 2003). A figura 1 mostra 0 diagrama de blocos da dinâmica da brucelose bovina nesta população.

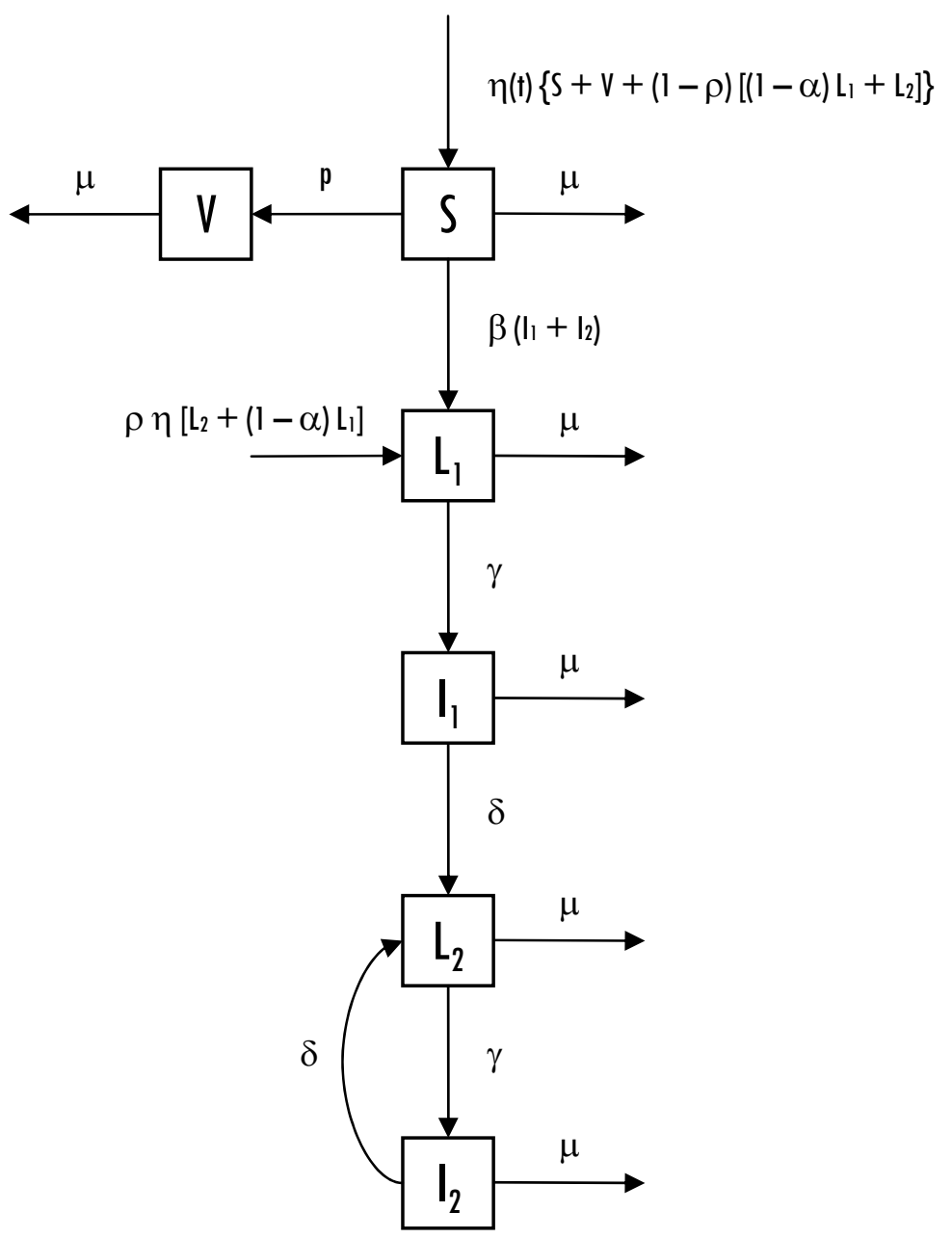

Figura 1 - Diagrama de blocos mostrando a dinâmica da brucelose em populações bovinas de exploração leiteira 
0 sistema de equações diferenciais mostrado a seguir representa a dinâmica da brucelose na população de fêmeas leiteiras:

$$
\begin{gathered}
\frac{d S(t)}{d t}=[1-p(t)] \cdot \eta(t) \cdot\left\{S+V+(1-\rho) \cdot\left[(1-\alpha) \cdot L_{1}+L_{2}\right]\right\}-\mu \cdot S(t)-\lambda(t) \cdot S(t) \\
\frac{d L_{1}(t)}{d t}=\lambda(t) \cdot S(t)+\rho \eta(t) \cdot\left[L_{2}(t)+(1-\alpha) L_{1}(t)\right]-(\gamma+\mu) \cdot L_{1} \\
\frac{d l_{1}(t)}{d t}=\gamma \cdot L_{1}-(\delta+\mu) \cdot I_{1} \\
\frac{d L_{2}(t)}{d t}=\delta \cdot\left(I_{1}+I_{2}\right)-(\gamma+\mu) \cdot L_{2} \\
\frac{d I_{2}(t)}{d t}=\gamma \cdot L_{2}-(\mu+\delta) \cdot I_{2} \\
\frac{d V(t)}{d t}=p(t) \cdot \eta(t) \cdot\left\{S+V+(1-\rho) \cdot\left[(1-\alpha) \cdot L_{1}+L_{2}\right]\right\}-\mu \cdot V \\
\frac{d N(t)}{d t}=\eta(t) \cdot\left[S+V+(1-\alpha) \cdot L_{1}+L_{2}\right]-\mu N(t)
\end{gathered}
$$

onde $N(t)=S(t)+L_{1}(t)+l_{1}(t)+L_{2}(t)+I_{2}(t)+V(t)$ é a população total de fêmeas leiteiras no tempo $t$ e $\lambda(t)=\beta \cdot\left[I_{1}(t)+I_{2}(t)\right]$ é também conhecido como força de infecção. A notação $p(t)$ refere-se à proporção de cobertura vacinal.

Em uma situação de equilíbrio da população em que a população se mantenha constante, tem-se que:

$$
\frac{d N(t)}{d t}=0
$$

o que é equivalente a:

$$
\eta(t)=\frac{\mu N}{S+V+(1-\alpha) \cdot L_{1}+L_{2}}
$$

Assim, para que se tenha um rebanho com tamanho constante ao longo do tempo, é necessário que a taxa $\eta(t)$, que se refere à natalidade e reposição, obedeça à relação acima.

Podemos notar que, para um rebanho em que não haja abortos $(\alpha \rightarrow 0)$, tem-se que $\eta(t)=\mu$, ou seja, as taxas de natalidade e mortalidade se compensarão, mantendo a população constante. 
0 modelo prevê que a vacinação se dá nas fêmeas do compartimento $S$, assumindo-se que, ao ingressarem neste compartimento, são elegíveis para a vacinação, ou seja, animais recém nascidos e bezerras poderiam ser vacinadas.

Uma vez determinado o coeficiente $\beta$, foram simuladas intervenções, na dependência da situação epidemiológica da brucelose no Estado de São Paulo. Preconiza-se que, em situações de prevalência elevada, deve-se vacinar o rebanho com vacina $B 19$, a uma cobertura de, no mínimo 80\%, para que a doença possa cair a níveis de $2 \%$ de prevalência, o que possibilitaria a adoção de medidas como diagnóstico e sacrifício de reatores (ACHA; SZYFRES, 1986; PAULIN; FERREIRA NETO, 2003).

0 cálculo do coeficiente de transmissão $\beta$, bem como as simulações de intervenções no sistema, foram feitas no programa Mathcad 2001 Professional (Mathsoft Engeneering and Education Inc, 2001). 


\section{RESULTADOS}

\subsection{ESTUDO DE PREVALÊNCIAS}

A aplicação do conceito de regionalização resultou na divisão do território do Estado de São Paulo em sete circuitos de produção pecuária.

0 tamanho da amostra de unidades primárias, por circuito produtor, foi determinado pela Equação l, em 150 propriedades por circuito produtor, o que totalizaria 1050 propriedades. No Estado de São Paulo, no entanto, foram visitadas 1075 propriedades. Destas, cinco propriedades $(0,46 \%)$ apresentavam fêmeas bubalinas com idade maior que 24 meses, sendo que somente duas $(0,19 \%)$ tinham na criação de búfalos a principal atividade econômica. Assim, essas duas últimas foram excluídas do estudo e somente as prevalências relacionadas à população bovina foram calculadas. Outras 34 propriedades amostradas (3,16\%) também criavam bubalinos além dos bovinos, porém sem atividade reprodutiva, mantendo somente machos castrados no rebanho, tendo na criação de bovinos a principal atividade econômica. Portanto, o tamanho da amostra de unidades primárias foi 1073.

Através das simulações da sensibilidade e especificidade de rebanho, realizadas no programa Herdacc (University of Guelph, 1995), selecionou-se dois tamanhos de amostra diferenciados, um para propriedades com até 100 animais e outro para propriedades com um número maior ou igual a 100 animais. Nas propriedades com até 100 fêmeas com idade superior a 24 meses, considerou-se um tamanho de amostra de 10 animais. Nas popriedades com até 10 fêmeas com idade superior a 24 meses, colheu-se 
sangue de todas. Nas propriedades com 100 ou mais fêmeas com idade superior a 24 meses, adotou-se um tamanho de amostra de 15 animais.

Foram testados, ao todo, 8761 soros, sendo que $795(9,0 \%)$ resultaram positivos no teste do antígeno acidificado tamponado. Destes, $187(23,5 \%)$ resultaram positivos e $14(1,8 \%)$ inconclusivos no teste do mercaptoetanol, sendo que estes últimos resultaram negativos na reação de fixação do complemento. Observou-se perdas amostrais nos circuitos 1 (cinco propriedades), 3 (duas propriedades) e 6 (quatro propriedades), devido à perda de soros durante 0 processameto. 0 quadro 1 mostra a distribuição, por circuito produtor, do número total de propriedades com atividade reprodutiva, do número total de fêmeas bovinas, do número de propriedades amostradas e do número de fêmeas bovinas com idade igual ou superior a 24 meses amostradas.

\begin{tabular}{|ccccc|}
\hline Cirvito Produtor & $\begin{array}{c}\text { Propriedades com } \\
\text { atividade reprodutiva } \\
\text { de bovinos }\end{array}$ & $\begin{array}{c}\text { Fêmeas bovinas com } \\
\text { idade } \geq 24 \text { meses }\end{array}$ & $\begin{array}{c}\text { Propriedades } \\
\text { amostradas }\end{array}$ & $\begin{array}{c}\text { Fêmeas } \\
\text { amostradas }\end{array}$ \\
\hline 1 & 29.091 & 1.333 .508 & 145 & 1.428 \\
2 & 35.052 & 1.071 .847 & 151 & 1.230 \\
3 & 29.875 & 1.220 .983 & 148 & 1.321 \\
4 & 14.970 & 378.485 & 153 & 1.200 \\
5 & 22.551 & 351.553 & 179 & 1.161 \\
6 & 18.247 & 351.612 & 146 & 1.107 \\
7 & 10.213 & 224.226 & 151 & 8.761 \\
\hline
\end{tabular}

Fonte: Levantamento das Unidades de Produção Agropecuária (LUPA). Coordenadoria de Assistência Técnica Integral, 2001.

Quadro 1 - Distribuição do número de propridades com atividade reprodutiva e fêmeas bovinas com idade igual ou superior a 24 meses amostradas, e respectivos tamanhos de amostra, por circuito produtor e para a totalidade do Estado de São Paulo - São Paulo - 2004

As atividades de campo foram realizadas pelos médicos veterinários da Coordenadoria de Defesa Agropecuária (CDA) do Estado de São Paulo, entre outubro e dezembro de 2001. Visitas subsequientes foram realizadas nas propriedades na proximidade de Campinas e na região do Vale do Ribeira, para nova aferição das coordenadas geográficas. 
Utilizando-se o programa Epilnfo 6.04d (CDC, 2001), calculou-se as prevalências de focos de brucelose e de fêmeas com idade superior a 24 meses soropositivas para brucelose (tabelas 1 e 2).

Tabela 1 - Prevalência aparente de focos de brucelose bovina no Estado de São Paulo - São Paulo - 2004

\begin{tabular}{ccccrrr}
\hline $\begin{array}{c}\text { Circuito } \\
\text { produtor }\end{array}$ & $\begin{array}{c}\text { Propriedades } \\
\text { com atividade } \\
\text { reprodutiva de } \\
\text { bovinos }\end{array}$ & $\begin{array}{c}\text { Número de } \\
\text { propriedades } \\
\text { visitadas }\end{array}$ & $\begin{array}{c}\text { Número de } \\
\text { focos de } \\
\text { brucelose }\end{array}$ & $\begin{array}{c}\text { Prevalência } \\
(\%)\end{array}$ & $\begin{array}{c}\text { IC 95\% } \\
(\%)\end{array}$ & $\begin{array}{c}\text { Peso } \\
\text { estatístico }\end{array}$ \\
\hline 1 & 29.091 & 145 & 15 & 10,34 & {$[5,91 ; 16,49]$} & 200,63 \\
2 & 35.052 & 151 & 15 & 9,93 & {$[5,67 ; 15,85]$} & 232,13 \\
3 & 29.875 & 148 & 15 & 10,13 & {$[5,78 ; 16,17]$} & 201,86 \\
4 & 14.970 & 153 & 17 & 11,11 & {$[6,61 ; 17,19]$} & 97,84 \\
5 & 22.551 & 179 & 13 & 7,26 & {$[3,92 ; 12,10]$} & 125,98 \\
6 & 18.247 & 146 & 12 & 8,22 & {$[4,32 ; 13,92]$} & 124,98 \\
7 & 10.213 & 151 & 18 & 11,92 & {$[7,22 ; 18,18]$} & 67,64 \\
\hline SP & 159.999 & 1073 & 105 & $9,70^{\circ}$ & {$[7,80 ; 11,60]$} & ponderado \\
\hline
\end{tabular}

aEfeito do deseho amostral $=1,16$.

Tabela 2 - Prevalência aparente de fêmeas com idade superior a 24 meses soropositivas para brucelose bovina no Estado de São Paulo - São Paulo - 2004

\begin{tabular}{ccccccc}
\hline $\begin{array}{c}\text { Circuito } \\
\text { produtor }\end{array}$ & $\begin{array}{c}\text { Fêmeas bovinas } \\
\text { com idade } \geq 24 \\
\text { meses }\end{array}$ & $\begin{array}{c}\text { Número de } \\
\text { soros } \\
\text { coletados }\end{array}$ & $\begin{array}{c}\text { Número de } \\
\text { animais } \\
\text { soropositivos }\end{array}$ & $\begin{array}{c}\text { Prevalência } \\
(\%)\end{array}$ & $\begin{array}{c}\text { IC 95\% } \\
(\%)\end{array}$ & $\begin{array}{c}\text { Peso } \\
\text { estatístico }\end{array}$ \\
\hline 1 & 1.333 .508 & 1.428 & 29 & 2,44 & {$[0,76 ; 4,12]$} & 27,04 \\
2 & 1.071 .847 & 1.230 & 32 & 1,84 & {$[0,39 ; 3,29]$} & 21,73 \\
3 & 1.220 .983 & 1.321 & 28 & 7,98 & {$[0,00 ; 18,61]$} & 24,76 \\
4 & 378.485 & 1.200 & 32 & 5,52 & {$[0,72 ; 10,32]$} & 7,67 \\
5 & 351.553 & 1.161 & 17 & 1,86 & {$[0,45 ; 3,27]$} & 7,13 \\
6 & 351.612 & 1.107 & 17 & 1,68 & {$[0,48 ; 2,88]$} & 7,13 \\
7 & 224.226 & 1.314 & 32 & 2,17 & {$[0,77 ; 3,56]$} & 4,55 \\
\hline SP & 4.932 .214 & 8.761 & 187 & $3,81^{\circ}$ & {$[0,72 ; 6,90]$} & ponderado \\
\hline
\end{tabular}

"Efeito do deseho amostral $=59,43$.

0 efeito do desenho amostral, por circuito produtor, foi calculado durante o cálculo de prevalência de fêmeas soropositivas, em 4,43 no Circuito 1, 3,72 no Circuito 2, 52,88 no Circuito 3, 13,80 no Circuito 4, 3,28 no Circuito 5, 2,52 no Circuito 6 e 3,14 no Circuito 7. 
As prevalências aparentes de focos de brucelose bovina, estratificadas por tipo de exploração (nos circuitos produtores e no Estado de São Paulo) estão mostrados na tabela 3. Ponderou-se as prevalências para 0 Estado de São Paulo do mesmo modo que 0 cálculo de prevalências de focos de brucelose.

Tabela 3 - Prevalência aparente de focos de brucelose bovina estratificada por tipo de exploração - São Paulo- 2004

\begin{tabular}{|c|c|c|c|c|c|c|c|c|c|}
\hline \multirow{3}{*}{ Circuito } & \multicolumn{9}{|c|}{ Prevalência de focos de brucelose } \\
\hline & \multicolumn{3}{|c|}{ Corte } & \multicolumn{3}{|c|}{ Leite } & \multicolumn{3}{|c|}{ Misto } \\
\hline & $\mathrm{n}$ & $\%$ & IC (95\%)(\%) & $n$ & $\%$ & IC (95\%) (\%) & $n$ & $\%$ & IC (95\%)(\%) \\
\hline 1 & $4 / 43$ & 9,3 & {$[2,6 ; 22,1]$} & $4 / 26$ & 15,4 & {$[4,4 ; 34,9]$} & $7 / 71$ & 9,9 & {$[4,1 ; 19,3]$} \\
\hline 2 & $2 / 21$ & 9,5 & {$[1,2 ; 30,4]$} & $6 / 59$ & 10,2 & {$[3,8 ; 20,8]$} & $7 / 67$ & 10,4 & {$[4,3 ; 20,3]$} \\
\hline 3 & $5 / 47$ & 10,6 & {$[3,5 ; 23,1]$} & $4 / 39$ & 10,3 & {$[2,9 ; 24,2]$} & $6 / 61$ & 9,8 & {$[3,7 ; 20,2]$} \\
\hline 4 & $3 / 24$ & 12,5 & {$[2,7 ; 32,4]$} & $8 / 46$ & 17,4 & {$[7,8 ; 31,4]$} & $6 / 83$ & 7,2 & {$[2,7 ; 15,1]$} \\
\hline 5 & $5 / 40$ & 12,5 & {$[4,2 ; 26,8]$} & $5 / 69$ & 7,2 & {$[2,4 ; 16,1]$} & $3 / 68$ & 4,4 & {$[0,9 ; 12,4]$} \\
\hline 6 & $1 / 18$ & 5,6 & {$[0,1 ; 27,3]$} & $7 / 42$ & 16,7 & {$[7,0 ; 31,4]$} & $4 / 86$ & 4,7 & {$[1,3 ; 11,5]$} \\
\hline 7 & $0 / 16$ & 0,0 & {$[0,0 ; 20,6]$} & $10 / 71$ & 14,1 & {$[7,0 ; 24,4]$} & $8 / 64$ & 12,5 & {$[5,6 ; 23,2]$} \\
\hline$S P$ & $20 / 209$ & $9,9^{a}$ & {$[5,6 ; 14,1]$} & $44 / 353$ & $11,9^{b}$ & {$[8,3 ; 15,5]$} & $41 / 502$ & $8,4^{c}$ & {$[5,8 ; 11,1]$} \\
\hline
\end{tabular}

Analisando-se as prevalências de focos e de fêmeas soropositivas para brucelose, observa-se que, através do teste binomial de duas proporções, realizado no programa de computador Minitab Release 14 (Minitab Inc., 2003), não há diferença estatística entre os circuitos produtores (tabelas 1 e 2). Ao estratificar as prevalências de focos por tipo de exploração, e comparando-as nos circuitos produtores e no Estado (tabela 3), através dos testes exato de Fischer e binomial de duas proporções (Minitab Inc., 2003), também verificou-se que que não há diferenças estatisticamente significativas. 


\subsection{CARACTERIZAÇÃO EPIDEMIOLÓGICA DA AMOSTRA}

A caracterização epidemiológica da amostra seguiu dois direcionamentos: um sumarizando as frequiências das variáveis por propriedades e outro mostrando as frequências por animais (fêmeas bovinas com idade superior a 24 meses e total de bovinos), de modo a permitir a identificação da tipologia das propriedades. Todas as frequiências foram estratificadas por circuito produtor e, posteriormente, totalizadas para 0 Estado de São Paulo.

Inicialmente, estudou-se as frequências das variáveis, por propriedades. Foram construídas tabelas com as frequêencias das variáveis qualitativas (e respectivos intervalos de confiança), e diagramas de blocos para as variáveis quantitativas. A seguir são apresentados estes resultados, sendo que as variáveis foram dispostas na ordem em que aparecem no questionário epidemiológico (ANEXO A).

Tabela 4 - Distribuição dos tipos de exploração nas propriedades, por circuitos produtores e no Estado de São Paulo - São Paulo - 2004

\begin{tabular}{|c|c|c|c|c|c|c|c|c|c|c|}
\hline \multirow{3}{*}{ Circuito } & \multicolumn{9}{|c|}{ Tipo de Exploração } & \multirow{3}{*}{ Total } \\
\hline & \multicolumn{3}{|c|}{ Corte } & \multicolumn{3}{|c|}{$\begin{array}{l}\text { Leite } \\
\end{array}$} & \multicolumn{3}{|c|}{ Misto } & \\
\hline & $\mathrm{n}$ & $\%$ & IC (95\%) (\%) & $\mathrm{n}$ & $\%$ & IC (95\%)(\%) & $\mathrm{n}$ & $\%$ & IC (95\%)(\%) & \\
\hline 1 & 43 & 30,5 & {$[23,0 ; 38,8]$} & 27 & 19,1 & {$[13,0 ; 26,6]$} & 71 & 50,4 & {$[41,8 ; 58,9]$} & $141(100,0 \%)$ \\
\hline 2 & 21 & 14,3 & {$[9,1 ; 21,0]$} & 59 & 40,1 & {$[32,1 ; 48,5]$} & 67 & 45,6 & {$[37,4 ; 54,0]$} & $147(100,0 \%)$ \\
\hline 3 & 47 & 32,0 & {$[24,5 ; 40,2]$} & 39 & 26,5 & {$[19,6 ; 34,4]$} & 61 & 41,5 & {$[33,4 ; 49,9]$} & $147(100,0 \%)$ \\
\hline 4 & 24 & 15,7 & {$[10,3 ; 22,4]$} & 46 & 30,1 & {$[22,9 ; 38,0]$} & 83 & 54,2 & {$[46,0 ; 62,3]$} & $153(100,0 \%)$ \\
\hline 5 & 40 & 22,6 & {$[16,7 ; 29,5]$} & 69 & 39,0 & {$[31,8 ; 46,6]$} & 68 & 38,4 & {$[31,2 ; 46,0]$} & $177(100,0 \%)$ \\
\hline 6 & 18 & 12,3 & {$[7,5 ; 18,8]$} & 42 & 28,8 & {$[21,6 ; 36,8]$} & 86 & 58,9 & {$[50,5 ; 67,0]$} & $146(100,0 \%)$ \\
\hline 7 & 16 & 10,5 & {$[6,1 ; 16,4]$} & 71 & 46,4 & {$[38,3 ; 54,6]$} & 66 & 43,1 & {$[35,2 ; 51,4]$} & $153(100,0 \%)$ \\
\hline SP & 209 & $21,3^{*}$ & {$[18,7 ; 24,0]$} & 353 & $31,8^{*}$ & {$[28,9 ; 34,7]$} & 502 & $46,9^{*}$ & {$[43,7 ; 50,1]$} & $1064(100,0 \%)$ \\
\hline
\end{tabular}

*Resultados ponderados pelo número de propriedades nos circuitos (efeito de desenho amostral $=1,14$ ). 
Tabela 5 - Distribuição dos tipos de criação nas propriedades, por circuitos produtores e no Estado de São Paulo - São Paulo - 2004

\begin{tabular}{|c|c|c|c|c|c|c|c|c|c|c|}
\hline \multirow{3}{*}{ Circuito } & \multicolumn{9}{|c|}{ Tipo de Criação } & \multirow{3}{*}{ Tot } \\
\hline & \multicolumn{3}{|c|}{ Confinado } & \multicolumn{3}{|c|}{ Semi-confinado } & \multicolumn{3}{|c|}{ Extensivo } & \\
\hline & $n$ & $\%$ & IC (95\%) (\%) & $\mathrm{n}$ & $\%$ & IC (95\%)(\%) & $\mathrm{n}$ & $\%$ & IC (95\%)(\%) & \\
\hline 1 & 2 & 1,4 & {$[0,2 ; 5,1]$} & 6 & 4,3 & {$[1,6 ; 9,2]$} & 131 & 94,3 & {$[89,0 ; 97,5]$} & $139(100,0 \%$ \\
\hline 2 & 1 & 0,7 & {$[0,0 ; 3,8]$} & 9 & 6,2 & {$[2,9 ; 11,4]$} & 136 & 93,1 & {$[87,8 ; 96,7]$} & $146(100,0 \%$ \\
\hline 3 & 0 & 0,0 & {$[0,0 ; 2,5]$} & 17 & 11,6 & {$[6,9 ; 18,0]$} & 129 & 88,4 & {$[82,0 ; 93,1]$} & $146(100,0 \%$ \\
\hline 4 & 3 & 2,0 & {$[0,4 ; 5,7]$} & 31 & 20,5 & {$[14,4 ; 27,9]$} & 117 & 77,5 & {$[70,0 ; 83,9]$} & $151(100,0 \%$ \\
\hline 5 & 3 & 1,7 & {$[0,4 ; 4,9]$} & 50 & 28,2 & {$[21,7 ; 35,5]$} & 124 & 70,1 & {$[62,7 ; 76,7]$} & $177(100,0 \%$ \\
\hline 6 & 0 & 0,0 & {$[0,0 ; 2,5]$} & 17 & 11,7 & {$[7,0 ; 18,1]$} & 128 & 88,3 & {$[81,9 ; 93,0]$} & $145(100,0 \%$ \\
\hline 7 & 1 & 0,7 & {$[0,0 ; 3,6]$} & 68 & 44,7 & {$[36,7 ; 53,0]$} & 83 & 54,6 & {$[46,3 ; 62,7]$} & $152(100,0 \%)$ \\
\hline SP & 10 & $0,9^{*}$ & {$[0,3 ; 1,4]$} & 198 & $14,5^{*}$ & {$[12,5 ; 16,5]$} & 848 & $84,6^{*}$ & {$[82,5 ; 86,6]$} & $1056(100,0 \%$ \\
\hline
\end{tabular}

*Resultados ponderados pelo número de propriedades nos circuitos (efeito de desenho amotral $=1,06$ ).

Tabela 6 - Distribuição da frequiência de ordenha nas propriedades, por circuitos produtores e no Estado de São Paulo - São Paulo - 2004

\begin{tabular}{|c|c|c|c|c|c|c|c|c|c|c|}
\hline \multirow{3}{*}{ Circuito } & \multicolumn{9}{|c|}{ Número de ordenhas } & \multirow{3}{*}{ Total } \\
\hline & \multicolumn{3}{|c|}{0} & \multicolumn{3}{|c|}{1} & \multicolumn{3}{|c|}{$\geq 2$} & \\
\hline & $n$ & $\%$ & IC (95\%)(\%) & $n$ & $\%$ & IC (95\%)(\%) & $n$ & $\%$ & IC (95\%) (\%) & \\
\hline 1 & 28 & 23,5 & {$[16,2 ; 32,2]$} & 85 & 71,4 & {$[62,4 ; 79,3]$} & 6 & 5,1 & {$[1,9 ; 10,7]$} & $119(100,0 \%)$ \\
\hline 2 & 22 & 15,8 & {$[10,2 ; 23,0]$} & 110 & 79,1 & {$[71,3 ; 85,6]$} & 7 & 5,1 & {$[2,0 ; 10,1]$} & $139(100,0 \%)$ \\
\hline 3 & 28 & 20,6 & {$[14,1 ; 28,4]$} & 102 & 75,0 & {$[66,9 ; 82,0]$} & 6 & 4,4 & {$[1,6 ; 9,4]$} & $136(100,0 \%)$ \\
\hline 4 & 20 & 14,1 & {$[8,8 ; 20,9]$} & 94 & 66,2 & {$[57,8 ; 73,9]$} & 28 & 19,7 & {$[13,5 ; 27,2]$} & $142(100,0 \%)$ \\
\hline 5 & 26 & 16,6 & {$[11,1 ; 23,3]$} & 105 & 66,9 & {$[58,9 ; 74,2]$} & 26 & 16,6 & {$[11,1 ; 23,3]$} & $157(100,0 \%)$ \\
\hline 6 & 22 & 16,1 & {$[10,3 ; 23,3]$} & 106 & 77,4 & {$[69,4 ; 84,1]$} & 9 & 6,5 & {$[3,0 ; 12,1]$} & $137(100,0 \%)$ \\
\hline 7 & 10 & 6,5 & {$[3,2 ; 11,7]$} & 93 & 60,8 & {$[52,6 ; 68,6]$} & 50 & 32,7 & {$[25,3 ; 40,7]$} & $153(100,0 \%)$ \\
\hline SP & 156 & $17,3^{*}$ & {$[14,7 ; 19,9]$} & 695 & $72,6^{*}$ & {$[69,7 ; 75,6]$} & 132 & $10,1^{*}$ & {$[8,3 ; 11,8]$} & $983(100,0 \%)$ \\
\hline
\end{tabular}

*Resultados ponderados pelo número de propriedades nos circuitos (efeito de desenho amostral $=1,19$ ).

Tabela 7 - Distribuição dos tipos de ordenha nas propriedades, por circuitos produtores e no Estado de São Paulo - São Paulo - 2004

\begin{tabular}{|c|c|c|c|c|c|c|c|c|c|c|c|c|c|}
\hline \multirow{3}{*}{ Circuito } & \multicolumn{12}{|c|}{ Tipo de ordenha } & \multirow{3}{*}{ Total } \\
\hline & \multicolumn{3}{|c|}{ Manual } & \multicolumn{3}{|c|}{ Mecânica ao pé } & \multicolumn{3}{|c|}{ Mecânica em sala } & \multicolumn{3}{|c|}{ Não ordenha } & \\
\hline & $\mathrm{n}$ & $\%$ & IC (95\%) & $\mathrm{n}$ & $\%$ & IC (95\%) & $\mathrm{n}$ & $\%$ & IC (95\%) & $\mathrm{n}$ & $\%$ & IC (95\%) & \\
\hline 1 & 24 & 21,2 & {$[14,1 ; 29,9]$} & 81 & 71,7 & {$[62,4 ; 79,8]$} & 5 & 4,4 & {$[1,5 ; 10,0]$} & 3 & 2,7 & {$[0,6 ; 7,6]$} & $113(100,0 \%)$ \\
\hline 2 & 10 & 8,1 & {$[3,9 ; 14,3]$} & 113 & 91,1 & {$[84,7 ; 95,5]$} & 0 & 0,0 & {$[0,0 ; 2,9]$} & 1 & 0,8 & {$[0,0 ; 4,4]$} & $124(100,0 \%)$ \\
\hline 3 & 23 & 17,6 & {$[11,5 ; 25,2]$} & 104 & 79,4 & {$[71,4 ; 86,0]$} & 2 & 1,5 & {$[0,2 ; 5,4]$} & 2 & 1,5 & {$[0,2 ; 5,4]$} & $131(100,0 \%)$ \\
\hline 4 & 18 & 13,1 & {$[8,0 ; 20,0]$} & 98 & 71,5 & {$[63,2 ; 78,9]$} & 8 & 5,8 & {$[2,6 ; 11,2]$} & 13 & 9,6 & {$[5,1 ; 15,7]$} & $137(100,0 \%)$ \\
\hline 5 & 15 & 10,3 & {$[5,9 ; 16,4]$} & 111 & 76,0 & {$[68,3 ; 82,7]$} & 18 & 12,3 & {$[7,5 ; 18,8]$} & 2 & 1,4 & {$[0,2 ; 4,9]$} & $146(100,0 \%)$ \\
\hline 6 & 13 & 10,3 & {$[5,6 ; 17,0]$} & 108 & 85,7 & {$[78,4 ; 91,3]$} & 4 & 3,2 & {$[0,9 ; 7,9]$} & 1 & 0,8 & {$[0,0 ; 4,3]$} & $126(100,0 \%)$ \\
\hline 7 & 9 & 6,0 & {$[2,8 ; 11,2]$} & 128 & 85,9 & {$[79,3 ; 91,1]$} & 6 & 4,0 & {$[1,5 ; 8,6]$} & 6 & 4,1 & {$[1,5 ; 8,6]$} & $149(100,0 \%)$ \\
\hline SP & 112 & $13,0 *$ & {$[10,7 ; 15,4]$} & 743 & $80,6^{*}$ & {$[77,9 ; 83,2]$} & 43 & $4,0^{*}$ & {$[2,8 ; 5,2]$} & 28 & & {$[1,5 ; 3,4]$} & $926(100,0 \%)$ \\
\hline
\end{tabular}

*Resultados ponderados pelo número de propriedades nos circuitos (efeito de desenho amostral $=1,17$ ). 
A distribuição dos valores das variáveis quantitativas, como 0 número de vacas em lactação e a produção de leite foram feitas através de diagramas de blocos (figuras 2 e 3). Com base nestas duas variáveis, produziu-se uma terceira, a produtividade de leite (litros/vaca em lactação), e sua distribuição também foi representada num diagrama de blocos (figura 4). 0 número mediano de vacas em lactação, por propriedade visitada, no Estado de São Paulo foi calculado em 7,0 animais (primeiro quartil = 3,0; terceiro quartil $=17,0) \cdot$ A produção mediana de leite, por propriedade amostrada, no Estado de São Paulo foi igual a 30,0 litros (primeiro quartil $=12,0$ litros; terceiro quartil $=90,0$ litros). A produtividade mediana de leite, por propriedade, foi calculada em 5,0 litros no Estado de São Paulo (primeiro quartil = 3,3 litros; terceiro quartil $=6,5$ litros).

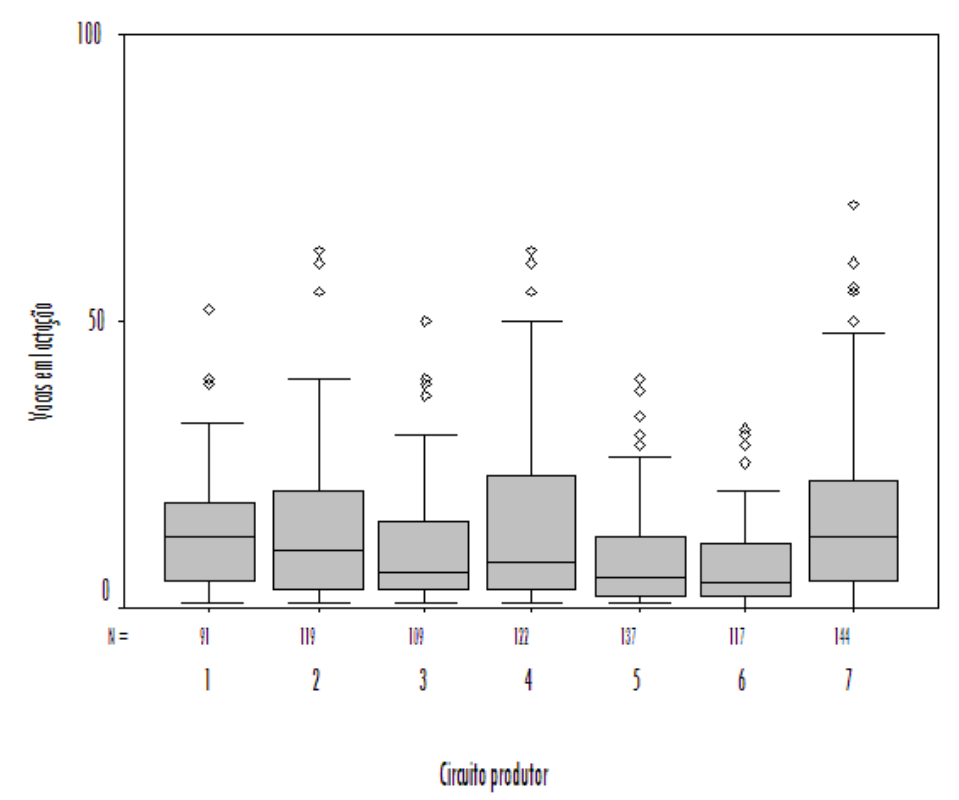

Figura 2 - Número de vacas em lactação nas propriedades, por circuito produtor. Os símbolos sobre os diagramas de blocos representam valores aberrantes 


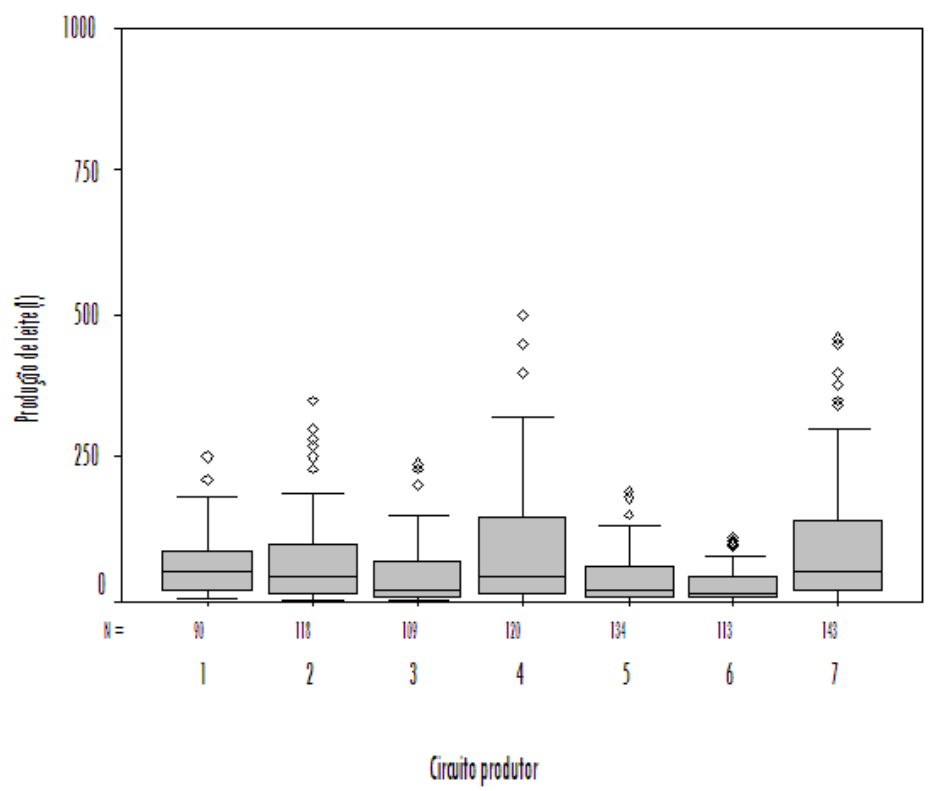

Figura 3 - Produção de leite (em litros) nas propriedades, por circuito produtor. Os símbolos sobre os diagramas de blocos representam valores aberrantes

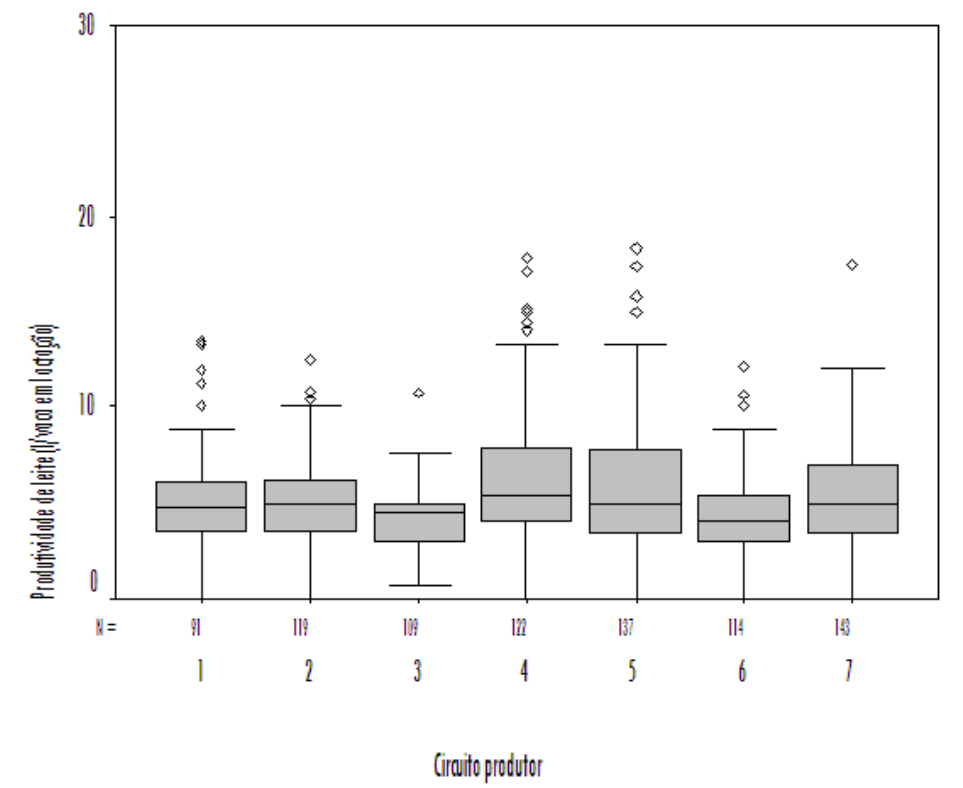

Figura 4 - Produtividade de leite (em litros/vaca em lactação) das propriedades, por circuito produtor. Os símbolos sobre os diagramas de blocos representam valores aberrantes 
Tabela 8 - Distribuição dos tipos de protocolo reprodutivo nas propriedades, por circuitos produtores e no Estado de São Paulo - São Paulo - 2004

\begin{tabular}{|c|c|c|c|c|c|c|c|c|c|c|}
\hline \multirow{3}{*}{ Circuito } & \multicolumn{9}{|c|}{ Uso de Inseminação Artificial } & \\
\hline & \multicolumn{3}{|c|}{ Não } & \multicolumn{3}{|c|}{$\begin{array}{l}\text { Associada a repasse } \\
\text { com touro }\end{array}$} & \multicolumn{3}{|c|}{$\begin{array}{l}\text { Inseminação artificial } \\
\text { somente }\end{array}$} & \\
\hline & $\mathrm{n}$ & $\%$ & IC (95\%)(\%) & $\mathrm{n}$ & $\%$ & IC $(95 \%)(\%)$ & $\mathrm{n}$ & $\%$ & IC (95\%)(\%) & \\
\hline 1 & 124 & 95,4 & {$[90,2 ; 98,3]$} & 3 & 2,3 & {$[0,5 ; 6,6]$} & 3 & 2,3 & {$[0,5 ; 6,6]$} & $130(100,0 \%$ \\
\hline 2 & 134 & 96,4 & {$[91,8 ; 98,8]$} & 5 & 3,6 & {$[1,2 ; 8,2]$} & 0 & 0,0 & {$[0,0 ; 2,6]$} & $139(100,0 \%$ \\
\hline 3 & 141 & 96,6 & {$[92,2 ; 98,9]$} & 4 & 2,7 & {$[0,8 ; 6,9]$} & 1 & 0,7 & {$[0,0 ; 3,8]$} & $146(100,0 \%)$ \\
\hline 4 & 120 & 82,8 & {$[75,6 ; 88,5]$} & 16 & 11,0 & {$[6,4 ; 17,3]$} & 9 & 6,2 & {$[2,9 ; 11,4]$} & $145(100,0 \%)$ \\
\hline 5 & 156 & 91,2 & {$[85,9 ; 95,0]$} & 11 & 6,4 & {$[3,2 ; 11,2]$} & 4 & 2,4 & {$[0,6 ; 5,9]$} & $171(100,0 \%)$ \\
\hline 6 & 132 & 93,0 & {$[87,4 ; 96,6]$} & 8 & 5,6 & {$[2,5 ; 10,8]$} & 2 & 1,4 & {$[0,2 ; 5,0]$} & $142(100,0 \%)$ \\
\hline 7 & 139 & 94,6 & {$[89,6 ; 97,4]$} & 8 & 5,4 & {$[2,4 ; 10,4]$} & 0 & 0,0 & {$[0,0 ; 2,5]$} & $147(100,0 \%)$ \\
\hline SP & 946 & $93,7^{*}$ & {$[92,2 ; 95,2]$} & 55 & $4,7^{*}$ & {$[3,4 ; 6,0]$} & 19 & $1,6^{*}$ & {$[0,9 ; 2,4]$} & $1020(100,0 \%$ \\
\hline
\end{tabular}

*Resultados ponderados pelo número de propriedades nos circuitos (efeito de desenho amostral $=0,98$ ).

Tabela 9 - Distribuição das raças de bovinos nas propriedades, por circuitos produtores e no Estado de São Paulo - São Paulo - 2004

\begin{tabular}{|c|c|c|c|c|c|c|c|}
\hline \multirow{3}{*}{ Circuito } & \multicolumn{6}{|c|}{ Raças de bovinos } & \multirow{3}{*}{ Total } \\
\hline & \multicolumn{3}{|c|}{${\text { Especializadas }{ }^{0}}$} & \multicolumn{3}{|c|}{ Não especializadas } & \\
\hline & $\mathrm{n}$ & $\%$ & IC (95\%) (\%) & $n$ & $\%$ & IC (95\%)(\%) & \\
\hline 1 & 53 & 39,0 & {$[30,7 ; 47,7]$} & 83 & 61,0 & {$[52,3 ; 69,3]$} & $136(100,0 \%)$ \\
\hline 2 & 21 & 15,1 & {$[9,6 ; 22,2]$} & 118 & 84,9 & {$[77,8 ; 90,4]$} & $139(100,0 \%)$ \\
\hline 3 & 63 & 44,7 & {$[36,3 ; 53,3]$} & 78 & 55,3 & {$[46,7 ; 63,7]$} & $141(100,0 \%)$ \\
\hline 4 & 45 & 29,6 & {$[22,5 ; 37,5]$} & 107 & 70,4 & {$[62,5 ; 77,5]$} & $152(100,0 \%)$ \\
\hline 5 & 42 & 24,1 & {$[18,0 ; 31,2]$} & 132 & 75,9 & {$[68,8 ; 82,0]$} & $174(100,0 \%)$ \\
\hline 6 & 31 & 22,1 & {$[15,6 ; 29,9]$} & 109 & 77,9 & {$[70,1 ; 84,4]$} & $140(100,0 \%)$ \\
\hline 7 & 34 & 22,8 & {$[16,3 ; 30,4]$} & 115 & 77,2 & {$[69,6 ; 83,7]$} & $149(100,0 \%)$ \\
\hline SP & 289 & $28,9^{*}$ & {$[26,1 ; 31,8]$} & 742 & $71,1^{*}$ & {$[68,2 ; 73,9]$} & $1031(100,0 \%)$ \\
\hline
\end{tabular}

*Resultados ponderados pelo número de propriedades nos circuitos (efeito de desenho amostral $=1,08$ ).

anclui zebu, europeu de leite e europeu de corte.

bInclui metiço e outras raças.

Foram calculados os valores medianos do número de machos bovinos nas propriedades, por faixas etárias, no Estado de São Paulo: (a) machos castrados $=8,0$ (primeiro quartil $=3,0$; terceiro quartil $=$ 22,8), (b) 0 a 6 meses de idade $=3,0$ (primeiro quartil $=2,0$; terceiro quartil $=8,0),(c) 6$ a 12 meses de idade $=5,0$ (primeiro quartil $=2,0$; terceiro quartil $=10,0$ ), (d) 12 a 24 meses de idade $=3,0$ (primeiro quartil $=1,8$; terceiro quartil $=10,0)$ e $(e)$ maiores que 24 meses de idade $=1,0$ (primeiro quartil $=1,0$; terceiro quartil $=2,0$ ). Os valores correspondentes aos circuitos produtores estão nos diagramas de blocos da figura 5. 


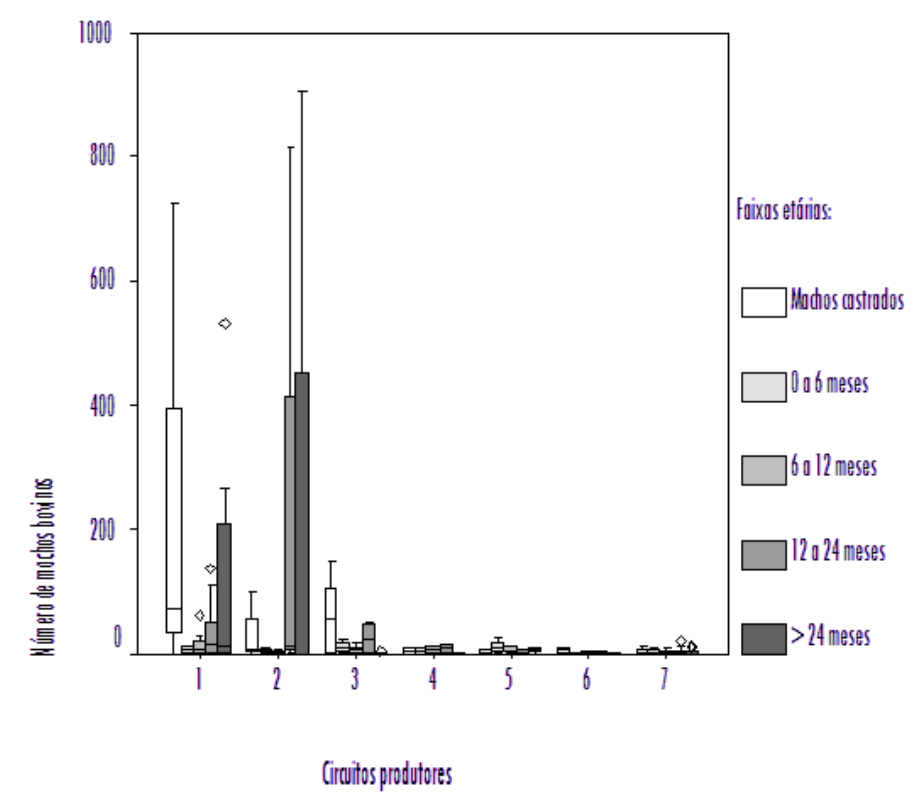

Figura 5-Estudo das faixas etárias de machos bovinos nas propriedades, por circuito produtor. Os símbolos sobre os diagramas de blocos representam valores aberrantes

Foram calculados também os valores medianos do número de fêmeas bovinas nas propriedades, por faixas etárias, no Estado de São Paulo: (a) 0 a 6 meses de idade $=4,0$ (primeiro quartil $=2,0$; terceiro quartil $=9,0),($ b) 6 a 12 meses de idade $=5,0$ (primeiro quartil $=2,0$; terceiro quartil $=10,0),(c) 12$ a 24 meses de idade $=6,0($ primeiro quartil $=2,0$; terceiro quartil $=15,0)$ e $($ d) maiores que 24 meses de idade $=14,0$ (primeiro quartil $=5,0$; terceiro quartil $=39,0$ ). 0 s valores correspondentes aos circuitos produtores estão nos diagramas de blocos da figura 6. 


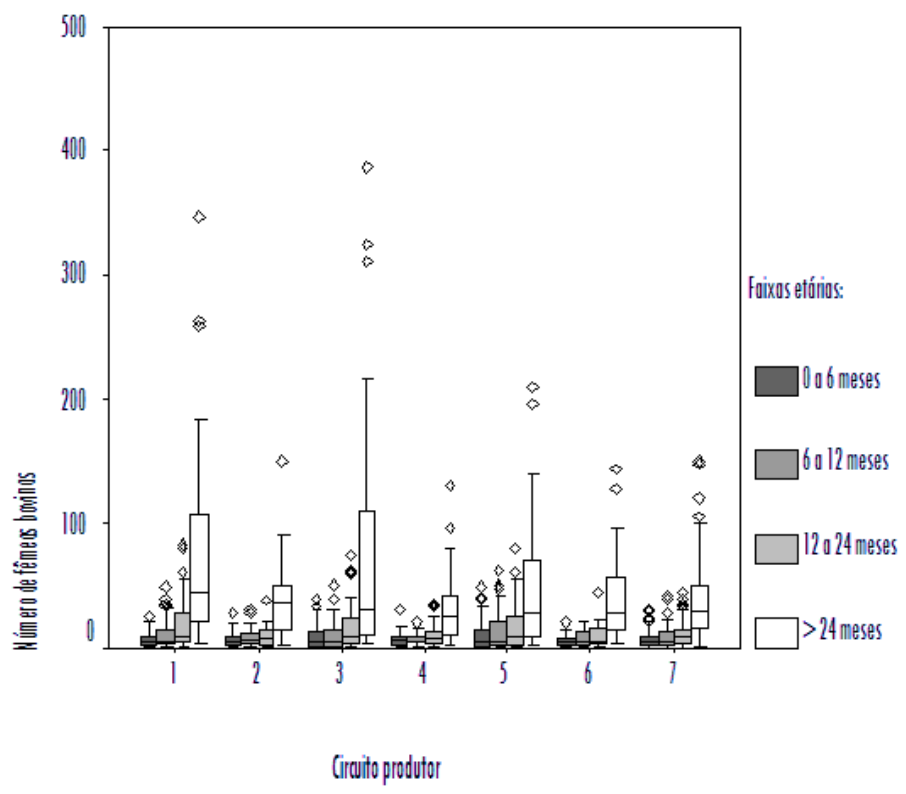

Figura 6 - Estudo das faixas etárias de fêmeas bovinas nas propriedades, por circuito produtor. Os símbolos sobre os diagramas de blocos representam valores aberrantes

0 valor mediano do número total de bovinos nas propriedades, no Estado de São Paulo é 37,5 (primeiro quartil $=14,0$; terceiro quartil $=87,0$ ). 0 s valores correspondentes aos circuitos produtores estão nos diagramas de blocos da figura 7 .

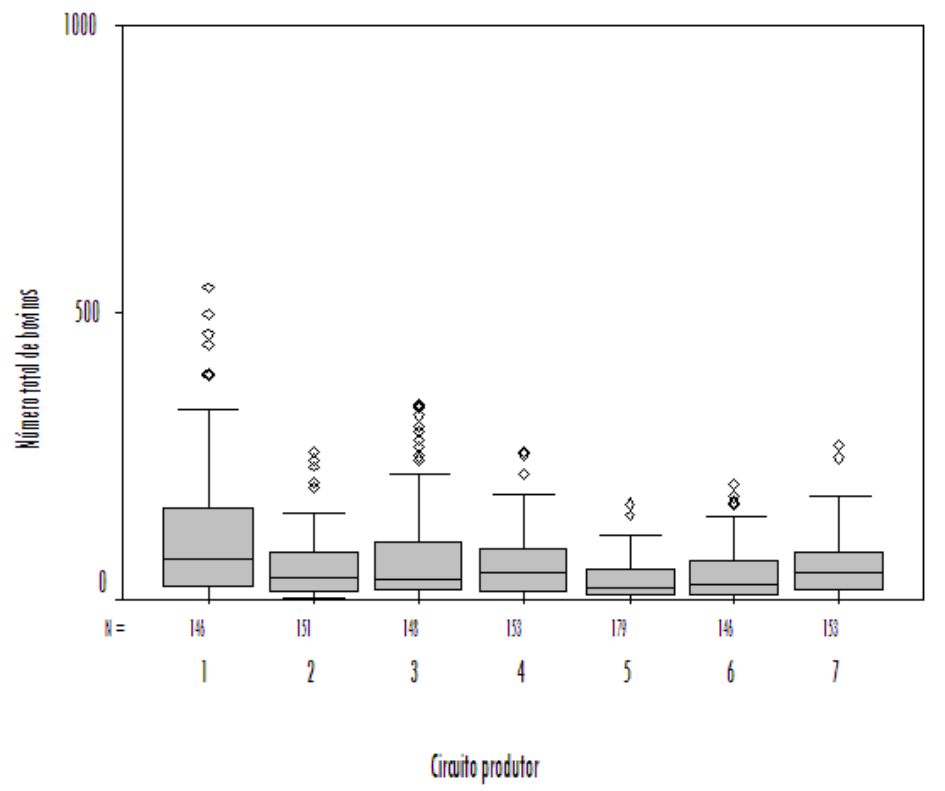

Figura 7 - Número total de bovinos nas propriedades, por circuito produtor. Os símbolos sobre os diagramas de blocos representam valores aberrantes 
Calculou-se as frequiências de ocorrência de espécies domésticas nas propriedades, no Estado de São Paulo: (a) ovinos $/$ caprinos $=22,0 \%(I C=[18,0 ; 25,0]),(b)$ equiinos $=82,0 \%(I C=[78,0 ; 85,0]),(c)$ suínos $=51,0 \%(I C=[47,0 ; 55,0]),(\mathrm{d})$ aves $=72,0 \%(\mathrm{IC}=[68,0 ; 75,0]),(\mathrm{e})$ caninos $=82,0 \%(\mathrm{IC}=[79,0 ; 86,0] \mathrm{e}$ (f) felinos $=51,0(\mathrm{IC}=[47,0 ; 56,0])$. Os valores correspondentes aos circuitos produtores estão no gráfico da figura 8.

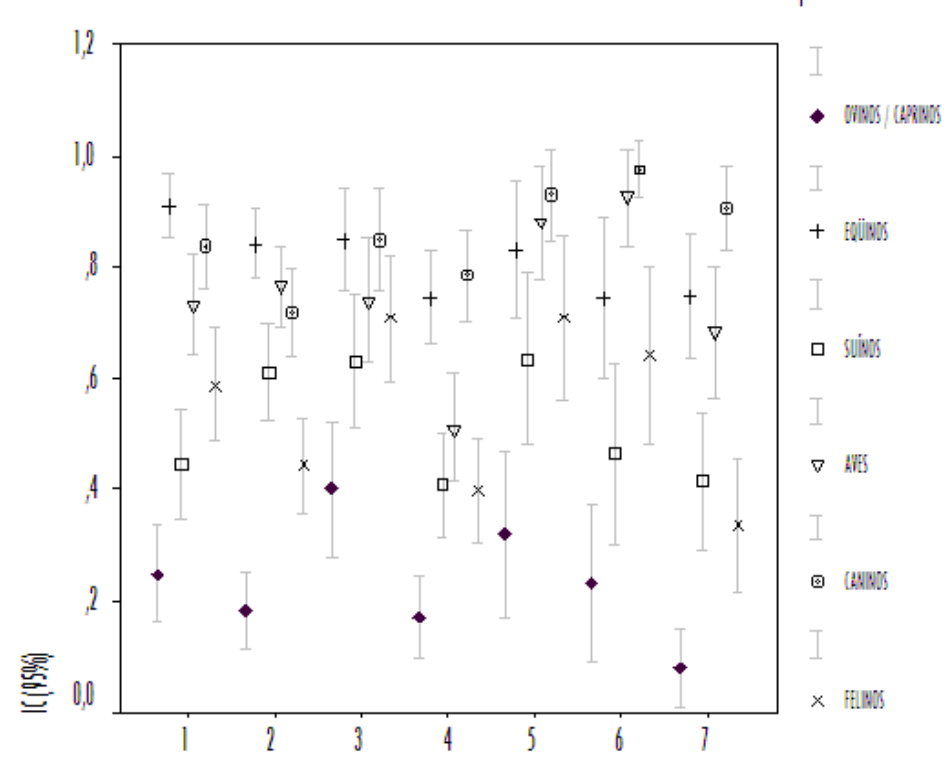

Circito produtor

Figura 8 - Frequiência de ocorrência de outras espécies domésticas, que não a bovina, nas propriedades, por circuito produtor. As linhas representam os intervalos de confiança

Calculou-se também as frequiências de ocorrência de espécies silvestres nas propriedades, no Estado de São Paulo: (a) ausência de animais silvestres $=30,0 \%(I C=[26,0 ; 34,0])$, (b) cervídeos $=12,0 \%$ (IC $=$ $[9,0 ; 15,0]),(c)$ capivaras $=25,0 \%(I C=[21,0 ; 28,0])$ e $(d)$ outras espécies $=10,0 \%(I C=[7,6 ; 13,0]) .0 \mathrm{~s}$ valores correspondentes aos circuitos produtores estão no gráfico da figura 9. 


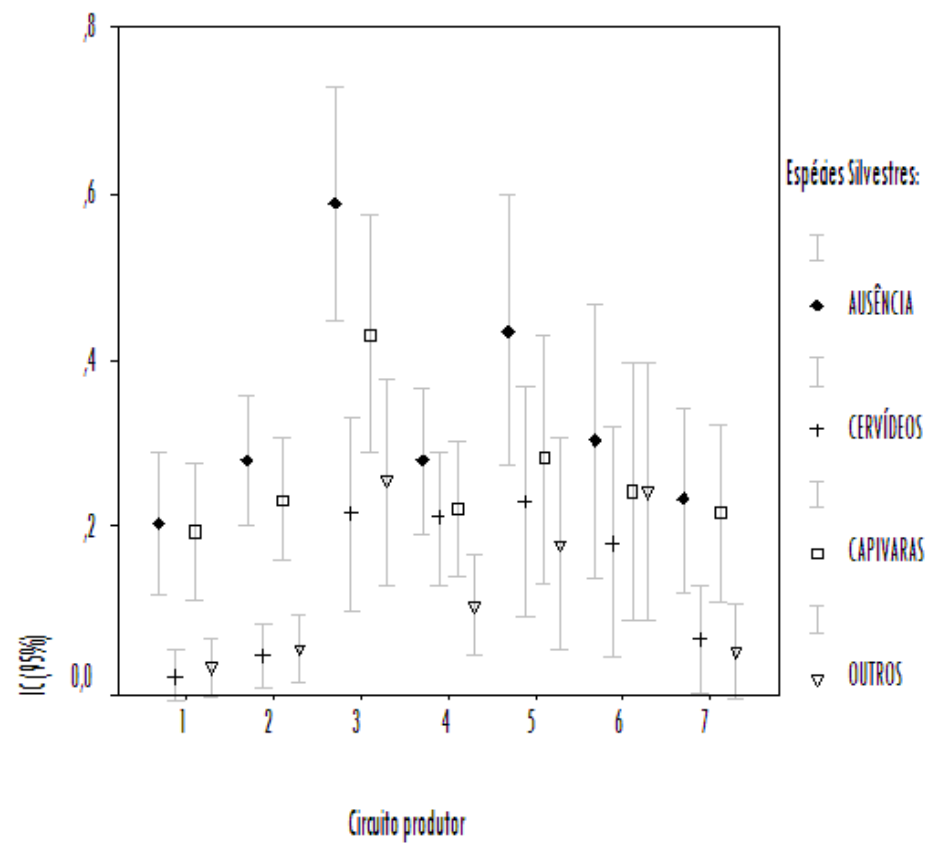

Figura 9 - Frequiência de ocorrência de espécies silvestres nas propriedades, por circuito produtor. As linhas representam os intervalos de confiança

Tabela 10 - Distribuição da ocorrência de abortos (sem causa comprovada) de outubro de 2000 a dezembro de 2001 nas propriedades, por circuitos produtores e no Estado de São Paulo - São Paulo 2004

\begin{tabular}{|c|c|c|c|c|c|c|c|}
\hline \multirow{3}{*}{ Circuito } & \multicolumn{6}{|c|}{ Abortos } & \multirow{3}{*}{ Total } \\
\hline & \multicolumn{3}{|c|}{ Não } & \multicolumn{3}{|c|}{ Sim } & \\
\hline & $\mathrm{n}$ & $\%$ & IC (95\%) (\%) & $\mathrm{n}$ & $\%$ & IC (95\%)(\%) & \\
\hline 1 & 114 & 93,4 & {$[87,5 ; 97,1]$} & 8 & 6,6 & {$[2,9 ; 12,5]$} & $122(100 \%)$ \\
\hline 2 & 122 & 92,4 & {$[86,5 ; 96,3]$} & 10 & 7,6 & {$[3,7 ; 13,5]$} & $132(100 \%)$ \\
\hline 3 & 123 & 86,6 & {$[79,9 ; 91,7]$} & 19 & 13,4 & {$[8,2 ; 20,1]$} & $142(100 \%)$ \\
\hline 4 & 124 & 84,3 & {$[77,4 ; 89,8]$} & 23 & 15,7 & {$[10,2 ; 22,5]$} & $147(100 \%)$ \\
\hline 5 & 145 & 83,3 & {$[76,9 ; 88,5]$} & 29 & 16,7 & {$[11,5 ; 23,0]$} & $174(100 \%)$ \\
\hline 6 & 111 & 80,4 & {$[72,8 ; 86,7]$} & 27 & 19,6 & {$[13,3 ; 27,2]$} & $138(100 \%)$ \\
\hline 7 & 93 & 71,5 & {$[63,0 ; 79,1]$} & 37 & 28,5 & {$[20,9 ; 37,0]$} & $130(100 \%)$ \\
\hline SP & 832 & $86,6^{*}$ & {$[84,5 ; 88,7]$} & 153 & $13,4^{*}$ & {$[11,2 ; 15,5]$} & $985(100 \%)$ \\
\hline
\end{tabular}

*Resultados ponderados pelo número de propriedades nos circuitos (efeito de desenho amostral $=1,00$ ). 
Tabela 11 - Distribuição dos tipos de manejo de material abortado nas propriedades, por circuitos produtores e no Estado de São Paulo - São Paulo - 2004

\begin{tabular}{|c|c|c|c|c|c|c|c|c|c|c|}
\hline \multirow{3}{*}{ Circuito } & \multicolumn{9}{|c|}{ Destino do aborto } & \\
\hline & \multicolumn{3}{|c|}{ Não faz nada } & \multicolumn{3}{|c|}{ Alimenta porcos ou cães } & \multicolumn{3}{|c|}{ Adequado $^{\circ}$} & \\
\hline & $\mathrm{n}$ & $\%$ & IC (95\%)(\%) & $\mathrm{n}$ & $\%$ & IC $(95 \%)(\%)$ & $\mathrm{n}$ & $\%$ & IC (95\%) (\%) & \\
\hline 1 & 18 & 42,9 & {$[27,7 ; 59,0]$} & 0 & 0,0 & {$[0,0 ; 8,4]$} & 24 & 57,1 & {$[41,0 ; 72,3]$} & $42\left(100,0^{0}\right)$ \\
\hline 2 & 28 & 43,8 & {$[31,4 ; 56,7]$} & 1 & 1,6 & {$[0,0 ; 8,4]$} & 35 & 54,6 & {$[41,7 ; 67,2]$} & $64(100,0 \%$ \\
\hline 3 & 30 & 39,0 & {$[28,0 ; 50,7]$} & 0 & 0,0 & {$[0,0 ; 4,7]$} & 47 & 61,0 & {$[49,2 ; 72,0]$} & $77(100,0 \%$ \\
\hline 4 & 21 & 29,2 & {$[19,0 ; 41,1]$} & 2 & 2,8 & {$[0,3 ; 9,7]$} & 49 & 68,0 & {$[56,0 ; 78,6]$} & $72(100,0 \%$ \\
\hline 5 & 72 & 67,9 & {$[58,2 ; 76,7]$} & 2 & 1,9 & {$[0,2 ; 6,6]$} & 32 & 30,2 & {$[21,7 ; 39,9]$} & $106(100,0 \%$ \\
\hline 6 & 49 & 61,3 & {$[49,7 ; 71,9]$} & 1 & 1,3 & {$[0,0 ; 6,8]$} & 30 & 37,4 & {$[26,9 ; 49,0]$} & $80(100,0 \%$ \\
\hline 7 & 57 & 49,6 & {$[40,1 ; 59,0]$} & 6 & 5,2 & {$[1,9 ; 11,0]$} & 52 & 45,2 & {$[35,9 ; 54,8]$} & $115(100,0 \%)$ \\
\hline SP & 275 & $48,4^{*}$ & {$[44,0 ; 52,8]$} & 12 & $1,6^{*}$ & {$[0,6 ; 2,5]$} & 269 & $50,0^{*}$ & {$[45,6 ; 54,4]$} & $556(100,0 \%$ \\
\hline
\end{tabular}

*Resultados ponderados pelo número de propriedades nos circuitos (efeito de desenho amostral = 1,12).

anclui enterro, jogar em fossa e queima.

Tabela 12 - Distribuição da utilização de testes diagnósticos para deteç̧ão de brucelose nas propriedades, por circuitos produtores e no Estado de São Paulo - São Paulo - 2004

\begin{tabular}{|c|c|c|c|c|c|c|c|}
\hline \multirow{3}{*}{ Circuito } & \multicolumn{6}{|c|}{ Testes para brucelose } & \multirow{3}{*}{ Total } \\
\hline & \multicolumn{3}{|c|}{ Não } & \multicolumn{3}{|c|}{ Sim } & \\
\hline & $\mathrm{n}$ & $\%$ & IC (95\%) (\%) & $\mathrm{n}$ & $\%$ & IC (95\%)(\%) & \\
\hline 1 & 108 & 80,6 & {$[72,9 ; 86,9]$} & 26 & 19,4 & {$[13,1 ; 27,1]$} & $134(100 \%)$ \\
\hline 2 & 139 & 92,7 & {$[87,3 ; 96,3]$} & 11 & 7,3 & {$[3,7 ; 12,7]$} & $150(100 \%)$ \\
\hline 3 & 117 & 82,4 & {$[75,1 ; 88,3]$} & 25 & 17,6 & {$[11,7 ; 24,9]$} & $142(100 \%)$ \\
\hline 4 & 106 & 70,2 & {$[62,2 ; 77,4]$} & 45 & 29,8 & {$[22,6 ; 37,8]$} & $151(100 \%)$ \\
\hline 5 & 140 & 81,4 & {$[74,8 ; 86,9]$} & 32 & 18,6 & {$[13,1 ; 25,2]$} & $172(100 \%)$ \\
\hline 6 & 121 & 85,2 & {$[78,3 ; 90,6]$} & 21 & 14,8 & {$[9,4 ; 21,7]$} & $142(100 \%)$ \\
\hline 7 & 102 & 67,5 & {$[59,5 ; 74,9]$} & 49 & 32,5 & {$[25,1 ; 40,5]$} & $151(100 \%)$ \\
\hline SP & 833 & $82,4^{*}$ & {$[80,1 ; 84,8]$} & 209 & $17,6^{*}$ & {$[15,2 ; 19,9]$} & $1042(100 \%)$ \\
\hline
\end{tabular}

*Resultados ponderados pelo número de propriedades nos circuitos (efeito de desenho amostral $=1,02$ ).

Tabela 13 - Distribuição dos tipos de reposição de bovinos nas propriedades, por circuitos produtores e no Estado de São Paulo - São Paulo - 2004

\begin{tabular}{|c|c|c|c|c|c|c|c|}
\hline \multirow{3}{*}{ Circuito } & \multicolumn{6}{|c|}{ Compra de reprodutores } & \multirow{3}{*}{ Total } \\
\hline & \multicolumn{3}{|c|}{ Não } & \multicolumn{3}{|c|}{ Sim } & \\
\hline & $\mathrm{n}$ & $\%$ & IC (95\%) (\%) & $\mathrm{n}$ & $\%$ & IC (95\%)(\%) & \\
\hline 1 & 79 & 56,4 & {$[47,8 ; 64,8]$} & $61(\%)$ & 43,6 & {$[35,2 ; 52,2]$} & $140(100,0 \%)$ \\
\hline 2 & 103 & 70,1 & {$[62,0 ; 77,3]$} & $44(\%)$ & 29,9 & {$[22,7 ; 38,0]$} & $147(100,0 \%)$ \\
\hline 3 & 83 & 57,6 & {$[49,1 ; 65,8]$} & $61(\%)$ & 42,4 & {$[34,2 ; 50,9]$} & $144(100,0 \%)$ \\
\hline 4 & 98 & 64,5 & {$[56,3 ; 72,1]$} & $54(\%)$ & 35,5 & {$[27,9 ; 43,7]$} & $152(100,0 \%)$ \\
\hline 5 & 103 & 58,9 & {$[51,2 ; 66,2]$} & $72(\%)$ & 41,1 & {$[33,8 ; 48,8]$} & $175(100,0 \%)$ \\
\hline 6 & 89 & 61,4 & {$[52,9 ; 69,3]$} & $56(\%)$ & 38,6 & {$[30,7 ; 47,1]$} & $145(100,0 \%)$ \\
\hline 7 & 97 & 63,8 & {$[55,6 ; 71,4]$} & $55(\%)$ & 36,2 & {$[28,6 ; 44,4]$} & $152(100,0 \%)$ \\
\hline SP & 652 & $61,8^{*}$ & {$[58,7 ; 64,9]$} & $403(\%)$ & $38,2^{*}$ & {$[35,1 ; 41,3]$} & $1055(100,0 \%)$ \\
\hline
\end{tabular}

*Resultados ponderados pelo número de propriedades nos circuitos (efeito de desenho amostral $=1,13$ ). 
Tabela 14 - Distribuição da ocorrência de venda de reprodutores nas propriedades, por circuitos produtores e no Estado de São Paulo - São Paulo - 2004

\begin{tabular}{|c|c|c|c|c|c|c|c|}
\hline \multirow{3}{*}{ Circuito } & \multicolumn{6}{|c|}{ Venda de reprodutores } & \multirow{3}{*}{ Total } \\
\hline & \multicolumn{2}{|c|}{ Não } & & \multicolumn{3}{|c|}{ Sim } & \\
\hline & $\mathrm{n}$ & $\%$ & IC (95\%)(\%) & $\mathrm{n}$ & $\%$ & IC (95\%)(\%) & \\
\hline 1 & 101 & 71,6 & {$[63,4 ; 78,9]$} & 40 & 28,4 & {$[21,1 ; 36,6]$} & $141(100 \%)$ \\
\hline 2 & 113 & 78,5 & {$[70,9 ; 84,9]$} & 31 & 21,5 & {$[15,1 ; 29,1]$} & $144(100 \%)$ \\
\hline 3 & 115 & 79,9 & {$[72,4 ; 86,1]$} & 29 & 20,1 & {$[13,9 ; 27,6]$} & $144(100 \%)$ \\
\hline 4 & 112 & 74,2 & {$[66,4 ; 80,9]$} & 39 & 25,8 & {$[19,1 ; 33,6]$} & $151(100 \%)$ \\
\hline 5 & 134 & 75,7 & {$[68,7 ; 81,8]$} & 43 & 24,3 & {$[18,2 ; 31,3]$} & $177(100 \%)$ \\
\hline 6 & 99 & 68,8 & {$[60,5 ; 76,2]$} & 45 & 31,3 & {$[23,8 ; 39,5]$} & $144(100 \%)$ \\
\hline 7 & 99 & 66,4 & {$[58,3 ; 74,0]$} & 50 & 33,6 & {$[26,0 ; 41,7]$} & $149(100 \%)$ \\
\hline SP & 773 & $74,8^{*}$ & {$[72,0 ; 77,6]$} & 277 & $25,2^{*}$ & {$[22,4 ; 28,0]$} & $1050(100 \%)$ \\
\hline
\end{tabular}

*Resultados ponderados pelo número de propriedades nos circuitos (efeito de desenho amostral = 1,12).

Tabela 15 - Distribuição da prática de vacinação contra brucelose nas propriedades, por circuitos produtores e no Estado de São Paulo - São Paulo - 2004

\begin{tabular}{|c|c|c|c|c|c|c|c|c|c|c|}
\hline \multirow{3}{*}{ Circuito } & \multicolumn{9}{|c|}{ Vacinação contra brucelose } & \multirow{3}{*}{ Total } \\
\hline & \multicolumn{3}{|c|}{ Não vacina } & \multicolumn{3}{|c|}{ Fêmeas até 8 meses } & \multicolumn{3}{|c|}{ Fêmeas de qualquer idade } & \\
\hline & $\mathrm{n}$ & $\%$ & IC (95\%) (\%) & $\mathrm{n}$ & $\%$ & IC (95\%)(\%) & $n$ & $\%$ & IC (95\%)(\%) & \\
\hline 1 & 15 & 11,1 & {$[6,3 ; 17,7]$} & 120 & 88,9 & {$[82,3 ; 93,6]$} & 0 & 0,0 & {$[0,0 ; 2,7]$} & $135(100,0 \%)$ \\
\hline 2 & 12 & 8,0 & {$[4,2 ; 13,6]$} & 137 & 91,3 & {$[85,6 ; 95,3]$} & 1 & 0,7 & {$[0,0 ; 3,7]$} & $150(100,0 \%)$ \\
\hline 3 & 20 & 13,7 & {$[8,6 ; 20,4]$} & 125 & 85,6 & {$[78,9 ; 90,9]$} & 1 & 0,7 & {$[0,0 ; 3,8]$} & $146(100,0 \%)$ \\
\hline 4 & 35 & 23,0 & {$[16,6 ; 30,5]$} & 116 & 76,3 & {$[68,7 ; 82,8]$} & 1 & 0,7 & {$[0,0 ; 3,6]$} & $152(100,0 \%)$ \\
\hline 5 & 19 & 10,9 & {$[6,7 ; 16,4]$} & 156 & 89,1 & {$[83,6 ; 93,3]$} & 0 & 0,0 & {$[0,0 ; 2,1]$} & $175(100,0 \%)$ \\
\hline 6 & 17 & 11,8 & {$[7,0 ; 18,2]$} & 127 & 88,2 & {$[81,8 ; 93,0]$} & 0 & 0,0 & {$[0,0 ; 2,5]$} & $144(100,0 \%)$ \\
\hline 7 & 39 & 27,1 & {$[20,0 ; 35,1]$} & 105 & 72,9 & {$[64,9 ; 80,0]$} & 0 & 0,0 & {$[0,0 ; 2,5]$} & $144(100,0 \%)$ \\
\hline SP & 157 & $12,8^{*}$ & {$[10,7 ; 14,8]$} & 886 & $86,9^{*}$ & {$[84,8 ; 89,0]$} & 3 & $0,0^{*}$ & {$[0,0 ; 0,7]$} & $1043(100,0 \%)$ \\
\hline
\end{tabular}

*Resultados ponderados pelo número de propriedades nos circuitos (efeito de desenho amostral $=1,04$ ).

Calculou-se a distribuição dos destinos de reprodutores para abate nas propriedades, no Estado de São Paulo: (a) não abatem $=45,0 \%$ (IC $=[41,8 ; 48,1])$, (b) abatedouro com inspeção $=34,3 \%$ (IC $=[31,3$; $37,3]),(c)$ abatedouro sem inspeção $=13,7 \%$ (IC $=[11,4 ; 15,9])$ e (d) abate na propriedade $=7,1 \%$ (IC $=$ $[5,5 ; 8,7])$. Os valores correspondentes aos circuitos produtores estão no gráfico da figura 10. 


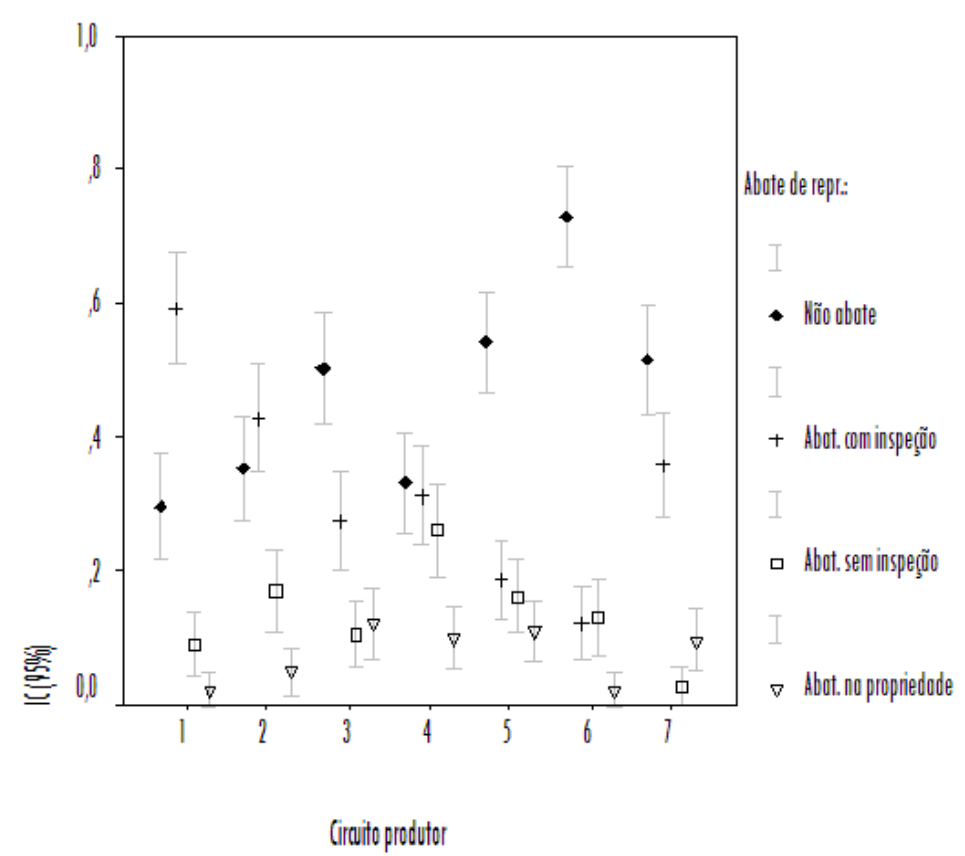

Figura 10 - Distribuição de destino de reprodutores para abate nas propriedades, por circuito produtor. As linhas representam os intervalos de confiança.

Tabela 16 - Distribuição da prática de aluguel de pastos nas propriedades, por circuitos produtores e no Estado de São Paulo - São Paulo - 2004

\begin{tabular}{|c|c|c|c|c|c|c|c|}
\hline \multirow{3}{*}{ Circuito } & \multicolumn{6}{|c|}{ Aluguel de pastos } & \multirow{3}{*}{ Total } \\
\hline & \multicolumn{2}{|c|}{ Não } & & \multicolumn{2}{|c|}{ Sim } & & \\
\hline & $\mathrm{n}$ & $\%$ & IC (95\%) (\%) & $\mathrm{n}$ & $\%$ & IC (95\%) (\%) & \\
\hline 1 & 124 & 86,1 & {$[79,4 ; 91,3]$} & 20 & 13,9 & {$[8,7 ; 20,6]$} & $144(100,0 \%)$ \\
\hline 2 & 127 & 86,4 & {$[79,8 ; 91,5]$} & 20 & 13,6 & {$[8,5 ; 20,2]$} & $147(100,0 \%)$ \\
\hline 3 & 131 & 90,3 & {$[84,3 ; 94,6]$} & 14 & 9,7 & {$[5,4 ; 15,7]$} & $145(100,0 \%)$ \\
\hline 4 & 132 & 86,3 & {$[79,8 ; 91,3]$} & 21 & 13,7 & {$[8,7 ; 20,2]$} & $153(100,0 \%)$ \\
\hline 5 & 142 & 82,1 & {$[75,5 ; 87,5]$} & 31 & 17,9 & {$[12,5 ; 24,5]$} & $173(100,0 \%)$ \\
\hline 6 & 102 & 70,3 & {$[62,2 ; 77,6]$} & 43 & 29,7 & {$[22,4 ; 37,8]$} & $145(100,0 \%)$ \\
\hline 7 & 132 & 88,0 & {$[81,7 ; 92,7]$} & 18 & 12,0 & {$[7,3 ; 18,3]$} & $150(100,0 \%)$ \\
\hline SP & 890 & $84,7^{*}$ & {$[82,5 ; 87,0]$} & 167 & $15,3^{*}$ & {$[13,0 ; 17,5]$} & $1057(100,0 \%)$ \\
\hline
\end{tabular}

*Resultados ponderados pelo número de propriedades nos circuitos (efeito de desenho amostral $=1,08$ ). 
Tabela 17 - Distribuição da presença de pastos comuns com outras propriedades, por circuitos produtores e no Estado de São Paulo - São Paulo - 2004

\begin{tabular}{|c|c|c|c|c|c|c|c|}
\hline \multirow{3}{*}{ Circuito } & \multicolumn{6}{|c|}{ Pasto comum com outra propriedade } & \multirow{3}{*}{ Total } \\
\hline & \multicolumn{3}{|c|}{ Não } & \multicolumn{3}{|c|}{ Sim } & \\
\hline & $\mathrm{n}$ & $\%$ & IC (95\%) (\%) & $\mathrm{n}$ & $\%$ & IC (95\%)(\%) & \\
\hline 1 & 127 & 90,7 & {$[84,6 ; 95,0]$} & 13 & 9,3 & {$[5,0 ; 15,4]$} & $140(100,0 \%)$ \\
\hline 2 & 130 & 89,0 & {$[82,8 ; 93,6]$} & 16 & 11,0 & {$[6,4 ; 17,2]$} & $146(100,0 \%)$ \\
\hline 3 & 126 & 88,1 & {$[81,6 ; 92,9]$} & 17 & 11,9 & {$[7,1 ; 18,4]$} & $143(100,0 \%)$ \\
\hline 4 & 141 & 92,8 & {$[87,4 ; 96,3]$} & 11 & 7,2 & {$[3,7 ; 12,6]$} & $152(100,0 \%)$ \\
\hline 5 & 170 & 96,6 & {$[92,7 ; 98,7]$} & 6 & 3,4 & {$[1,3 ; 7,3]$} & $176(100,0 \%)$ \\
\hline 6 & 125 & 86,8 & {$[80,2 ; 91,9]$} & 19 & 13,2 & {$[8,1 ; 19,8]$} & $144(100,0 \%)$ \\
\hline 7 & 133 & 87,5 & {$[81,2 ; 92,3]$} & 19 & 12,5 & {$[7,7 ; 18,8]$} & $152(100,0 \%)$ \\
\hline SP & 952 & $90,2^{*}$ & {$[88,3 ; 92,2]$} & 101 & $9,8^{*}$ & {$[7,8 ; 11,7]$} & $1053(100,0 \%)$ \\
\hline
\end{tabular}

*Resultados ponderados pelo número de propriedades nos circuitos (efeito de desenho amostral $=1,17$ ).

Tabela 18 - Distribuição da ocorrência de áreas alagadiças nas propriedades, por circuitos produtores e no Estado de São Paulo - São Paulo - 2004

\begin{tabular}{|c|c|c|c|c|c|c|c|}
\hline \multirow{3}{*}{ Circuito } & \multicolumn{6}{|c|}{ Presença de áreas alagadiças } & \multirow{3}{*}{ Total } \\
\hline & \multicolumn{3}{|c|}{ Não } & \multicolumn{3}{|c|}{ Sim } & \\
\hline & $\mathrm{n}$ & $\%$ & IC (95\%) (\%) & $\mathrm{n}$ & $\%$ & IC (95\%)(\%) & \\
\hline 1 & 119 & 83,2 & {$[76,1 ; 88,9]$} & 24 & 16,8 & {$[11,1 ; 23,9]$} & $143(100 \%)$ \\
\hline 2 & 104 & 69,8 & {$[61,7 ; 77,0]$} & 45 & 30,2 & {$[23,0 ; 38,2]$} & $149(100 \%)$ \\
\hline 3 & 92 & 63,0 & {$[54,6 ; 70,8]$} & 54 & 37,0 & {$[29,1 ; 45,4]$} & $146(100 \%)$ \\
\hline 4 & 124 & 82,1 & {$[75,1 ; 87,9]$} & 27 & 17,9 & {$[12,1 ; 24,9]$} & $151(100 \%)$ \\
\hline 5 & 137 & 79,7 & {$[72,8 ; 85,4]$} & 35 & 20,3 & {$[14,6 ; 27,1]$} & $172(100 \%)$ \\
\hline 6 & 83 & 58,5 & {$[49,9 ; 66,6]$} & 59 & 41,5 & {$[33,3 ; 50,1]$} & $142(100 \%)$ \\
\hline 7 & 118 & 78,7 & {$[71,2 ; 84,9]$} & 32 & 21,3 & {$[15,1 ; 28,8]$} & $150(100 \%)$ \\
\hline SP & 777 & $72,8^{*}$ & {$[69,9 ; 75,6]$} & 276 & $27,2^{*}$ & {$[24,4 ; 30,1]$} & $1053(100 \%)$ \\
\hline
\end{tabular}

*Resultados ponderados pelo número de propriedades nos circuitos (efeito de desenho amostral $=1,13$ ).

Tabela 19 - Distribuição da presença de piquete de parição nas propriedades, por circuitos produtores e no Estado de São Paulo - São Paulo - 2004

\begin{tabular}{|c|c|c|c|c|c|c|c|}
\hline \multirow{3}{*}{ Circuito } & \multicolumn{6}{|c|}{ Presença de piquete de parição } & \multirow{3}{*}{ Total } \\
\hline & \multicolumn{3}{|c|}{ Não } & \multicolumn{3}{|c|}{ Sim } & \\
\hline & $\mathrm{n}$ & $\%$ & IC (95\%) (\%) & $\mathrm{n}$ & $\%$ & IC (95\%)(\%) & \\
\hline 1 & 43 & 30,3 & {$[22,9 ; 38,5]$} & 99 & 69,7 & {$[61,4 ; 77,1]$} & $142(100,0 \%)$ \\
\hline 2 & 44 & 29,5 & {$[22,3 ; 37,5]$} & 105 & 70,5 & {$[62,4 ; 77,6]$} & $149(100,0 \%)$ \\
\hline 3 & 43 & 30,5 & {$[23,0 ; 38,8]$} & 98 & 69,5 & {$[61,2 ; 77,0]$} & $141(100,0 \%)$ \\
\hline 4 & 51 & 33,6 & {$[26,1 ; 41,7]$} & 101 & 66,4 & {$[58,3 ; 73,9]$} & $152(100,0 \%)$ \\
\hline 5 & 44 & 25,0 & {$[18,8 ; 32,1]$} & 132 & 75,0 & {$[67,9 ; 81,2]$} & $176(100,0 \%)$ \\
\hline 6 & 57 & 40,4 & {$[32,2 ; 49,0]$} & 84 & 59,6 & {$[51,0 ; 67,7]$} & $141(100,0 \%)$ \\
\hline 7 & 60 & 40,0 & {$[32,1 ; 48,3]$} & 90 & 60,0 & {$[51,7 ; 67,9]$} & $150(100,0 \%)$ \\
\hline SP & 342 & $31,5^{*}$ & {$[28,5 ; 34,5]$} & 709 & $68,5^{*}$ & {$[65,5 ; 71,5]$} & $1051(100,0 \%)$ \\
\hline
\end{tabular}

*Resultados ponderados pelo número de propriedades nos circuitos (efeito de desenho amostral $=1,13$ ). 
Calculou-se a distribuição dos destinos do leite produzido nas propriedades, no Estado de São Paulo: (a) não entrega leite $=56,3 \%(I C=[53,1 ; 59,4])$, (b) cooperativa $=14,6 \%(I C=[12,5 ; 17,0])$, (c) laticínio $=23,0 \%(\mathrm{IC}=[20,4 ; 25,8])$ e (d) direto ao consumidor $=6,1 \%(\mathrm{IC}=[4,6 ; 7,7])$. Os valores correspondentes aos circuitos produtores estão no gráfico da figura 11.

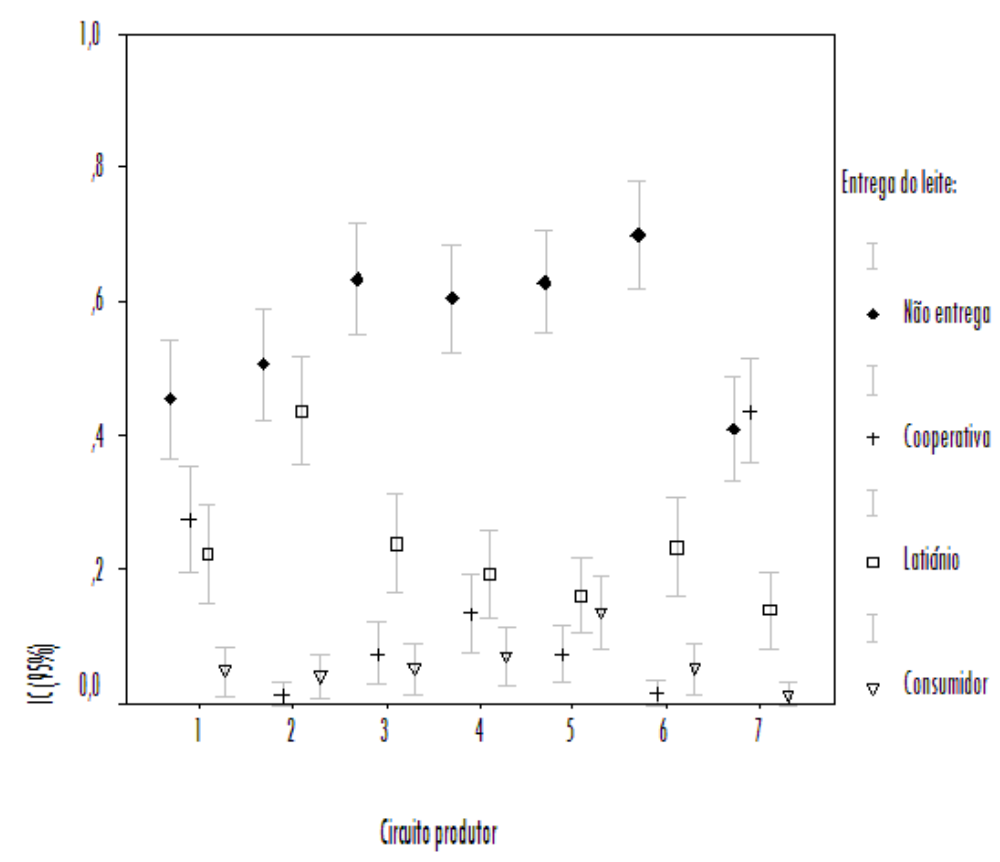

Figura 11 - Distribuição do tipo de entrega de leite das propriedades, por circuito produtor. As linhas representam os intervalos de confiança.

Calculou-se também a distribuição dos fatores relacionados à tecnificação da produção leiteira nas propriedades, no Estado de São Paulo: (a) resfriamento do leite $=15,4 \%$ (IC $=[13,0 ; 17,9])$, (b) entrega à granel $=30,4 \%(I C=[27,3 ; 33,7]),(c)$ produção de queijo e $/$ ou manteiga $=40,2 \%(I C=[37,0 ; 43,3])$ e (d) consumo de leite cru $=29,6 \%$ (IC $=[26,8 ; 32,6])$. Os valores correspondentes aos circuitos produtores estão no gráfico da figura 12. 


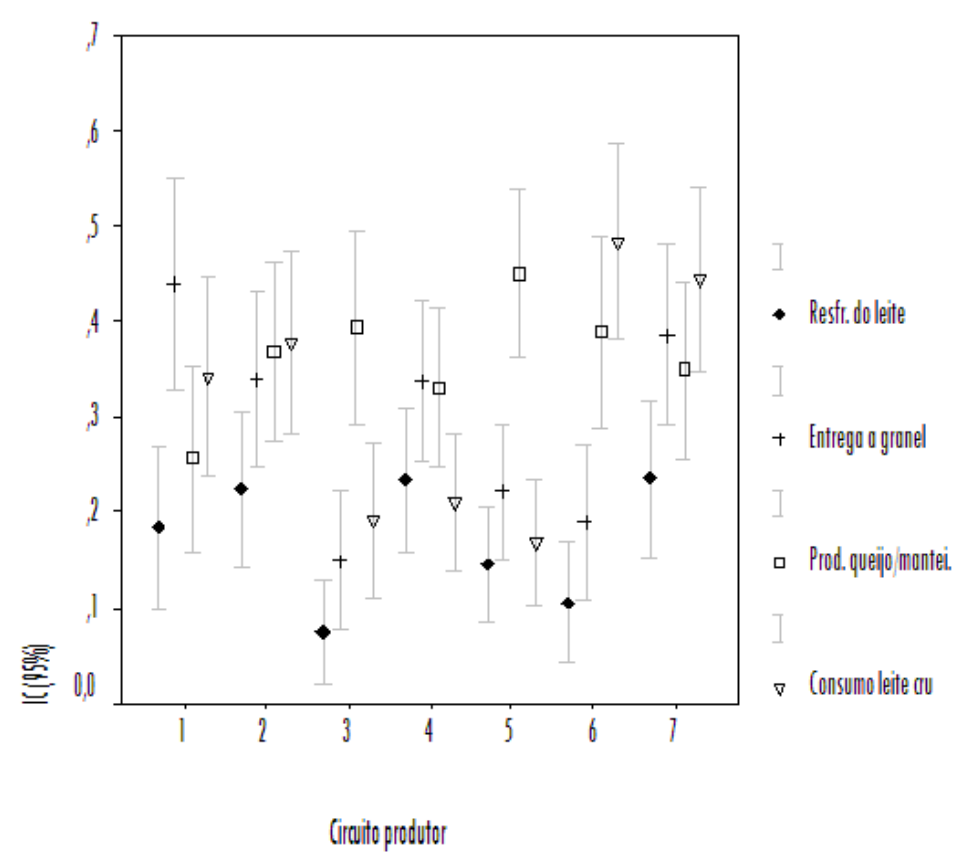

Figura 12 - Distribuição dos fatores relacionados à tecnificação da produção leiteira nas propriedades, por circuito produtor. As linhas representam os intervalos de confiança.

Tabela 20 - Distribuição da presença de assistência veterinária nas propriedades, por circuitos produtores e no Estado de São Paulo - São Paulo - 2004

\begin{tabular}{|c|c|c|c|c|c|c|c|}
\hline \multirow{3}{*}{ Circuito } & \multicolumn{6}{|c|}{ Assistência veterinária } & \multirow{3}{*}{ Total } \\
\hline & \multicolumn{2}{|c|}{ Não } & & \multicolumn{2}{|c|}{ Sim } & & \\
\hline & $\mathrm{n}$ & $\%$ & IC (95\%) (\%) & $\mathrm{n}$ & $\%$ & IC (95\%) (\%) & \\
\hline 1 & 55 & 40,1 & {$[31,9 ; 41,9]$} & 82 & 59,9 & {$[51,1 ; 68,1]$} & $137(100,0 \%)$ \\
\hline 2 & 92 & 63,0 & {$[54,6 ; 70,8]$} & 54 & 37,0 & {$[29,1 ; 45,4]$} & $146(100,0 \%)$ \\
\hline 3 & 95 & 67,9 & {$[59,4 ; 75,5]$} & 45 & 32,1 & {$[24,5 ; 40,5]$} & $140(100,0 \%)$ \\
\hline 4 & 85 & 57,4 & {$[49,0 ; 65,5]$} & 63 & 42,6 & {$[34,5 ; 50,9]$} & $148(100,0 \%)$ \\
\hline 5 & 108 & 62,4 & {$[54,8 ; 69,7]$} & 65 & 37,6 & {$[30,3 ; 45,2]$} & $173(100,0 \%)$ \\
\hline 6 & 122 & 85,9 & {$[79,1 ; 91,2]$} & 20 & 14,1 & {$[8,8 ; 20,9]$} & $142(100,0 \%)$ \\
\hline 7 & 76 & 51,4 & {$[43,0 ; 59,6]$} & 72 & 48,6 & {$[40,4 ; 57,0]$} & $148(100,0 \%)$ \\
\hline SP & 633 & $61,1^{*}$ & {$[58,0 ; 64,2]$} & 401 & $38,9^{*}$ & {$[35,8 ; 42,0]$} & $1034(100,0 \%)$ \\
\hline
\end{tabular}

*Resultados ponderados pelo número de propriedades nos circuitos (efeito de desenho amostral $=1,08$ ).

A última série de diagramas de blocos mostra a distribuição dos animais, segundo o tipo de exploração e tipo de criação (figuras 13 a 15). 


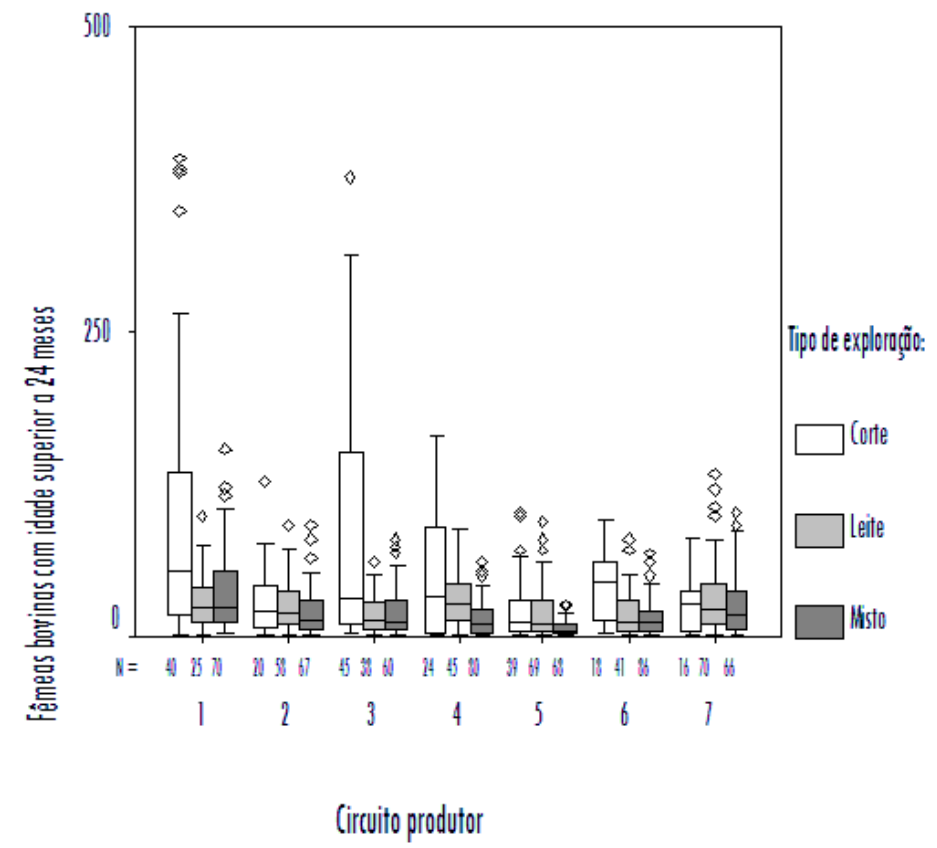

Figura 13 - Distribuição das fêmeas bovinas com idade superior a 24 meses segundo o tipo de exploração, por circuito produtor. 0 s símbolos sobre os diagramas de blocos representam valores aberrantes.

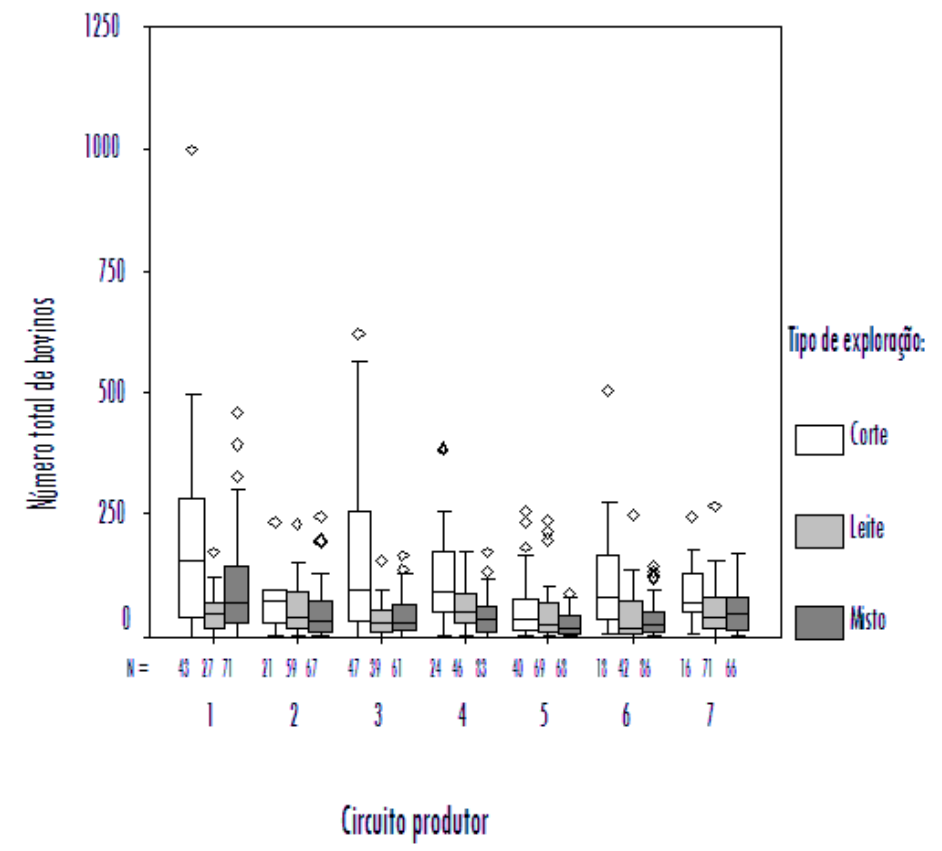

Figura 14 - Distribuição do total de bovinos segundo o tipo de exploração, por circuito produtor. Os símbolos sobre os diagramas de blocos representam valores aberrantes. 


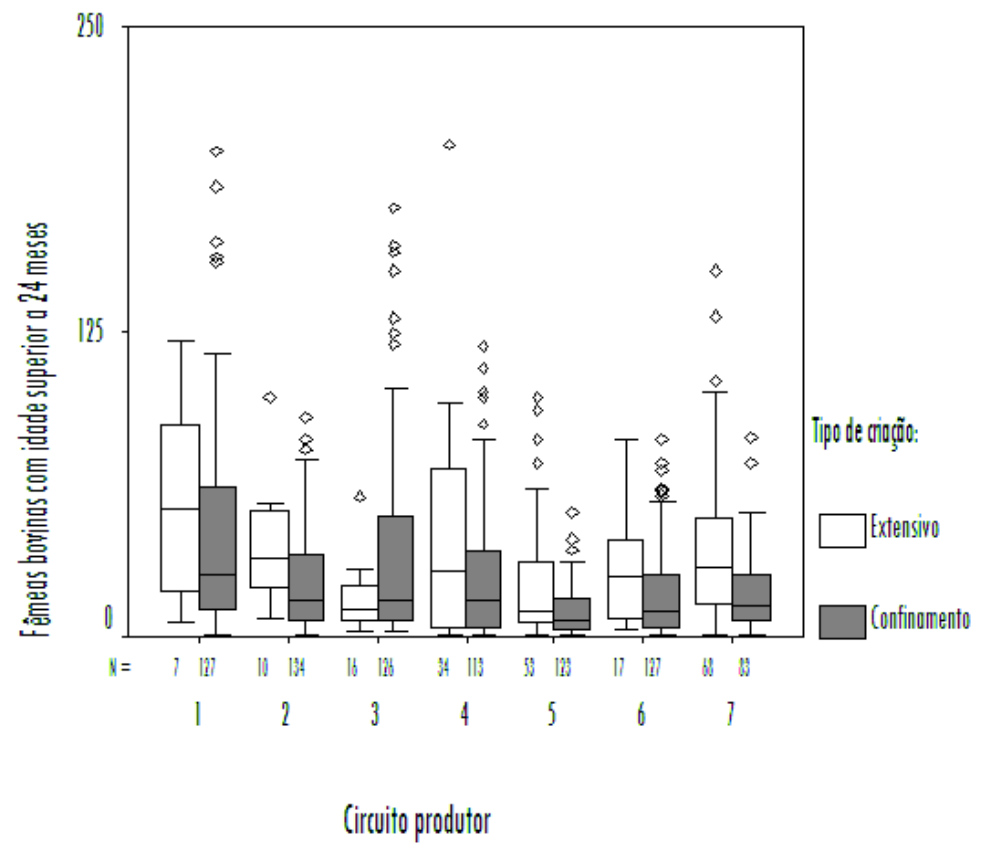

Figura 15 - Distribuição das fêmeas com idade superior a 24 meses segundo 0 tipo de criação, por circuito produtor. 0 s símbolos sobre os diagramas de blocos representam valores aberrantes.

\subsection{LOCALIZAÇÃO ESPACIAL DAS PROPRIEDADES VISITADAS E IDENTIFICAÇÃO DOS AGRUPAMENTOS DE PROPRIEDADES POSITIVAS}

As propriedades visitadas foram localizadas em um mapa georreferenciado do Estado de São Paulo, através das suas coordenadas geográficas, verificadas durante 0 inquérito. Inicialmente, atribuiu-se a estes pontos a condição foco ou livre de brucelose e, posteriormente as características levantadas no estudo epidemiológico, representados na forma de mapas temáticos (Mapas 1 a 15).

A avaliação da presença de aglomerados de propriedades positivas foi realizada como descrito em Material e Método com auxílio do programa de computador R (R Development Core Team, 2004). 


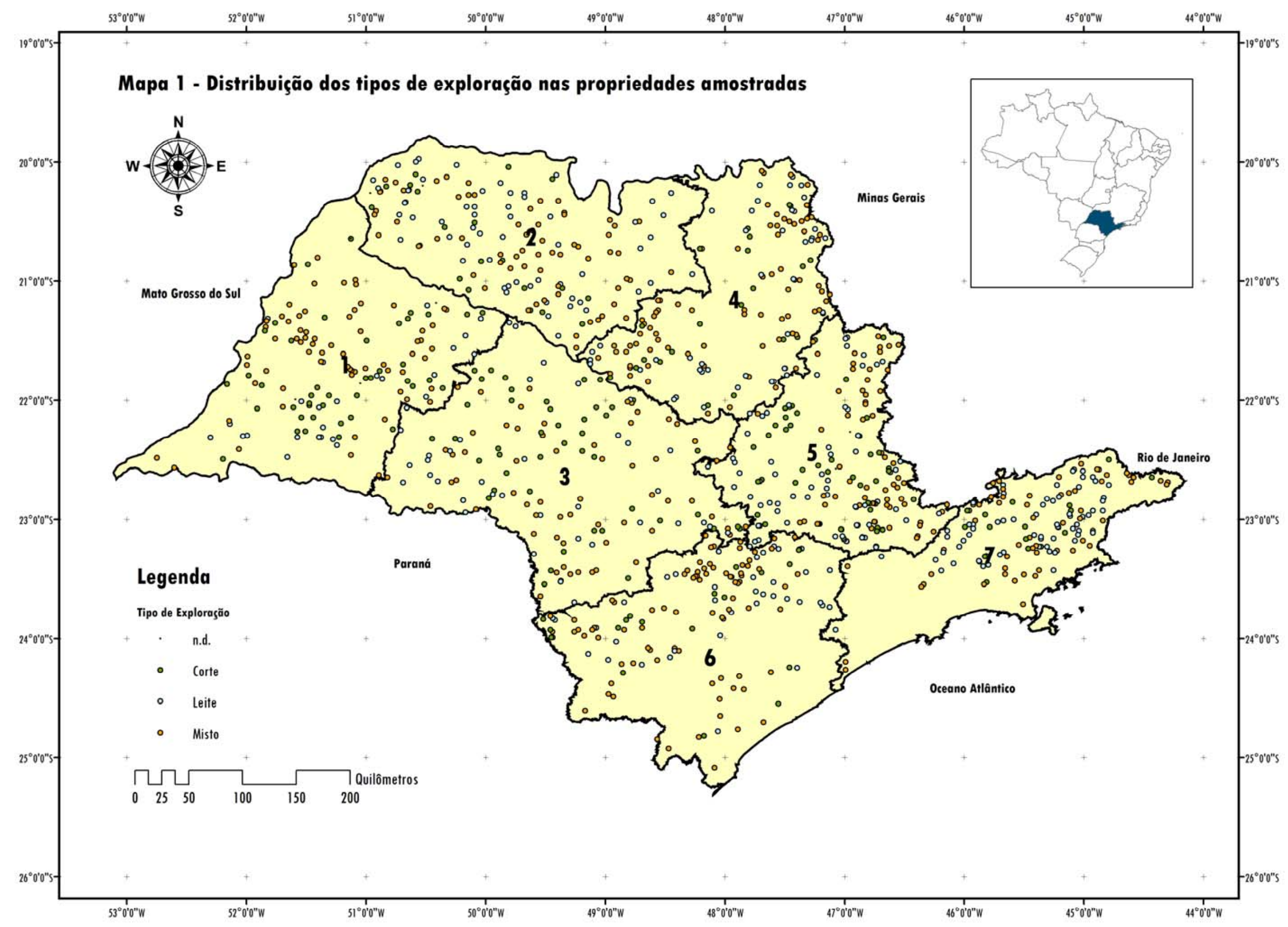




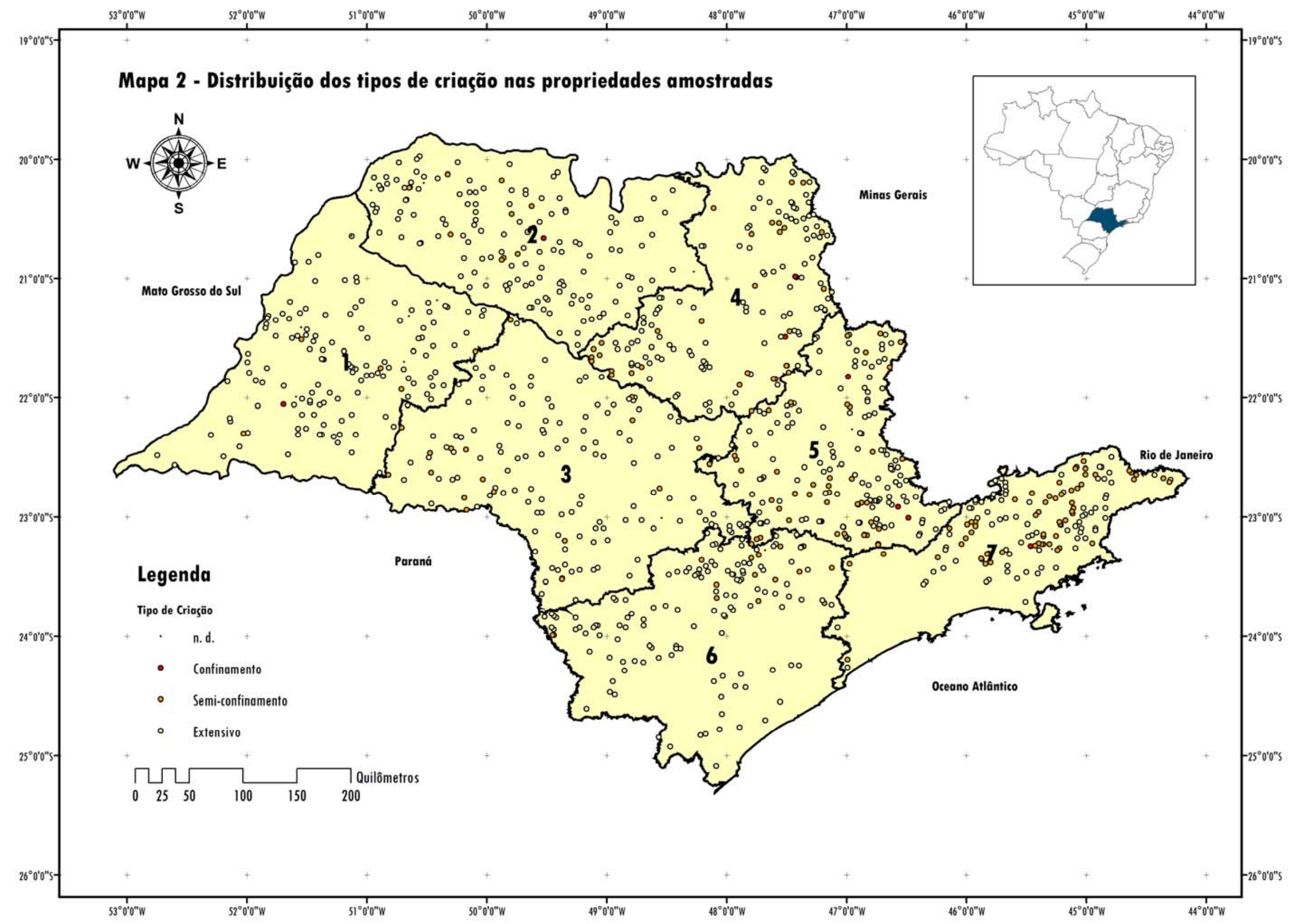




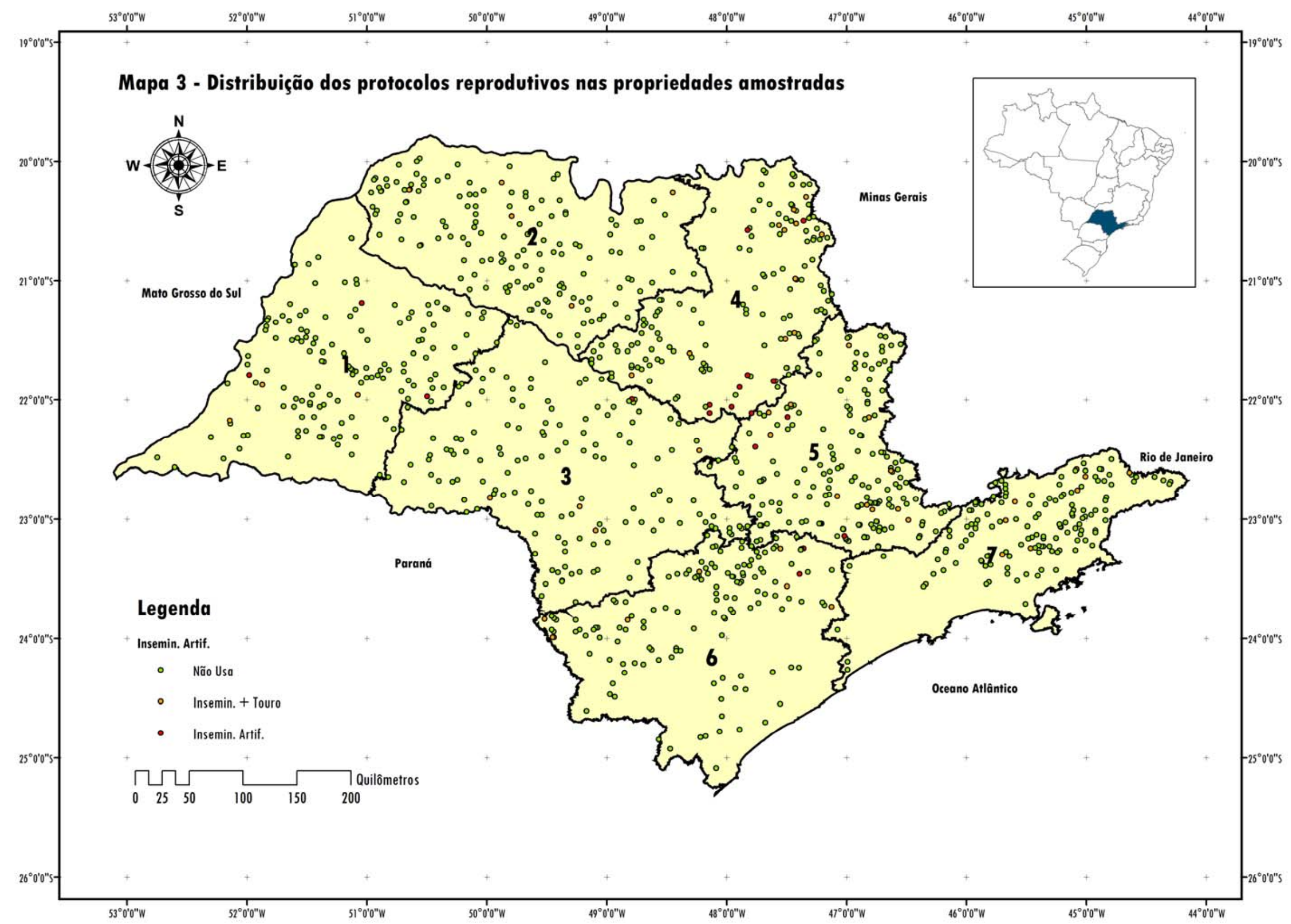




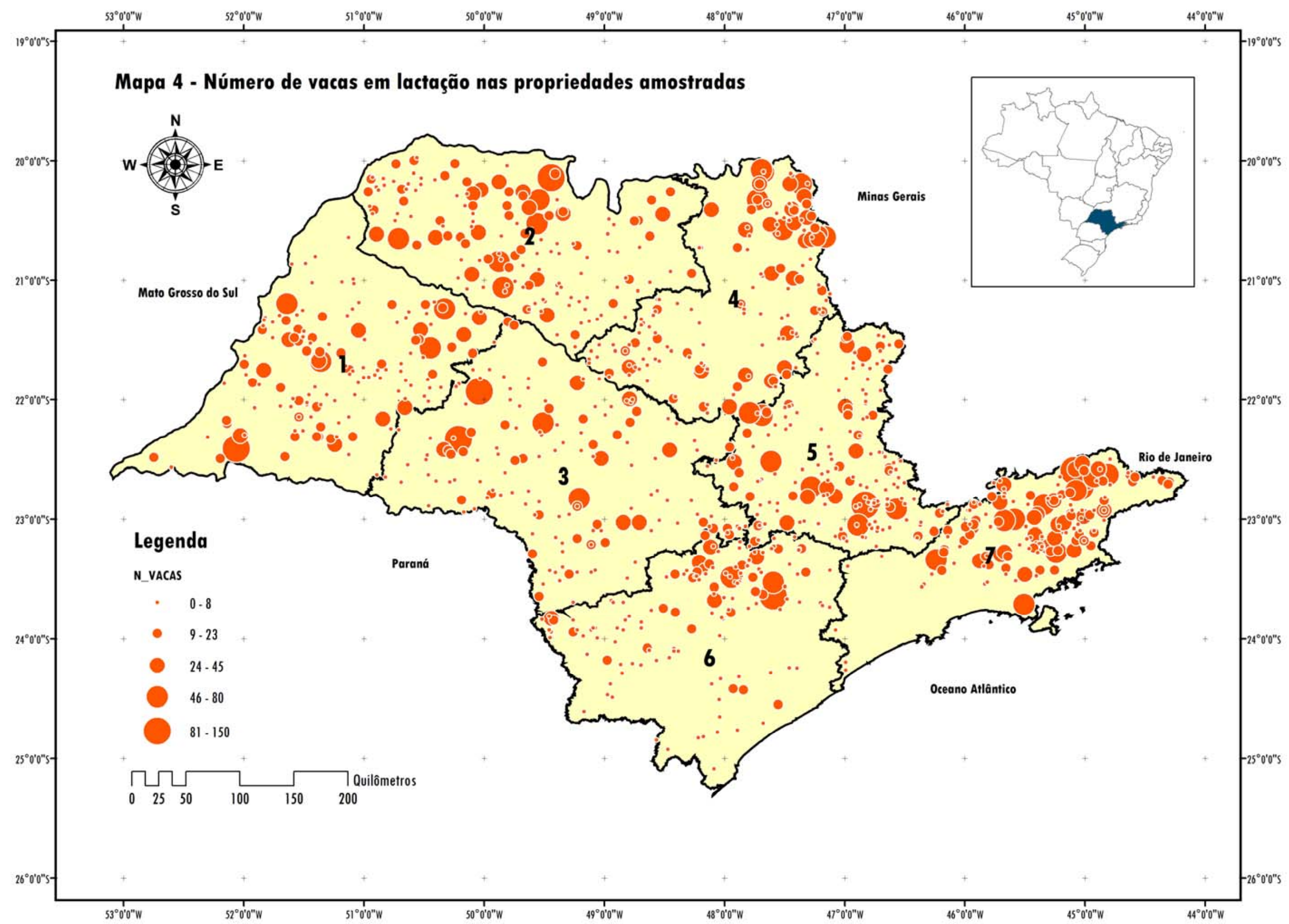




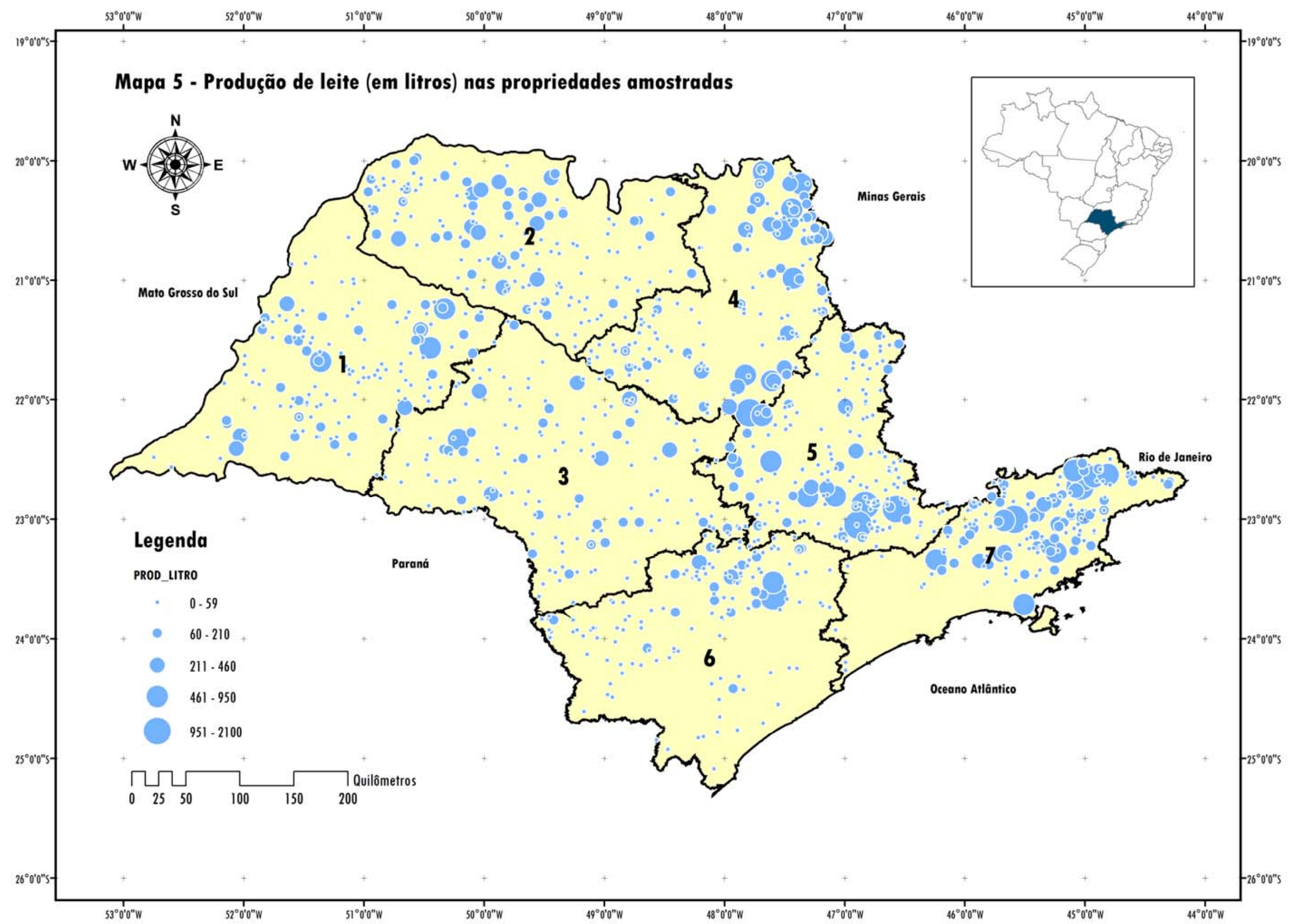




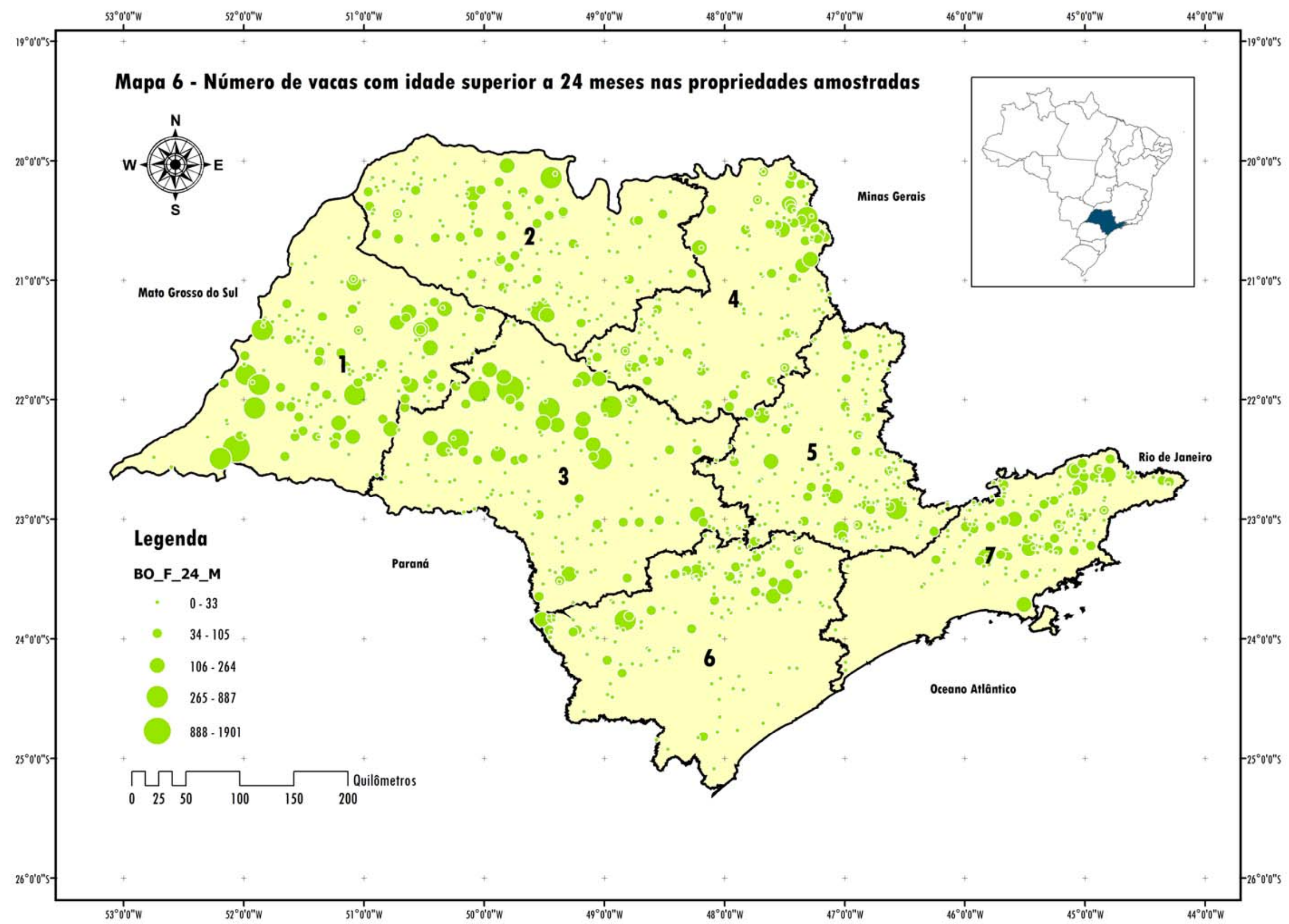




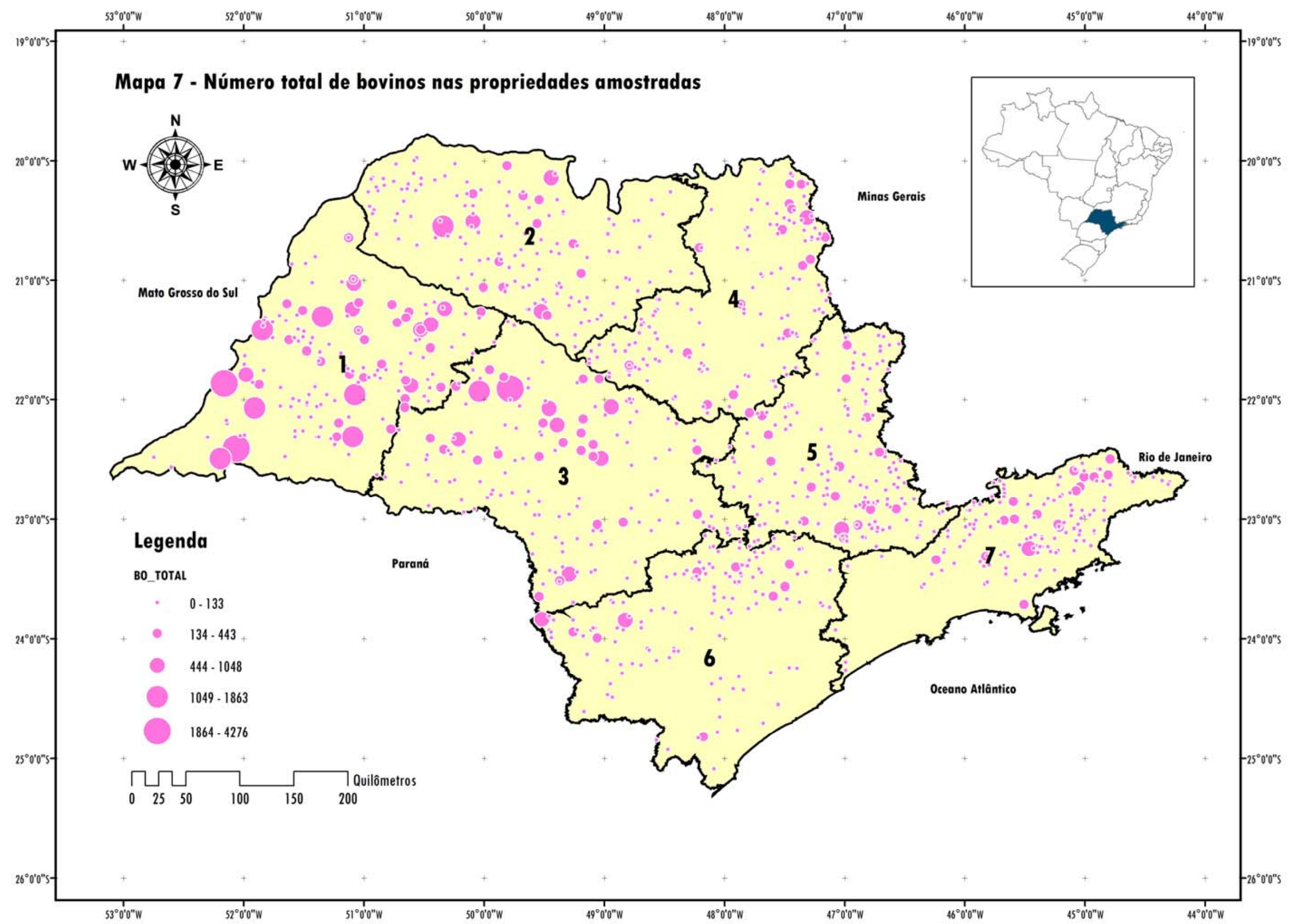




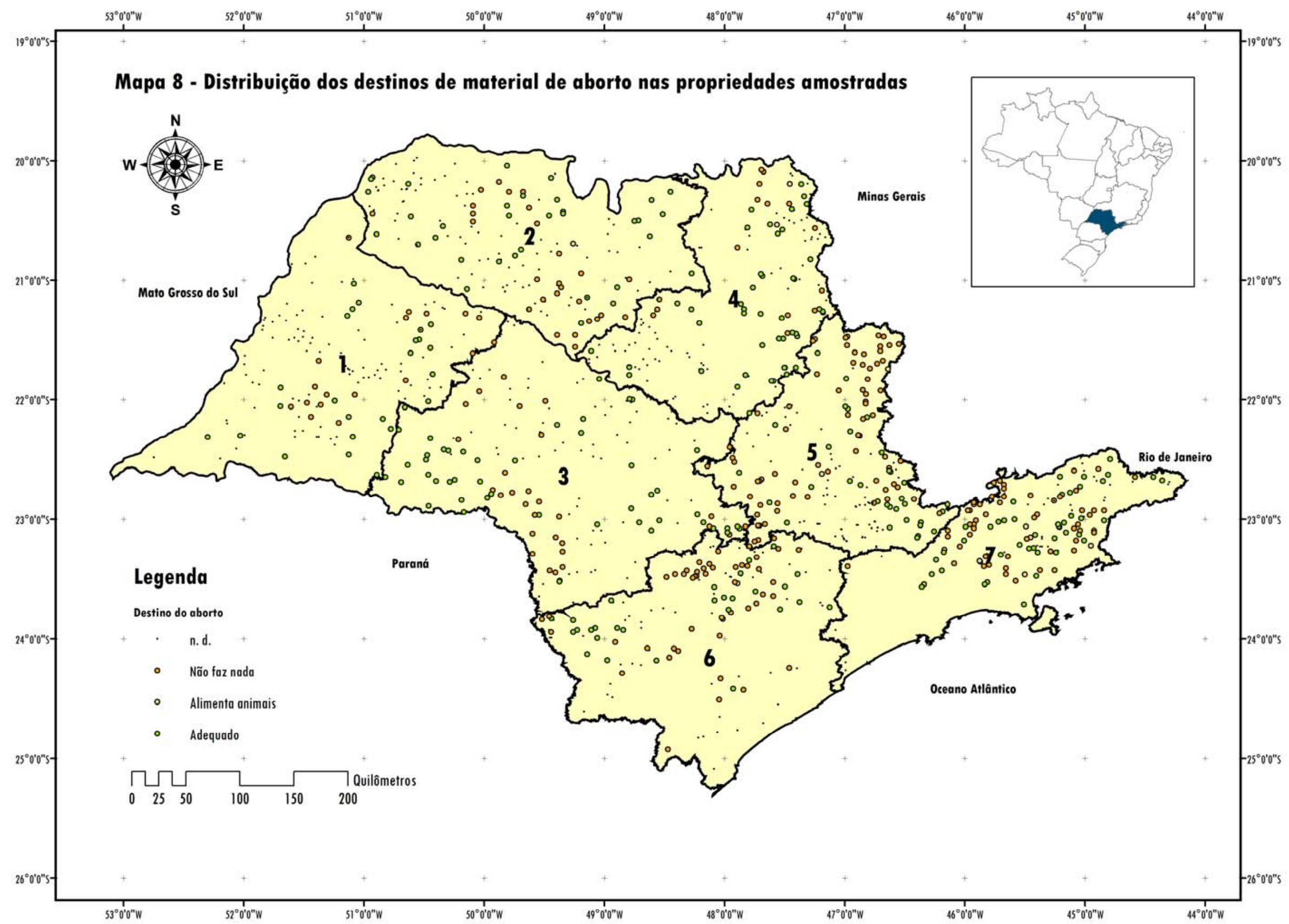




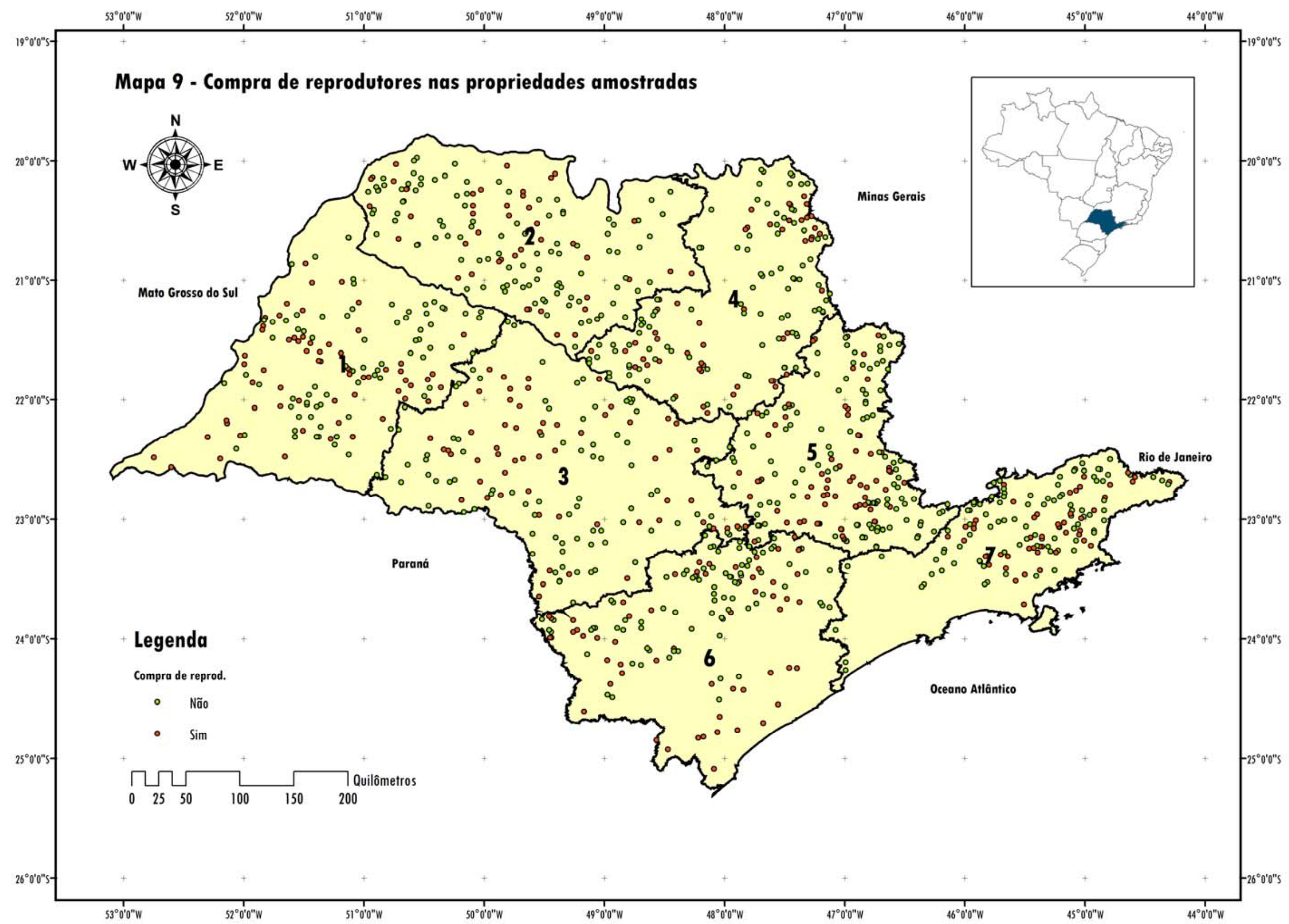




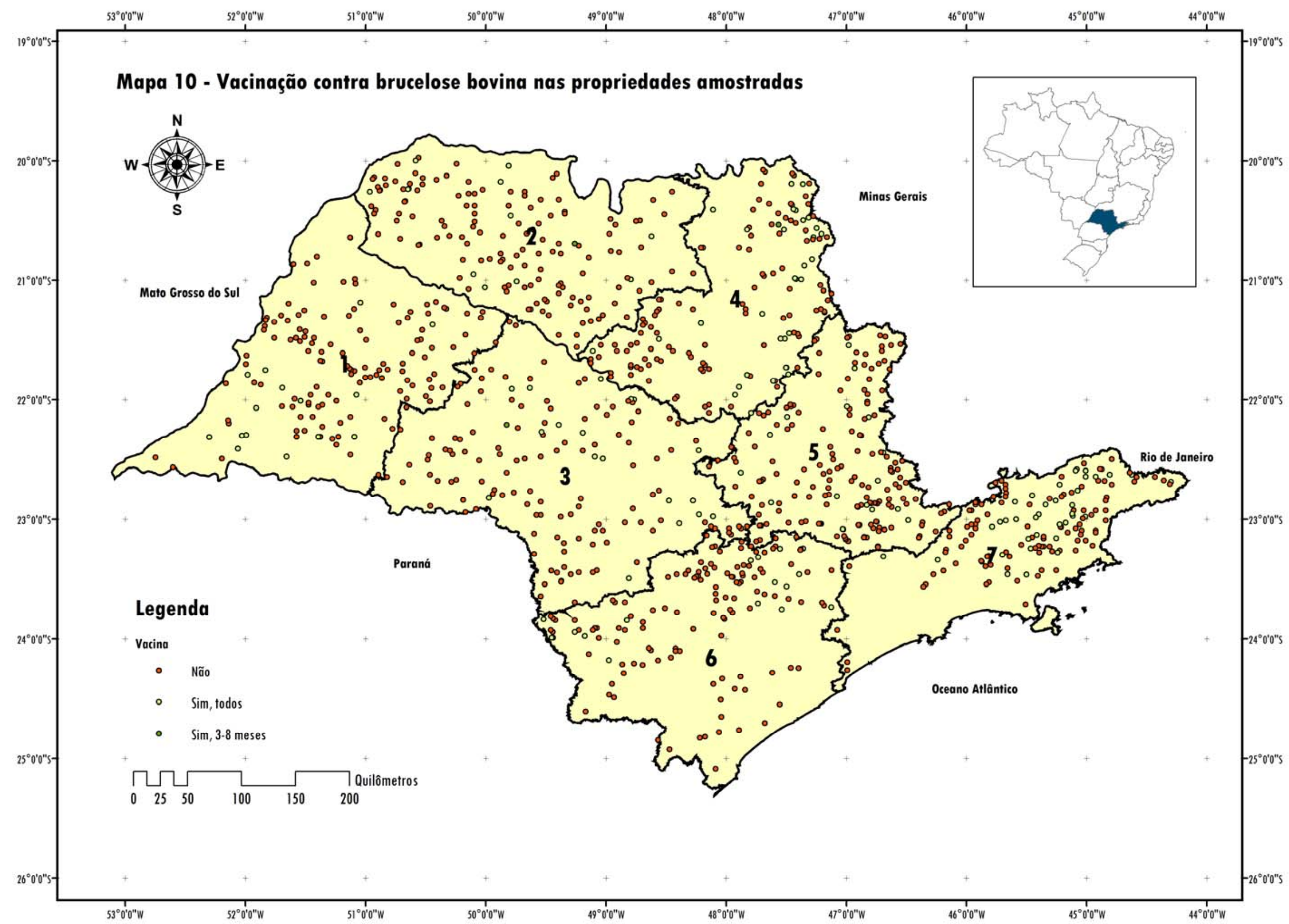




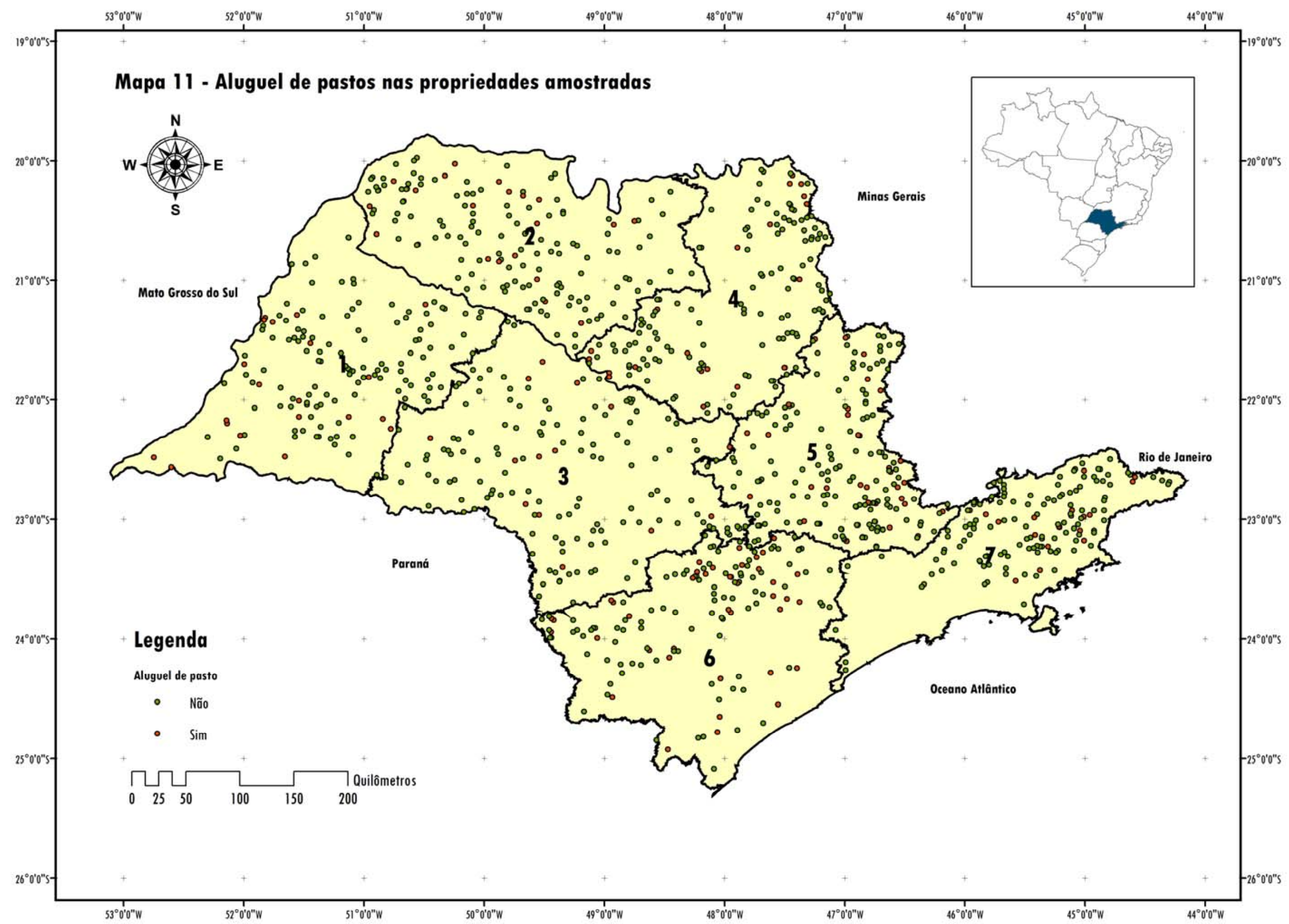




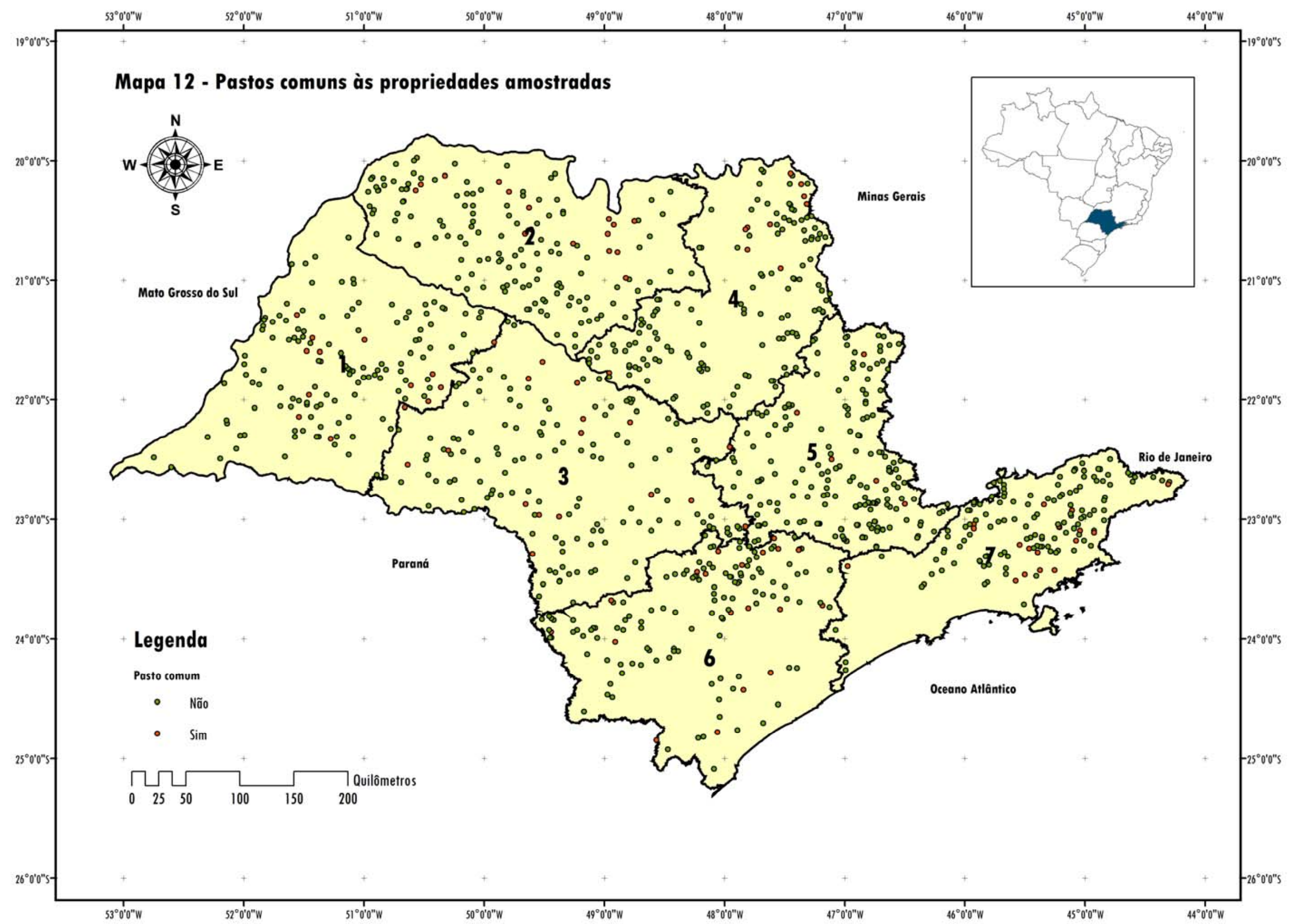




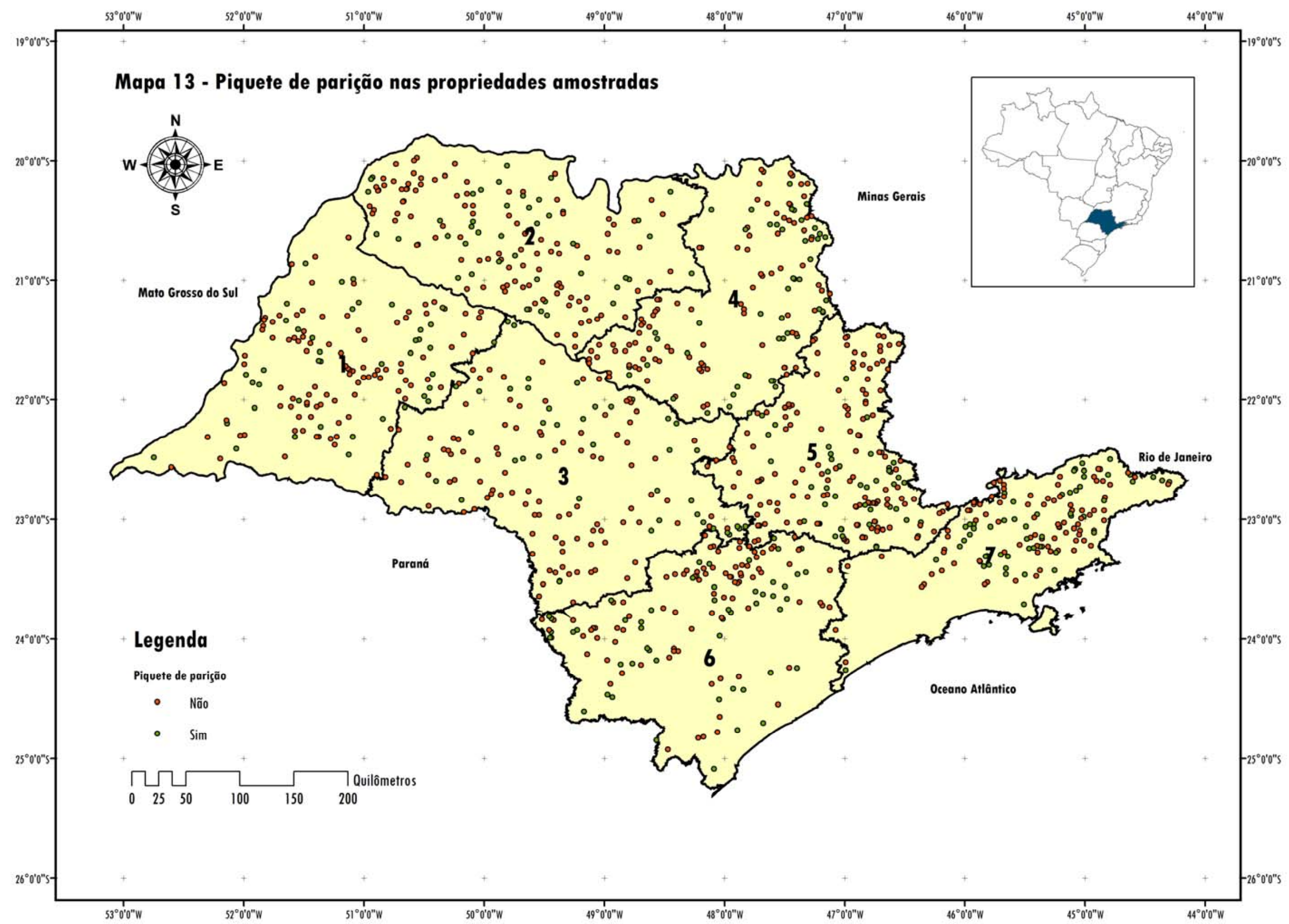




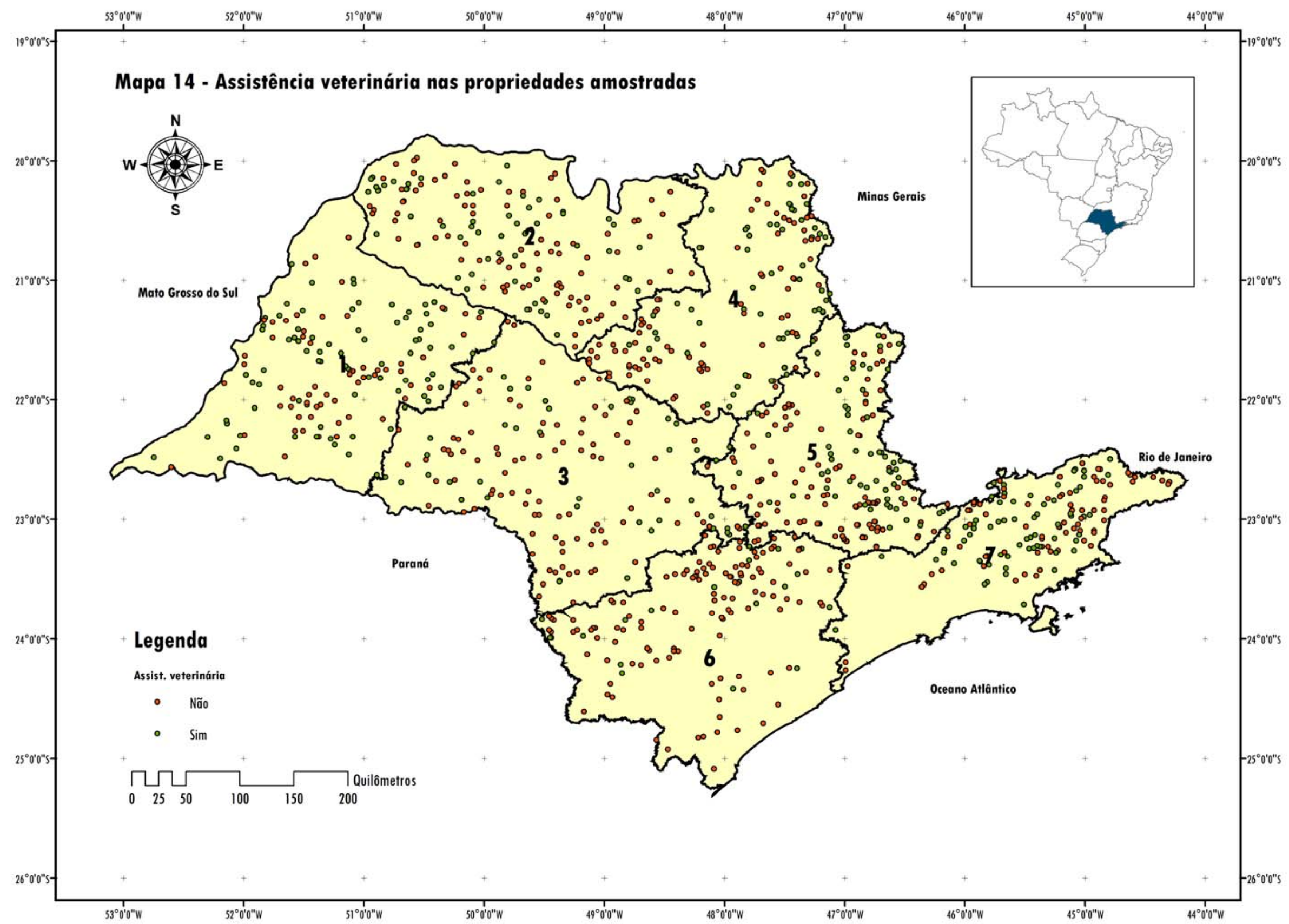




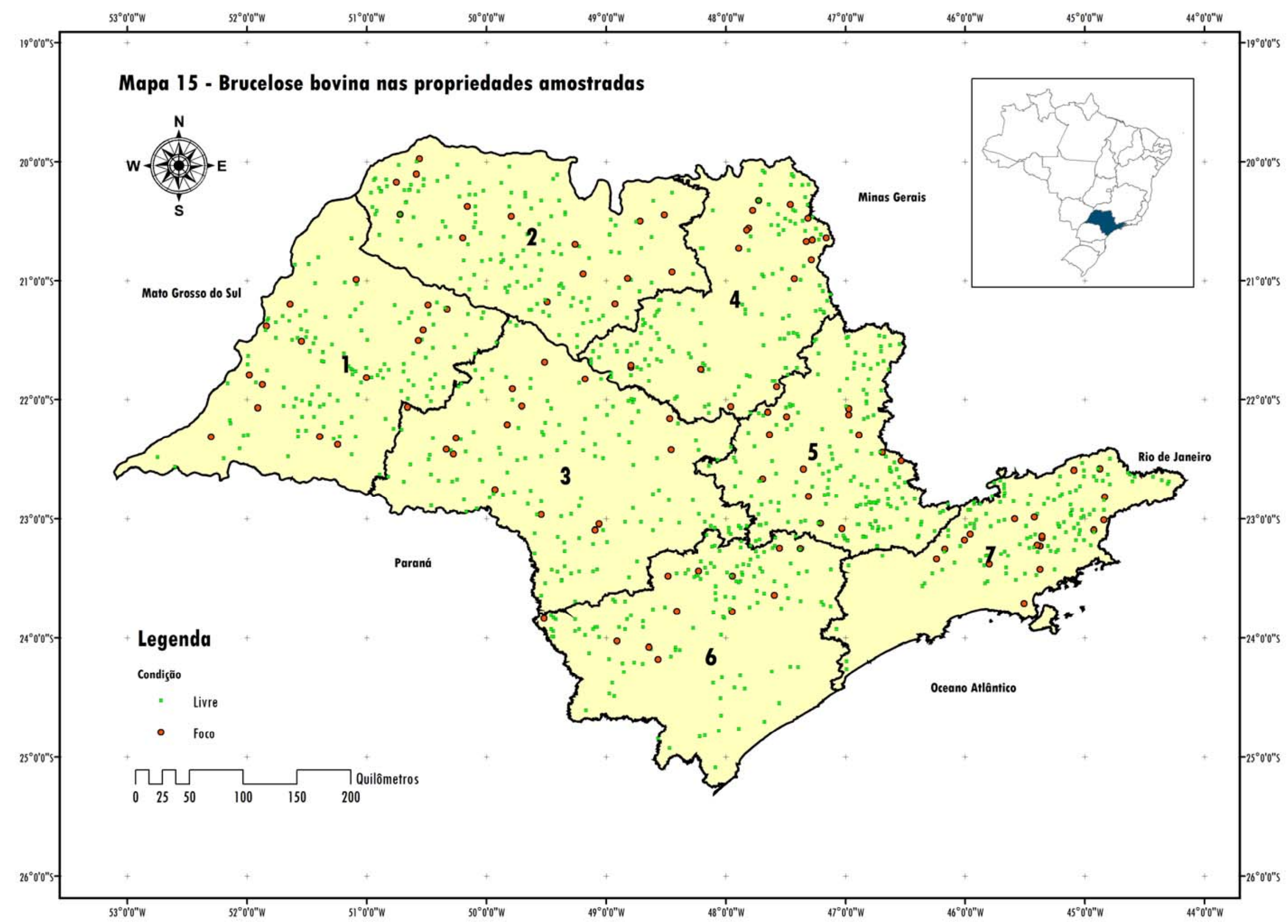


0 resultado é apresentado na Figura 16 que permite verificar que não há evidência de aglomerados de propriedades positivas pois a curva dada por $\hat{K}_{11}(h)-\hat{K}_{22}(h)$ não ultrapassa os limites superior e inferior para esta diferença sob a hipótese de identificação aleatória.

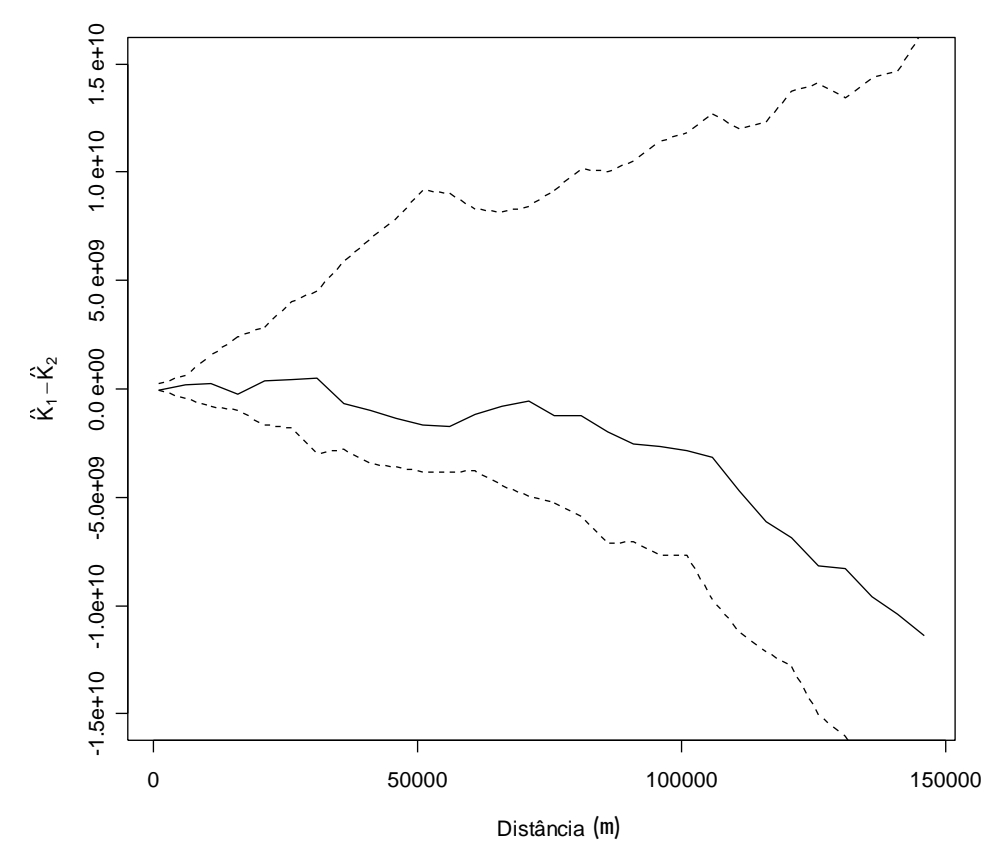

Figura 16 - Diferença entre os valores da função Kpara propriedades foco e não foco em função da distância em metros.

\subsection{ESTUDO DOS FATORES DE RISCO PARA A BRUCELOSE BOVINA}

A recategorização das variáveis, quando necessária, foi realizada para adequá-las a uma escala crescente de risco. Este processo de manipulação, realizado no banco de dados, resultou na recategorização das variáveis, descritas a seguir: 
(a) Tipo de exploração: corte; misto; leite.

(b) Tipo de criação: criação extensiva; certo grau de confinamento (confinado e semi-confinado).

(c) Manejo reprodutivo: uso de monta natural; uso de inseminação artificial associado ao uso de touro; uso de inseminação artificial.

(d) Raças predominantes: especializadas (zebu e europeu de leite e corte); não especializadas (mestiço e outras raças).

(e) Número de vacas com idade superior a 24 meses: adotou-se como ponto de corte o terceiro quartil da distribuição de valores observados (considerou-se que propriedades que apresentaram valores iguais ou superiores ao ponto de corte estvam sob risco).

(f) Número total de bovinos: adotou-se como ponto de corte o terceiro quartil.

(g) Presença de outras espécies domésticas na propriedade: ausência e presença.

(h) Presença de animais silvestres na propriedade: ausência e presença.

(i) Destino da placenta e feto abortados: destino adequado (enterra, joga, queima) e destino inadequado (alimento para porco e cão ou não faz nada).

(i) Compra de reprodutores: não compra e compra.

(k) Vacinação contra brucelose: vacina (bezerras de três a oito meses, e todos os animais) e não vacina.

(I) Abate de animais na propriedade: não abate e abate.

(m) Aluguel de pastos: não aluga e aluga.

(n) Pastos comuns com outras propriedades: não e sim.

(o) Pastos alagados: não e sim.

(p) Piquete de parição: sim e não.

(q) Assistência veterinária: sim e não. 


\subsubsection{Estudo dos fatores de risco no âmbito estadual}

As propriedades amostradas foram analisadas no âmbito estadual e, posteriormente, estratificadas pelo tipo de exploração (corte, leite e misto). Ao se analisar o Estado de São Paulo como um todo ( $\mathrm{n}=1064$ propriedades), verificou-se, na análise univariada, que os fatores mais associados à presença ou ausência da brucelose (variável dependente) foram: tipo de exploração $(p=11,6 \%)$, manejo reprodutivo $(p=3,2 \%)$, número de fêmeas bovinas com idade superior a 24 meses (utilizou-se como ponto de corte o terceiro quartil, ou seja, 39 animais; $p=0,2 \%$ ), número total de bovinos (também foi utilizado o terceiro quartil, ou 87 animais; $p<0,1 \%)$, compra de reprodutores $(p=0,7 \%)$, ausência de vacinação contra brucelose $(p=$ $2 \%)$, abate de reprodutores na propriedade $(p=2,6 \%)$, ausência de piquete para parição $(p=4,6 \%)$ e assistência veterinária $(p=7,6 \%$ ). 0 modelo múltiplo mostrou que propriedades com mais de 87 bovinos e propriedades que compram reprodutores apresentam maior chance de serem positivas para a brucelose bovina (Tabela 21).

Tabela 21 - Fatores de risco para brucelose bovina nas propriedades com atividade reprodutiva no Estado de São Paulo - São Paulo - 2004

\begin{tabular}{lccccc}
\hline Fatores de risco para brucelose bovina & Casos & Expostos & $\mathbf{p}$ & Odds Ratio & IC 95\% \\
\hline Propriedades com $\geq 87$ bovinos & 44 & 264 & $<0,1 \%$ & 2,25 & {$[1,47 ; 3,44]$} \\
Compra de reprodutores & 52 & 403 & $3,6 \%$ & 1,56 & {$[1,03 ; 2,36]$} \\
\hline $\mathrm{r}^{2}=4 \%$ & & & & &
\end{tabular}

Também foram estudados os fatores de risco para cada um dos circuitos produtores, inicialmente sem ser feita a estratificação pelo tipo de exploração. No Circuito 1 ( $=145)$, a análise univariada mostrou que os fatores de manejo mais associados à variável dependente foram: tipo de criação $(p=18,6 \%$, manejo reprodutivo $(p=19,3 \%$ ), ausência de vacinação contra brucelose $(p=5,2 \%)$, ausência de piquete de 
parição $(p=12,6 \%)$ e falta de assistência veterinária $(0,1 \%)$. 0 modelo múltiplo mostrou que a vacinação contra brucelose é fator de proteção para a doença (Tabela 22).

Tabela 22 - Fator protetor para brucelose bovina nas propriedades com atividade reprodutiva no Circuito Produtor 1 - São Paulo - 2004

\begin{tabular}{lccccc}
\hline Fator protetor para brucelose bovina & Casos & Expostos & $\mathbf{p}$ & Odds Ratio & IC 95\% \\
\hline Vacinação contra bucelose & 109 & 119 & $4 \%$ & 0,25 & {$[0,068 ; 0,94]$} \\
\hline $\mathrm{r}^{2}=6 \%$ & & & & &
\end{tabular}

No Circuito $2(\mathrm{n}=151)$, os fatores mais associados à variável dependente, na análise univariada, foram: número total de bovinos (foi utilizado como ponto de corte 0 terceiro quartil, ou 87 animais; $p=$ $11,5 \%)$ e destino inadequado do aborto $(p=0,4 \%)$. No entanto, nenhuma variável esteve associada à variável dependente no modelo múltiplo. No Circuito $3(\mathrm{n}=148)$, a análise univariada mostou que os fatores mais associados à presença ou ausência de brucelose bovina foram: número de fêmeas bovinas com idade superior a 24 meses (utilizou-se como ponto de corte 0 terceiro quartil, ou seja, 39 animais; $p=$ 8,2\%), número total de bovinos (também foi utilizado o terceiro quartil, ou 87 animais; $p=13 \%$ ) e compra de reprodutores $(p=14,4 \%$ ). Também não foi possível obter um modelo múltiplo estatisticamente significante. No Circuito $4(\mathrm{n}=153)$, os fatores mais associados à variável dependente, na análise univariada, foram: número total de bovinos (foi utilizado como ponto de corte 0 terceiro quartil, ou 87 animais; $p=0,2 \%)$, compra de reprodutores $(p=11,1 \%)$ e ausência de piquete de parição $(p=7,2 \%)$. Observou-se, através do modelo múltiplo, que manter 87 ou mais animais na propriedade foi fator de risco para brucelose (Tabela 23). 
Tabela 23 - Fator de risco para brucelose bovina nas propriedades com atividade reprodutiva no Circuito Produtor 4 - São Paulo - 2004

\begin{tabular}{lccccc}
\hline Fator de risco para brucelose bovina & Casos & Expostos & $\mathbf{p}$ & Odds Ratio & IC 95\% \\
\hline Propriedades com $\geq 87$ bovinos & 7 & 57 & $0,2 \%$ & 5,27 & {$[1,85 ; 15,045]$} \\
\hline $\mathrm{r}^{2}=12,2 \%$ & & & &
\end{tabular}

No Circuito $5(\mathrm{n}=179)$, observou-se, através da análise univariada, que os fatores mais associados à variável dependente foram: manejo reprodutivo $(p=10,8 \%)$, raças predominantes não especializadas $(p=$ 16,5\%), número de fêmeas com idade superior a 24 meses (neste estrato, considerou-se como ponto de corte 0 terceiro quartil, ou seja, 39 animais; $p=7,4 \%$ ), número total de bovinos (neste estrato, também considerou-se como ponto de corte o terceiro quartil, ou 87 animais; $p=3,4 \%$ ), compra de reprodutores ( $p$ $=0,6 \%)$, ausência de vacinação contra brucelose $(p=3,8 \%)$ e aluguel de pasto $(p=5,9 \%)$. 0 modelo múltiplo mostrou que a compra de reprodutores e a manutenção de 39 ou mais fêmeas com idade superior a 24 meses na propriedade são fatores de risco para brucelose (Tabela 24).

Tabela 24 - Fatores de risco para brucelose bovina nas propriedades com atividade reprodutiva no Circuito Produtor 5-São Paulo - 2004

\begin{tabular}{|c|c|c|c|c|c|}
\hline Fatores de risco para brucelose bovina & Casos & Expostos & $\mathbf{p}$ & Odds Ratio & IC $95 \%$ \\
\hline Compra de reprodutores & 10 & 72 & $2,9 \%$ & 5,97 & {$[1,20 ; 29,62]$} \\
\hline $\begin{array}{l}\text { Propriedades com } \geq 39 \text { fêmeas com idade } \\
\quad \geq 24 \text { meses }\end{array}$ & 3 & 10 & $4,6 \%$ & 5,39 & {$[1,03 ; 28,20]$} \\
\hline
\end{tabular}

No Circuito $6(n=146)$, os fatores mais associados à presença ou ausência de brucelose, segundo a análise univariada, foram: tipo de exploração $(p=6,1 \%)$, tipo de criação $(p=15,1 \%)$, manejo reprodutivo $(p<0,1 \%)$, destino inadequado do aborto $(p=19,4 \%)$, ausência de vacinação contra brucelose $(p=$ $12,4 \%)$ e uso de pasto comum $(p=5,4 \%)$. 0 modelo múltiplo indicou 0 uso de inseminação artificial e pasto comum com outras propriedades como fatores de risco para brucelose bovina (Tabela 25). 
Tabela 25 - Fatores de risco para brucelose bovina nas propriedades com atividade reprodutiva no Circuito Produtor 6 - São Paulo - 2004

\begin{tabular}{lccccc}
\hline Fatores de risco para brucelose bovina & Casos & Expostos & $\mathbf{p}$ & Odds Ratio & IC 95\% \\
\hline Uso de inseminação artificial ${ }^{0}$ & 4 & 12 & $0,3 \%$ & 10,05 & {$[2,21 ; 45,68]$} \\
Pasto comum com outra propriedade & 4 & 12 & $4,4 \%$ & 4,36 & {$[1,04 ; 18,25]$} \\
\hline
\end{tabular}

alnclui associação com monta natural.

$r^{2}=18,5 \%$

Finalmente, no Circuito $7(\mathrm{n}=151)$ os fatores de manejo mais associados à variável depedente, segundo a análise univariada, foram: tipo de criação $(p=17 \%)$ e número de fêmeas com idade superior a 24 meses (neste estrato, considerou-se como ponto de corte 0 terceiro quartil, ou seja, 39 animais; $p=$ 4\%). Esta última variável foi indicada como fator de risco na análise múltipla (Tabela 26).

Tabela 26 - Fator de risco para brucelose bovina nas propriedades com atividade reprodutiva no Circuito Produtor 7 - São Paulo - 2004

\begin{tabular}{lccccc}
\hline Fator de risco para brucelose bovina & Casos & Expostos & $\mathbf{p}$ & Odds Ratio & IC 95\% \\
\hline $\begin{array}{l}\text { Propriedades com } \geq 39 \text { fêmeas com idade } \\
\geq 24 \text { meses }\end{array}$ & 3 & 16 & $2,4 \%$ & 6,53 & {$[1,27 ; 33,43]$} \\
\hline$r^{2}=7,9 \%$ & & & & &
\end{tabular}

\subsubsection{Estudo dos fatores de risco em propriedades com exploração pecuária de corte}

Ao se analisar as propriedades com exploração de corte no Estado de São Paulo (n $=209$ ), as variáveis mais associadas à variável dependente, segundo a análise univariada, foram: manejo reprodutivo $(p=0,3 \%$ ), número de fêmeas com idade superior a 24 meses (neste estrato, considerou-se como ponto de corte 0 terceiro quartil, ou seja, 80 animais; $\mathrm{p}=1,6 \%$ ), número total de bovinos (neste estrato, também considerou-se como ponto de corte 0 terceiro quartil, ou 200 animais; $p=10,9 \%$ ) e ausência de vacinação 
contra brucelose $(p=0,9 \%)$. 0 modelo multivariado revelou como fator protetor a vacinação contra brucelose, como descrito na Tabela 27.

Tabela 27 - Fator protetor para brucelose bovina nas propriedades especializadas na exploração pecuária de corte no Estado de São Paulo - São Paulo - 2004

\begin{tabular}{lcccccc}
\hline Fator protetor para brucelose bovina & Casos & Expostos & $\mathbf{p}$ & Odds Ratio & IC 95\% \\
\hline Vacinação contra bucelose & 153 & 164 & $0,7 \%$ & 0,025 & {$[0,01 ; 0,68]$} \\
\hline $\mathrm{r}^{2}=7,1 \%$ & & & &
\end{tabular}

Ao considerar cada um dos circuitos produtores, a análise univariada das propriedades com aptidão para corte revelou que, no Circuito $1(n=43)$, os fatores mais associados à presença ou ausência da brucelose foram: manejo reprodutivo $(p=0,1 \%)$, número de fêmeas com idade superior a 24 meses (considerou-se, como ponto de corte, 0 terceiro quartil, ou seja, 80 animais; $p=2,2 \%$ ), número total de bovinos (neste estrato, também considerou-se como ponto de corte 0 terceiro quartil, ou 200 animais; $p=$ $13,7 \%$ ), ausência de vacinação contra brucelose $(p=1,3 \%)$, ausência de piqute de parição $(p=0,1 \%)$ e falta de assistência veterinária $(p=9,1 \%)$. 0 modelo múltiplo mostrou, assim como no Estado de São Paulo com um todo, que a vacinação contra brucelose representou um fator protetor para a brucelose bovina (Tabela 28).

Tabela 28 - Fator protetor para brucelose bovina nas propriedades especializadas na exploração pecuária de corte no Circuito Produtor 1 - São Paulo - 2004

\begin{tabular}{lccccc}
\hline Fator protetor para brucelose bovina & Casos & Expostos & $\mathbf{p}$ & Odds Ratio & IC 95\% \\
\hline Vacinação contra bucelose & 34 & 35 & $0,8 \%$ & 0,015 & {$[0,001 ; 0,33]$} \\
\hline $\mathrm{r}^{2}=45,2 \%$ & & & &
\end{tabular}

No Circuito $2(n=21)$, não houve associação das variáveis de criação com a variável dependente, e portanto, não houve como obter um modelo múltiplo. No Circuito $3(n=47)$, a única variável associada à 
presença ou ausência da brucelose, na análise univariada, foi a compra de reprodutores $(p=14,8 \%$ ), sendo que esta variável não manteve a significância estatística no modelo múltiplo. No Circuito 4 (n = 24), uma única variável esteve associada à variável dependente na análise univariada, número de fêmeas com idade superior a 24 meses (considerou-se, como ponto de corte, 0 terceiro quartil, ou seja, 80 animais; $p=$ 14,3\%), mas não no modelo múltiplo. № Circuito $5(\mathrm{n}=40)$, as variáveis mais associadas à variável dependente, no modelo univariado, foram: manejo reprodutivo $(p=8,2 \%)$, raças predominantes não especialiadas $(p=4,3 \%$ ), número total de bovinos (neste estrato, considerou-se como ponto de corte 0 terceiro quartil, ou 200 animais; $p=10,9 \%)$, compra de reprodutores $(p=16,2 \%)$ e ausência de vacinação contra brucelose $(p=2,2 \%)$. 0 modelo múltiplo também mostrou que a vacinação contra brucelose é fator protetor para a brucelose bovina (Tabela 29).

Tabela 29 - Fator protetor para brucelose bovina nas propriedades especializadas na exploração pecuária de corte no Circuito Produtor 5 - São Paulo - 2004

\begin{tabular}{lccccc}
\hline Fator protetor para brucelose bovina & Casos & Expostos & $\mathbf{p}$ & Odds Ratio & IC 95\% \\
\hline Vacinação contra bucelose & 29 & 31 & $1,5 \%$ & 0,069 & {$[0,008 ; 0,59]$} \\
\hline $\mathrm{r}^{2}=28 \%$ & & & &
\end{tabular}

No Circuito $6(n=18)$, as variáveis mais associadas à variável dependente, na análise univariada, foram: manejo reprodutivo $(p=18,8 \%$ ), número de fêmeas com idade superior a 24 meses (considerou-se, como ponto de corte, 0 terceiro quartil, ou seja, 80 animais; $p=16,7 \%$ ), número total de bovinos (neste estrato, considerou-se como ponto de corte 0 terceiro quartil, ou 200 animais; $p=16,7 \%$ ) e ausência de vacinação contra brucelose $(p=16,7 \%$ ). No entanto, não foi possível obter um modelo múltiplo estatisticamente significativo. Finalmente, não se observou focos de brucelose no Ciruito $7(n=16)$, assim não foi possível realizar a análise de fatores de risco neste estrato. 


\subsubsection{Estudo dos fatores de risco em propriedades com exploração pecuária mista}

Analisou-se as propriedades com exploração pecuária mista $(\mathrm{n}=502)$ e, na análise univariada, verificou-se que os fatores mais associados à presença ou ausência da brucelose (variável dependente) foram: número de fêmeas bovinas com idade superior a 24 meses (utilizou-se como ponto de corte 0 terceiro quartil, ou seja, 27 animais; $\mathrm{p}=0,8 \%$ ), número total de bovinos (também foi utilizado 0 terceiro quartil, ou 70 animais; $p=1,2 \%)$, destino inadequado de aborto $(p=17 \%)$, compra de reprodutores $(p=$ 2,2\%) e assistência veterinária $(p=5,6 \%)$. 0 modelo múltiplo mostrou que manter 27 ou mais fêmeas com idade superior a 24 meses na propriedade representa um fator de risco para 0 aparecimento da brucelose bovina (Tabela 30).

Tabela 30 - Fator de risco para brucelose bovina nas propriedades especializadas na exploração pecuária mista no Estado de São Paulo - São Paulo - 2004

\begin{tabular}{lccccc}
\hline Fator de risco para brucelose bovina & Casos & Expostos & $\mathbf{p}$ & Odds Ratio & IC 95\% \\
\hline $\begin{array}{l}\text { Propriedades com } \geq 27 \text { fêmeas com idade } \\
\geq 24 \text { meses }\end{array}$ & 17 & 121 & $1 \%$ & 2,38 & {$[1,23 ; 4,61]$} \\
\hline $\mathrm{r}^{2}=2,9 \%$ & & & & &
\end{tabular}

Também foram estudados os fatores de risco para cada um dos circuitos produtores. No Circuito l (n $=71$ ), a análise univariada mostrou que os fatores de manejo mais associados à variável dependente foram: tipo de criação $(p=4,7 \%)$ e falta de assistência veterinária $(4,2 \%) .0$ modelo múltiplo mostrou que manter os bovinos dentro de um sistema de criação com certo grau de confinamento representa um fator de risco para a brucelose (Tabela 31). 
Tabela 31 - Fator de risco para brucelose bovina nas propriedades especializadas na exploração pecuária mista no Circuito Produtor 1 - São Paulo - 2004

\begin{tabular}{lccccc}
\hline Fator de risco para brucelose bovina & Casos & Expostos & $\mathbf{p}$ & Odds Ratio & IC 95\% \\
\hline Certo grau de confinamento & 5 & 66 & $2,3 \%$ & 2,20 & {$[1,41 ; 105,95]$} \\
\hline $\mathrm{r}^{2}=13,2 \%$ & & & &
\end{tabular}

No Circuito 2 ( $\mathrm{n}=67)$, os fatores mais associados à variável dependente, na análise univariada, foram: número de fêmeas bovinas com idade superior a 24 meses (utilizou-se como ponto de corte 0 terceiro quartil, ou seja, 27 animais; $p=9,4 \%)$, destino inadequado do aborto $(p=0,6 \%)$ e ausência de piquete de parição $(p=5,4 \%$ ). 0 modelo múltiplo mostrou que a presença de piquete de parição na propriedade representou um fator de proteção para brucelose (Tabela 32).

Tabela 32 - Fator protetor para brucelose bovina nas propriedades especializadas na exploração pecuária mista no Circuito Produtor 2 - São Paulo - 2004

\begin{tabular}{lccccc}
\hline Fator protetor para brucelose bovina & Casos & Expostos & $\mathbf{p}$ & Odds Ratio & IC 95\% \\
\hline Piquete de parição & 47 & 50 & $4,6 \%$ & 0,19 & {$[0,038 ; 0,97]$} \\
\hline $\mathrm{r}^{2}=11,8 \%$ & & & & &
\end{tabular}

No Circuito $3(\mathrm{n}=61)$, a análise univariada mostou somente um fator associados à presença ou ausência de brucelose bovina, a compra de reprodutores $(p=0,3 \%$ ). Não foi possível obter um modelo múltiplo estatisticamente significante. No Circuito $4(\mathrm{n}=83)$, os fatores mais associados à variável dependente, na análise univariada, foram: manejo reprodutivo $(p=18,1 \%)$, número de fêmeas bovinas com idade superior a 24 meses (utilizou-se como ponto de corte 0 terceiro quartil, ou seja, 27 animais; $p=$ 10,7\%) e número total de bovinos (foi utilizado como ponto de corte o terceiro quartil, ou 87 animais; $p=$ 6,9\%). Não foi possível obter um modelo múltiplo estatisticamente significante. No Circuito 5 (n $=68$ ), observou-se, através da análise univariada, que os fatores mais associados à variável dependente foram: compra de reprodutores $(p=7,3 \%)$ e ausência de vacinação contra brucelose $(p=12,8 \%)$. Não foi 
possível, no entanto, obter um modelo múltiplo estatisticamente significante. № Circuito 6 ( $n=86)$, 0 único fator associado à presença ou ausência de brucelose, segundo a análise univariada, foi o manejo reprodutivo $(p=0,9 \%)$, sendo que esta variável não manteve a significância estatística no modelo múltiplo. Finalmente, no Circuito $7(n=66)$ não houve fatores associados à variável dependente, portanto, não foi possível obter um modelo múltiplo.

\subsubsection{Estudo dos fatores de risco em propriedades com exploração pecuária de leite}

Ao se analisar as propriedades com exploração de leite no Estado de São Paulo (n $=353$ ), as variáveis mais associadas à variável dependente, segundo a análise univariada, foram: raças predominantes não especializadas $(p=19,7 \%$ ), número de fêmeas com idade superior a 24 meses (neste estrato, considerou-se como ponto de corte 0 terceiro quartil, ou seja, 40 animais; $p=0,8 \%$ ), número total de bovinos (neste estrato, também considerou-se como ponto de corte 0 terceiro quartil, ou 80 animais; $p=$ $0,5 \%)$, compra de reprodutores $(p=6,2 \%)$, pasto comum com outras propriedades $(p=9,6 \%)$ e ausência de piquete de parição $(p=0,9 \%$ ). 0 modelo multivariado revelou que manter 80 ou mais bovinos na propriedade representa um fator de risco para a brucelose, como descrito na Tabela 33.

Tabela 33 - Fator de risco para brucelose bovina nas propriedades especializadas na exploração pecuária de leite no Estado de São Paulo - São Paulo - 2004

\begin{tabular}{lccccc}
\hline Fator de risco para brucelose bovina & Casos & Expostos & $\mathbf{p}$ & Odds Ratio & IC 95\% \\
\hline Propriedades com $\geq 80$ bovinos & 18 & 85 & $0,7 \%$ & 2,49 & {$[1,29 ; 4,81]$} \\
\hline $\mathrm{r}^{2}=3,7 \%$ & & &
\end{tabular}

$r^{2}=3,7 \%$ 
Considerando-se cada um dos circuitos produtores, a análise univariada das propriedades com aptidão para corte revelou que, nos Circuitos $1(n=27)$ e $2(n=59)$, não houve fatores associados à presença ou ausência da brucelose, portanto não foi possível obter modelos multivariados para estes circuitos. No Circuito $3(\mathrm{n}=39)$, a análise univariada mostrou que os fatores mais associados com a variável dependente foram: número de fêmeas com idade superior a 24 meses (considerou-se, como ponto de corte, 0 terceiro quartil, ou seja, 40 animais; $\mathrm{p}=0,5 \%$ ), número total de bovinos (neste estrato, também considerou-se como ponto de corte o terceiro quartil, ou 80 animais; $p=4,5 \%)$, aluguel de pasto $(p=$ $4,5 \%$ ) e pasto comum com outras propriedades $(\mathrm{p}=2,2 \%)$. 0 modelo múltiplo mostrou que manter 40 ou mais fêmeas com idade superior a 24 meses representa um fator de risco para a brucelose bovina (Tabela 34).

Tabela 34 - Fator de risco para brucelose bovina nas propriedades especializadas na exploração pecuária de leite no Circuito Produtor 3 - São Paulo - 2004

\begin{tabular}{lccccc}
\hline Fator de risco para brucelose bovina & Casos & Expostos & $\mathbf{p}$ & Odds Ratio & IC 95\% \\
\hline $\begin{array}{l}\text { Propriedades com } \geq 27 \text { fêmeas com idade } \\
\geq 24 \text { meses }\end{array}$ & 3 & 5 & $0,5 \%$ & 48,0 & {$[3,033 ; 697,40]$} \\
\hline $\mathrm{r}^{2}=46,7 \%$ & & & & &
\end{tabular}

No Circuito $4(\mathrm{n}=46)$, os fatores mais associados à presença ou ausência da brucelose, na análise univariada, foram: número total de bovinos (neste estrato, também considerou-se como ponto de corte 0 terceiro quartil, ou 80 animais; $p=9,2 \%$ ) e aluguel de pasto $(p=16,9 \%$ ). No entanto, não foi possível obter um modelo múltiplo estatisticamente significativo. № Circuito $5(\mathrm{n}=69)$, a única variável associada à presença ou ausência da brucelose, no modelo univariado, foi aluguel de pasto $(p=3,4 \%)$ que, no modelo múltiplo também mostrou-se associada à variável dependente (Tabela 35). 
Tabela 35 - Fator de risco para brucelose bovina nas propriedades especializadas na exploração pecuária de leite no Circuito Produtor 5 - São Paulo - 2004

\begin{tabular}{lcccccc}
\hline Fator de risco para brucelose bovina & Casos & Expostos & $\mathbf{p}$ & Odds Ratio & IC 95\% \\
\hline Aluguel de pasto & 3 & 12 & $2,4 \%$ & 9,17 & {$[1,34 ; 62,71]$} \\
\hline $\mathrm{r}^{2}=17,4 \%$ & & & & &
\end{tabular}

No Circuito 6 ( $\mathrm{n}=42)$, os fatores mais associadas à variável dependente, na análise univariada, foram: manejo reprodutivo $(p=5,6 \%)$, destino inadequado do aborto $(p=5,3 \%)$ e pasto comum com outras propriedades $(p=8,2 \%$ ). No entanto, não foi possível obter um modelo múltiplo estatisticamente significativo. Finalmente, no Ciruito $7(n=71)$, os fatores mais associados à presença ou ausência de brucelose, no modelo univariado, foram: tipo de criação $(p=17,1 \%)$ e ausência de piquete de parição $(p=$ 3,7\%). 0 modelo múltiplo revelou que a ausência de piquete separado para parição representa um fator protetor contra a brucelose bovina (Tabela 36).

Tabela 36 - Fator protetor para brucelose bovina nas propriedades especializadas na exploração pecuária de leite no Circuito Produtor 7 - São Paulo - 2004

\begin{tabular}{lccccc}
\hline Fator protetor para brucelose bovina & Casos & Expostos & $\mathbf{p}$ & Odds Ratio & IC 95\% \\
\hline Piquete de parição & 24 & 32 & $3,4 \%$ & 0,17 & {$[0,033 ; 0,88]$} \\
\hline $\mathrm{r}^{2}=13,7 \%$ & & & & &
\end{tabular}

\subsection{SIMULAÇÃO DE MEDIDAS DE CONTROLE DA BRUCELOSE BOVINA PROPOSTAS NO PNCETB ATRAVÉS DE MODELAGEM MATEMÁTICA}

0 coeficiente $\beta$ foi determinado através de simulações no programa Mathcad 2001 Professional (Mathsoft Engeneering and Education, 2001), em 7,98 $10^{-7}$ ano $^{-1}$, relacionado a uma prevalência de fêmeas positivas para brucelose de 3,81\%, estimada no estudo de prevalências. Assim, avaliou-se, como 
intervenção na população, a vacinação, através do modelo matemático proposto. Considerou-se que a vacina protege $100 \%$ dos animais vacinados.

A figura 17 mostra o comportamento da prevalência da brucelose na população de bovinos leiteiros, sob diferentes proporções de cobertura vacinal, ao longo do tempo.

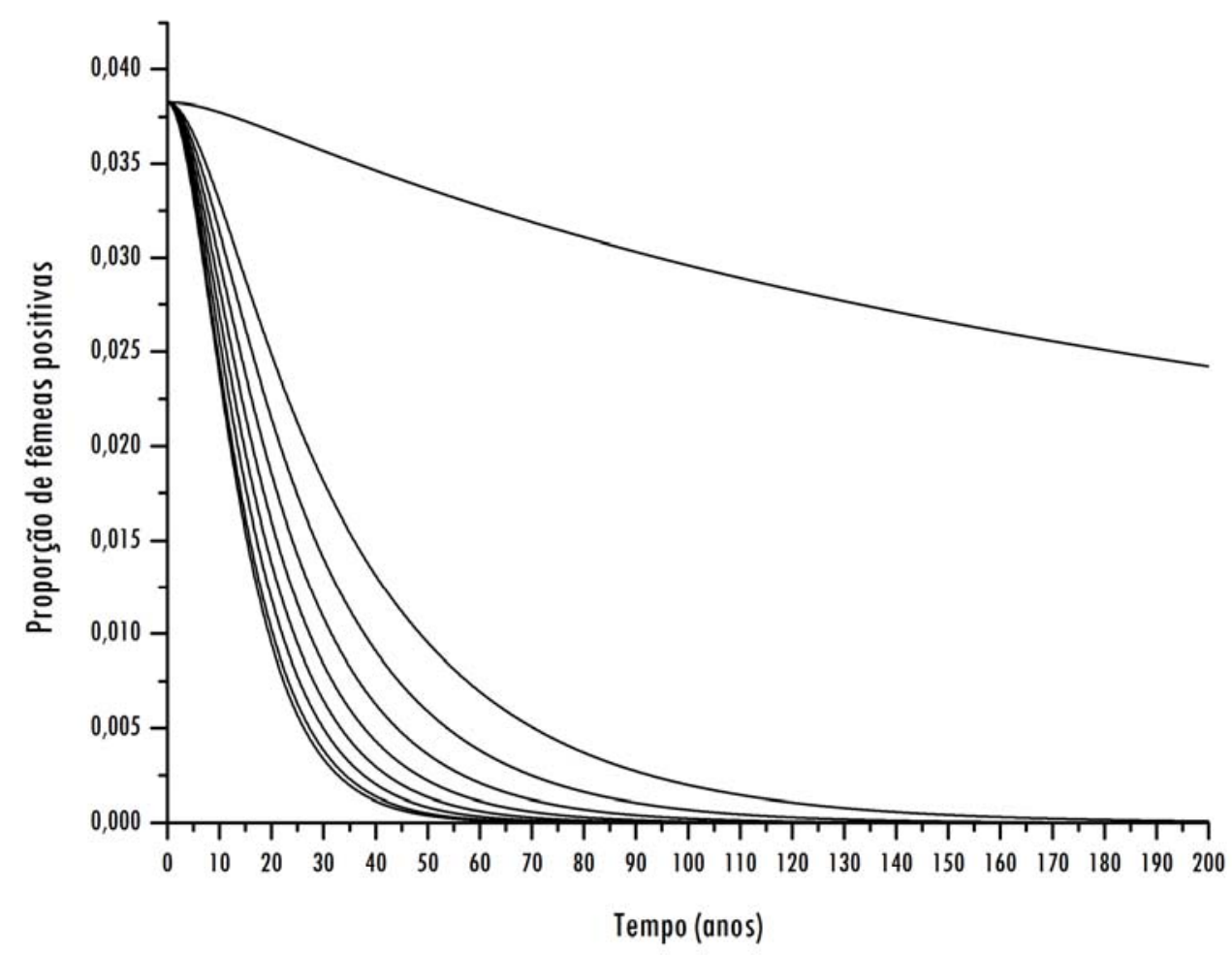

Figura 17 - Proporção de fêmeas positivas para brucelose ao longo de 200 anos, segundo coberturas vacinais de $95 \%, 90 \%, 80 \%$, $70 \%, 60 \%, 50 \%, 40 \%, 30 \%$ e $3 \%$, da esquerda para a direita

A figura 18 é uma magnificação da figura anterior, mostrando os primeiros 40 anos de vacinação, até ser alcançada uma prevalência de $2 \%$ de fêmeas. 


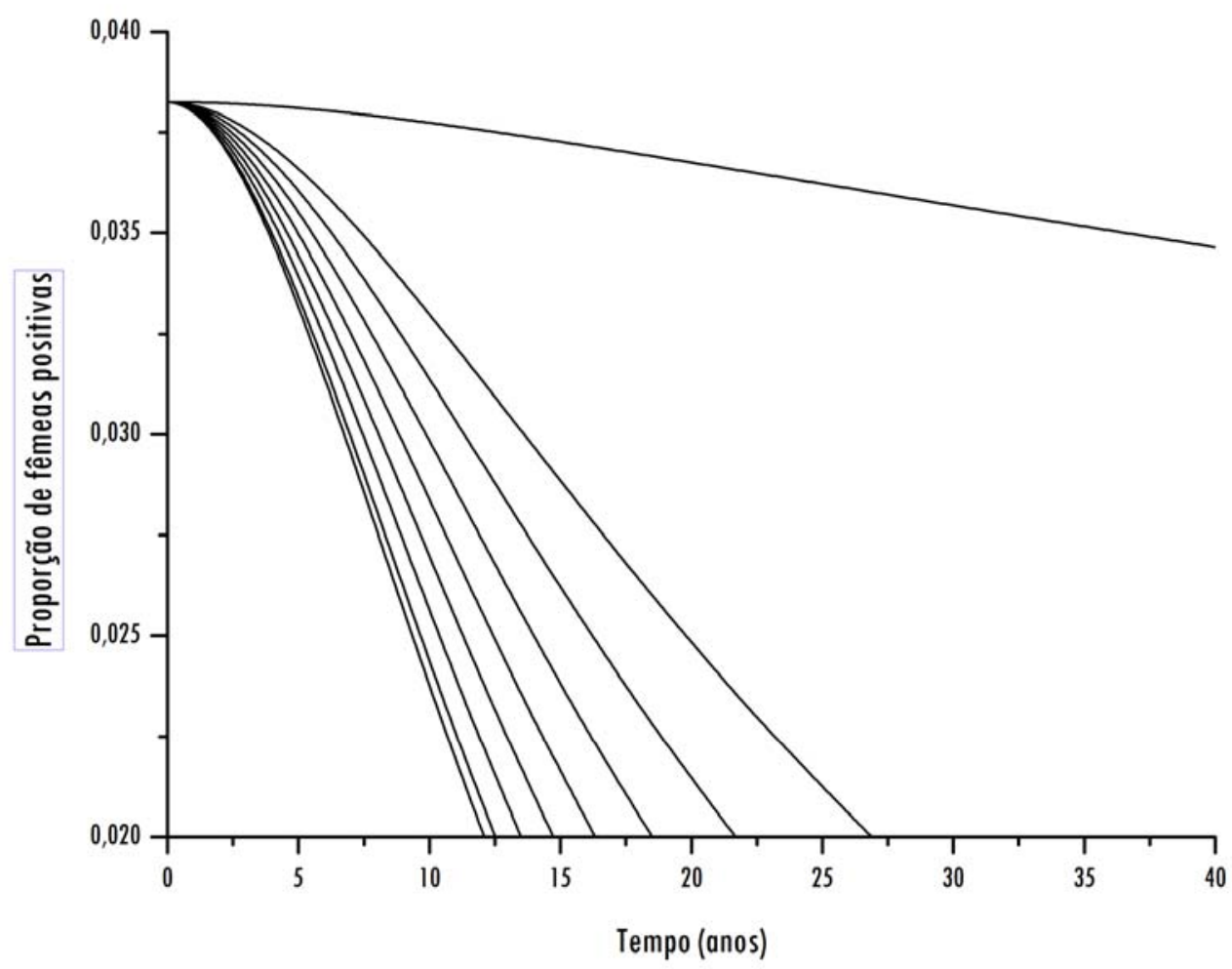

Figura 18 - Proporção de fêmeas positivas para brucelose ao longo de 40 anos, segundo coberturas vacinais de $95 \%, 90 \%, 80 \%, 70 \%$, $60 \%, 50 \%, 40 \%, 30 \%$ e $3 \%$, da esquerda para a direita

A figura 19 mostra a dinâmica do número de abortos, sob diferentes proporções de cobertura vacinal, ao longo do tempo. 0 valor de referência para 0 cálculo da proporção de abortos foi o número de abortos estimado no primeiro ano da simulação. 


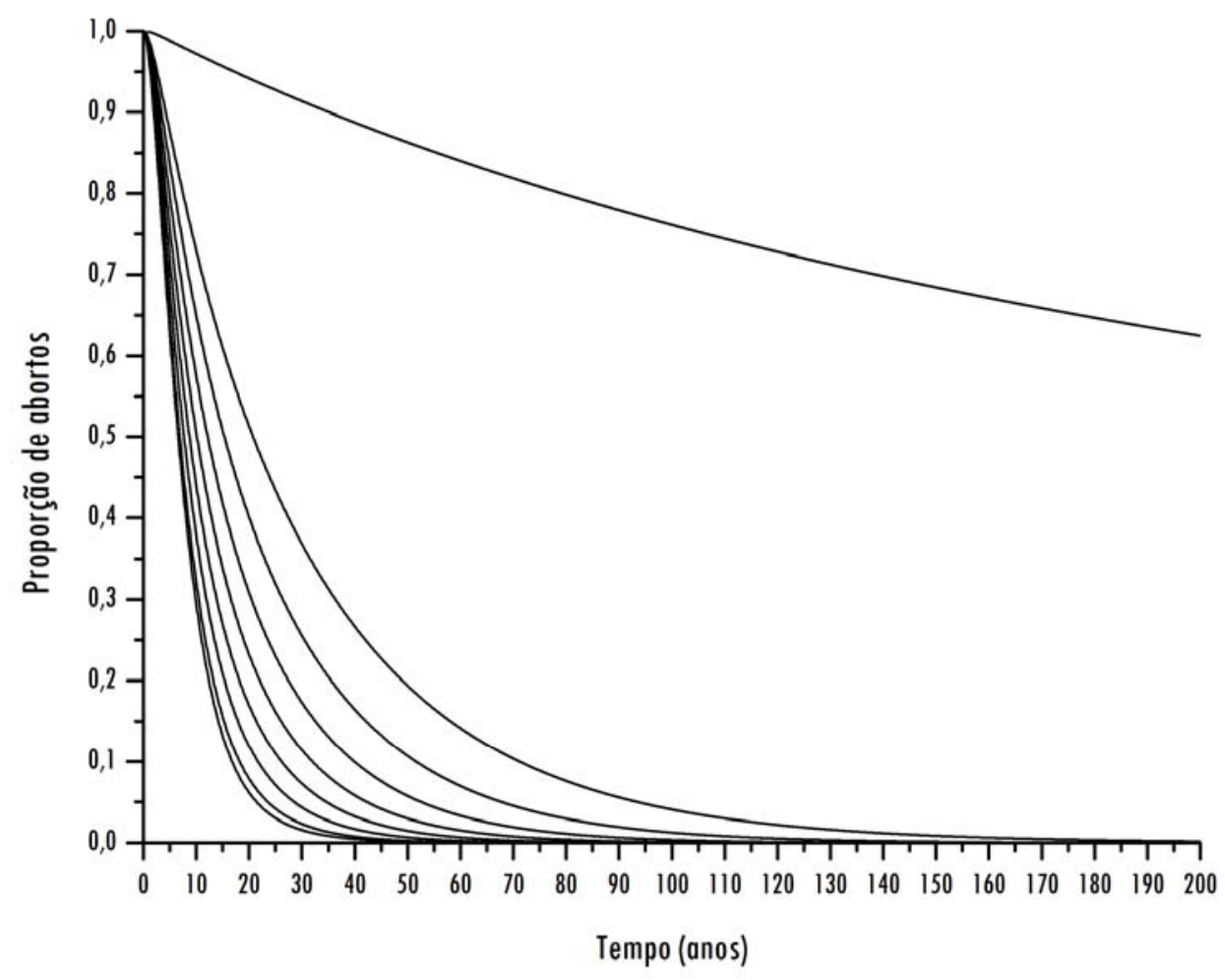

Figura 19 - Proporção de abortos por brucelose ao longo de 200 anos, segundo coberturas vacinais de $95 \%, 90 \%, 80 \%, 70 \%, 60 \%$, $50 \%, 40 \%, 30 \%$ e $3 \%$, da esquerda para a direita

A figura 20 é uma magnificação da figura anterior, mostrando os primeiros 40 anos de vacinação, até a proporção de abortos diminuir até a metade do valor inicial de referência. 


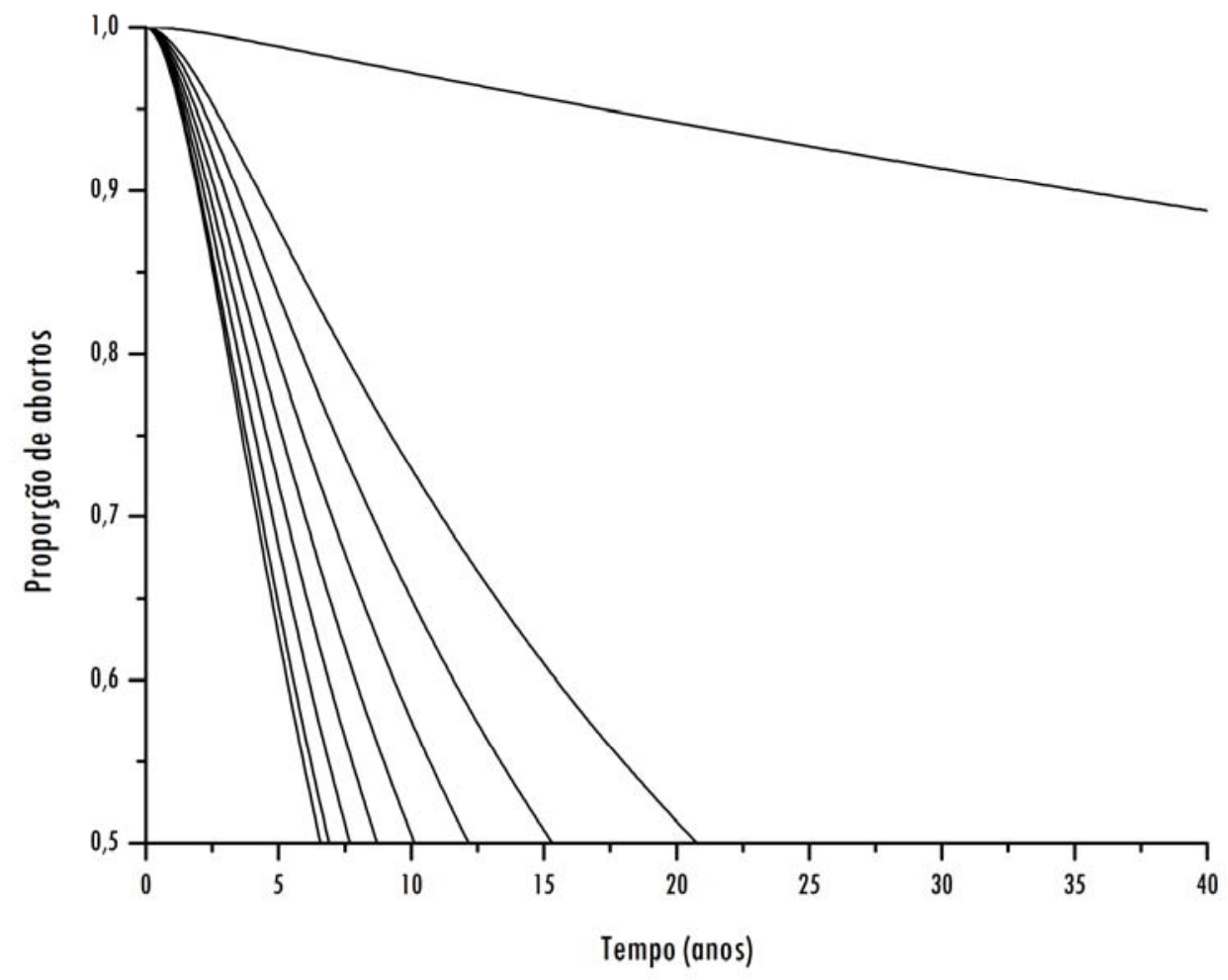

Figura 20 - Proporção de abortos por brucelose ao longo de 40 anos, segundo coberturas vacinais de $95 \%, 90 \%, 80 \%, 70 \%, 60 \%$, $50 \%, 40 \%, 30 \%$ e $3 \%$, da esquerda para a direita 


\section{DISCUSSÃO}

A primeira ação de um programa de controle e erradicação de uma doença é a determinação da sua situação epidemiológica inicial, de modo a permitir um planejamento adequado das atividades de intervenção e avaliação dos resultados obtidos. Apesar do PNCETB ter como objetivo, numa fase inicial de implementação, determinar a prevalência da brucelose nas espécies bovina e bubalina, no Estado de São Paulo, o estudo amostral foi adequado para fornecer elementos para a estudar situação da doença somente na primeira espécie. A população de bubalinos é de cerca de 50 mil animais no Estado, enquanto que a população bovina supera os 13 milhões (IBGE, 2000). Essa disparidade traduziu-se nos resultados do presente trabalho, pois o número de propriedades que tinham na produção de bubalinos a principal atividade econômica, que foram visitadas durante 0 estudo amostral, foi baixo (somente duas propriedades), o que impossibilitou o cálculo de prevalências da brucelose para esta espécie. Apesar de terem sido utilizados os cadastros de produtores de bovinos e bubalinos no cálculo da amostra, sugere-se 0 delineamento de um estudo específico para búfalas, nas regiões do Vale do Ribeira (na região sul do Estado) e no oeste do Estado, as principais regiões produtoras paulistas, para a determinação da prevalência da brucelose nessa população.

0 delineamento amostral foi direcionado a determinar a prevalência de focos de brucelose. Um efeito deste direcionamento pode ser evidenciado pelos valores dos efeitos de desenho amostral, no cálculo das prevalências para fêmeas. Nos circuitos produtores 3 e 4, observou-se efeitos de desenho do cálculo de prevalência de fêmeas soropositivas da ordem de 52,9 e 13,8, respectivamente. No Estado de São Paulo, 0 efeito de desenho amostral da estimativa da prevalência da brucelose em fêmeas foi 59,4. A razão disto é a presença de propriedades com um grande rebanho de fêmeas bovinas, onde foram coletadas, no máximo 15 amostras. Um exemplo é uma propriedade do Circuito 3 com um rebanho de 1900 fêmeas com idade 
superior a 24 meses, sendo que das 15 amostras coletadas, $5(33,3 \%)$ resultaram positivas. 0 impacto destas propriedades na prevalência de fêmeas nestes circuitos foi a elevação dos valores destes circuitos, com alargameto dos intervalos de confiança, em relação aos demais.

0 efeito do desenho amostral na estimativa da prevalência é a razão entre a variância da estimativa sob o desenho amostral usado e a variância da estimativa assumindo-se que os dados viessem de uma amostra simples aleatória (KISH, 1965). A amostragem por agrupamento (cluster ) tende a aumentar a variância, ou seja, amplia o intervalo de confiança, uma vez que os elementos de um mesmo agrupamento (cluster) tendem a ser mais semelhantes do que a população como um todo e acabam fornecendo menos informação sobre a população do que elementos de diferentes agrupamentos. Portanto, as estimativas serão provavelmente menos precisas do que as estimativas obtidas através da amostragem aleatória simples. A estratificação tende a reduzir a variância e acaba compensando, pelo menos parcialmente, 0 efeito oposto da amostragem por agrupamentos. Ao analisar o problema, observa-se que este viés é incontornável, visto que, estratificando-se a amostra por tamanho de rebanhos faria com que o enfoque do estudo se voltasse para a prevalência de fêmeas, e não de focos.

São raros os trabalhos científicos acerca de levantamentos regionais ou nacionais, apesar de alguns países considerados desenvolvidos terem erradicado a doença com sucesso.

Analisando-se as prevalências de focos e de fêmeas, entre os circuitos produtores e no Estado de São Paulo, observa-se que a brucelose está difundida de forma homogênea pelo território paulista. Mesmo entre os tipos de exploração, a doença apresenta-se espalhada da mesma forma. Em um estudo de prevalência, para determinação do estatus da brucelose bovina, realizado na Síria, também observou-se que a brucelose apresenta-se espalhada homogeneamente no território (DARWESH; BENKIRANE, 2001).

Na figura 16, verificou-se que, dentro de um raio de até $70 \mathrm{~km}$ a partir de cada ponto, não há evidências de aglomerados de focos, e que a partir desta distância, há uma tendência de agrupamentos de 
propriedades livres de brucelose (controles), sem que isso se reverta em agrupamentos de focos. Os resultados das análises espaciais reforçam, portanto, a tese de que a brucelose bovina encontra-se espalhada de forma homogênea no território paulista. Essa metodologia foi utilizada num estudo que avaliou a distribuição dos casos de leucemia infantil na Inglaterra, onde também a distribuição dos casos de uma doença foi influenciada pela distribuição da população. Havia uma tendência de agrupamento nesse estudo, porém observada somente quando se considerou grandes distâncias (GATRELL et al., 1996).

A descrição epidemiológica da amostra forneceu elementos para que se pudesse estudar as relações entre a tipologia das propriedades e os fatores de risco associados ao aparecimento da doença. Em resumo, no Circuito l existe o predomínio da exploração mista, porém a exploração de corte é expressiva no contexto estadual (a participação da exploração de leite é a mais baixa, no Estado). Há o predomínio da criação extensiva e baixa utilização de inseminação artificial e raças especializadas. As propriedades são grandes (na comparação com os outros circuitos produtores), mantendo um grande número de machos castrados e com idade avançada, além de um número expressivo de fêmeas em idade reprodutiva. As propriedades criam, quase que exclusivamente, bovinos, sem consórcio com outras espécies domésticas. Há um baixo número de propriedades que tiveram casos de abortos. Poucas delas testam os animais para brucelose, porém a maioria das propriedades vacina os animais. 0 comércio de animais é intenso, e as propriedades que enviam reprodutores para abate, o fazem principalmente para locais com inspeção. As práticas de aluguel de pasto, pastos comuns com outras propriedades e áreas alagadiças não são comuns. A maioria das propriedades utiliza piquetes de parição e a região apresenta a maior porcentagem de propriedades com assistência veterinária no Estado.

No Circuito 2, existe 0 predomínio das explorações mista e leite. Há o predomínio da criação extensiva, baixa utilização de inseminação artificial e raças especializadas. 0 tamanho das propriedades é próximo da mediana estadual, mantendo um grande número de machos com idade avançada, além de um 
número expressivo de fêmeas em idade reprodutiva. 0 tipo de ordenha predominante é a mecânica ao pé, sendo mais comumente realizada uma vez por dia. 0 número de vacas em lactação e a produção leiteira são próximos da mediana estadual, porém a produtividade é elevada. É comum o consórcio da criação de bovinos com a criação de aves e súnos. Há um baixo número de propriedades que tiveram casos de abortos. Poucas delas testam os animais para brucelose, porém a maioria das propriedades vacina os animais. 0 comércio de animais é intenso, e as propriedades que enviam reprodutores para abate, o fazem para locais com inspeção, principalmente. As práticas de aluguel de pasto e pastos comuns com outras propriedades não são comuns. Grande parte das propriedades possui áreas alagadiças e a maioria utiliza piquetes de parição. A maioria das propriedades não entrega o leite produzido, consumindo-o na própria fazenda e produzindo queijo ou manteiga. 0 restante entrega o leite para laticínios. A região apresenta um baixo número de propriedades com assistência veterinária.

No Circuito 3, existe o predomínio das explorações mista e corte (esta última tem expressão elevada no Estado). Há o predomínio da criação extensiva e baixa utilização de inseminação artificial. É elevada a utilização de raças especializadas. 0 tamanho das propriedades é próximo da mediana estadual, mantendo um grande número de machos castrados, além de um número expressivo de fêmeas com idade superior a 24 meses. É comum o consórcio da criação de bovinos com a criaçã̃o de aves e suínos. Há um baixo número de propriedades que tiveram casos de abortos. Poucas delas testam os animais para brucelose, porém a maioria das propriedades vacina os animais. 0 comércio de animais é intenso, porém a maioria das propriedades não enviam reprodutores para abate. As práticas de aluguel de pasto, pastos comuns com outras propriedades e áreas alagadiças não são comuns. A maioria das propriedades utiliza piquetes de parição. A região apresenta uma baixa taxa de assistência veterinária.

No Circuito 4, existe o predomínio da exploração mista. Há o predomínio da criação extensiva (semiconfinamento é importante nesta região), baixa utilização de inseminação artificial (porém é a mais 
expressiva no Estado) e raças especializadas. 0 tamanho das propriedades é próximo da mediana estadual, mantendo um baixo número de machos, porém um número expressivo de fêmeas com idade superior a 24 meses. 0 tipo de ordenha predominante é a mecânica ao pé, sendo mais comumente realizada uma vez por dia. 0 número de vacas em lactação e a produção leiteira são elevados, assim como a produtividade (é a mais expressiva no Estado). É baixa o consórcio da criação de bovinos com outras criações domésticas. Há um baixo número de propriedades que tiveram casos de abortos. Poucas delas testam os animais para brucelose, porém a maioria das propriedades vacina os animais. 0 comércio de animais é intenso, porém a maioria das propriedades não envia reprodutores para abate. As práticas de aluguel de pasto, pastos comuns com outras propriedades e áreas alagadiças não são comuns. A maioria das propriedades utiliza piquetes de parição. Grande parte das propriedades não entrega 0 leite produzido, produzindo queijo ou manteiga. 0 restante entrega 0 leite a granel. A região apresenta um baixo número de propriedades com assistência veterinária.

№ Circuito 5, existe o predomínio das explorações mista e leite, no entanto, a exploração de corte tem expressão no Estado. Há o predomínio da criação extensiva (semi-confinamento é importante nesta região), baixa utilização de inseminação artificial e raças especializadas. As propriedades são pequenas (as menores do Estado, em número de animais), mantendo poucos machos, porém de um número expressivo de fêmeas em idade reprodutiva. 0 tipo de ordenha predominante é a mecânica ao pé (salas de ordenha são importantes nesta região e no Estado), sendo mais comumente realizada uma vez por dia (a parcela de propriedades que ordenha 2 vezes é importante na região). 0 número de vacas em lactação e a produção leiteira nas propriedades são baixos, porém a produtividade é elevada. É comum o consórcio da criação de bovinos com a criação de aves e suínos. Há um baixo número de propriedades que tiveram casos de abortos. Poucas delas testam os animais para brucelose, porém a maioria das propriedades vacina os animais. 0 comércio de animais é intenso, porém a maioria das propriedades não envia reprodutores para 
abate. As práticas de aluguel de pasto, pastos comuns com outras propriedades e áreas alagadiças não são comuns. A maioria das propriedades utiliza piquetes de parição. A maioria das propriedades não entrega 0 leite produzido, produzindo queijo ou manteiga. 0 restante entrega o leite para laticínios. A região apresenta um baixo número de propriedades com assistência veterinária.

№ Circuito 6, existe o predomínio da exploração mista. Há o predomínio da criação extensiva, baixa utilização de inseminação artificial e raças especializadas. 0 tamanho dos rebanhos é pequeno, mantendo um baixo número de machos, porém um número expressivo de fêmeas com idade superior a 24 meses. 0 tipo de ordenha predominante é a mecânica ao pé, sendo mais comumente realizada uma vez por dia. 0 número de vacas em lactação e a produção leiteira são baixos, assim como a produtividade. 0 consórcio da criação de bovinos com a criação de aves é importante. Há um baixo número de propriedades que tiveram casos de abortos. Poucas delas testam os animais para brucelose, porém a maioria das propriedades vacina os animais. 0 comércio de animais é intenso, porém a maioria das propriedades não envia reprodutores para abate. As práticas de aluguel de pasto, pastos comuns com outras propriedades e utilização de piquetes de parição não são comuns. A maioria das propriedades possui áreas alagadiças. Grande parte das propriedades não entrega o leite produzido, consumindo-o na própria fazenda e produzindo queijo ou manteiga. A região apresenta um baixo número de propriedades com assistência veterinária.

Finalmente no Circuito 7, existe o predomínio das explorações mista e leite. Há um equilíbrio entre a criação extensiva e o semi-confinamento, baixa utilização de inseminação artificial e raças especializadas. 0 tamanho das propriedades, em número de animais, é próximo da mediana do Estado, mantendo poucos machos, porém de um número expressivo de fêmeas com idade superior a 24 meses. 0 tipo de ordenha predominante é a mecânica ao pé, sendo mais comumente realizada uma vez por dia (a parcela de propriedades que ordenha 2 vezes é a mais importante do Estado). 0 número de vacas em lactação e a produção leiteira nas propriedades são elevados, assim como a produtividade. É comum o consórcio da 
criação de bovinos com a criação de aves. Há um alto número de propriedades que tiveram casos de abortos. Poucas delas testam os animais para brucelose, porém a maioria das propriedades vacina os animais (menor cobertura no Estado). 0 comércio de animais é intenso, porém a maioria das propriedades não envia reprodutores para abate. As práticas de aluguel de pasto, pastos comuns com outras propriedades e áreas alagadiças não são comuns. Poucas propriedades utilizam piquetes de parição. A maioria das propriedades entrega o leite para cooperativas, e as que não entregam, utilizam o leite para consumo próprio. 0 restante entrega o leite para laticínios. A região apresenta um elevado número de propriedades com assistência veterinária.

Observando as peculiaridades de cada circuito produtor, pode-se separar o Estado em três grandes áreas, segundo as características dos sistemas de produção bovino. A primeira grande área, formada pelos Circuitos 1, 3 e a porção oeste do Circuito 2, concentra as grandes propriedades de exploração de corte, de criação extensiva, com rebanhos especializados e de caráter empresarial. Uma segunda grande área, formada pelos Circuitos 2, 4, 5, 7 e a porção norte do Circuito 6 (região de Sorocaba), concentra as propriedades de aptidão leiteira, com número pequeno de animais e alta produtividade. 0 Circuito 7 (Vale do Rio Paraíba) pode ser considerado uma bacia leiteira tradicional, uma vez que concentra propriedades comparativamente maiores, com alta produção leiteira e cadeia produtiva melhor estabelecida. Finalmente a última grande área é composta pelo Circuito 6 (Vale do Rio Ribeira), que é a área de produção pecuária menos tecnificada do Estado de São Paulo. Tendo em vista os fatores de risco inerentes a cada tipo de exploração e a nova proposta de divisão em circuitos produtores, a adoção das medidas de controle propostas no PNCETB deveriam ser feita de forma a respeitar tais particularidades, o que traria benefícios tanto em termos logísticos como de racionalização do emprego dos recursos financeiros.

Quanto aos fatores de risco, pode-se dizer que: (a) em propriedades de exploração de corte, a vacinação já constitui uma importante ferramenta no combate à doença. Não foi estudada a cobertura 
vacinal em animais, porém, uma parcela significativa destas propriedades vacina contra brucelose; (b) em propriedades de leite, os fatores de risco identificados foram propriedades com elevado número de fêmeas em idade reprodutiva e aluguel de pasto. Uma importante ferramenta no combate à doença é a prática de separar fêmeas no período do peri-parto em piquetes especiais, 0 que foi expressivo no Circuito 7, onde esta prática não é adotada com frequiência; (c) em propriedades de exploração mista, é fator de risco para brucelose submeter os animais a confinamento. Assim como na exploração leiteira, a prática de separar as fêmeas no período do peri-parto é fator protetor. Alguns trabalhos realizados em outros países subdesenvolvidos estudaram fatores de risco para brucelose bovina. Na Eritréa, o fator de risco mais importnte foi criar animais mestiços $(O R=5,21)$, devido à alta taxa de renovação do rebanho existente nesse tipo de propriedade (OMER et al., 2000). Num estudo realizado no Sri Lanka, foram analizados rebanhos bovinos e bubalinos, e os fatores de risco foram presença de animais maiores que 3 anos $(O R=$ 2,0), animais provenientes de zonas secas $(O R=5,0)$, tipo de criação extensivo (OR $=1,8)$ (SILVA; DANGOLLA; KULACHELVY, 2000). Apesar dos dois últimos fatores parecerem inusitados, foi apontado que, nessa região, existe a prática de vender os animais que são identificados como positivos e que são comprados nessas áreas.

Considerando-se a realidade estadual, de modo geral, a brucelose é comumente encontrada em propriedades com grande número de bovinos, e que realizam intenso comércio de animais. A compra de animais pode ser apontado como um importante fator de risco para a doença no Estado de São Paulo. Contribui com este fator a baixa cobertura vacinal, estimada em $3 \%$ das fêmeas com idade entre 3 e 8 meses no Estado de São Paulo (MAPA, 2000a). A adoção de um programa de vacinação poderia conter a doença, como é o caso do Estado de Minas Gerais, que iniciou seu programa em 1981 (obrigatório desde 1994) e, com isso, diminuiu a frequiência da brucelose (em fêmeas) de 6,7\% em 1980 (MAPA, 200a) para 
1,1\% em 2001, segundo dados preliminares do PNCETB, fornecidos por Gonçalves ${ }^{4}$ (2003). Nesse sentido, 0 grande aporte de doses de vacina B19 nesse Estado alcançou 43,3\% do total das 2.657.621 doses produzidas no país, em 1997 (MAPA, 2000a). 0 Estado do Rio Grande do Sul também adotou um programa de combate da brucelose, em 1965, porém os dados mais atualizados da prevalência da doença ainda não estão disponíveis.

Com vistas à erradicação da doença, 0 Estado de Minas Gerais deverá alterar a atual estratégia de combate à brucelose, provavelmente para medidas relacionadas à identificação e sacrifício dos animais positivos, dada a prevalência baixa da doença. 0 Estado de São Paulo deverá continuar adotando a vacinação, como estratégia de controle da doença, visto que a prevalência encontra-se num patamar mais elevado. Porém, será necessário um esforço mais intenso que 0 atualmente empregado. 0 modelo matemático proposto mostrou que, com a taxa de vacinação adotada atualmente, não será possível diminuir a prevalência da brucelose. Apesar de não ter sido validado com dados reais, pode-se comparar os efeitos da queda na prevalência entre os diferentes níveis de cobertura vacinal. Em todos os casos, seriam necessárias décadas para que a doença fosse erradicada, somente adotando-se esta medida. Porém, até ser alcançada uma prevalência de $2 \%$ de fêmeas positivas para brucelose, seriam necessários cerca de 15 anos, a uma cobertura vacinal de $70 \%$. Coberturas menores produzem um prolongamento desse prazo, sendo que sob coberturas menores que $50 \%$ das fêmeas, seriam necessários mais de duas décadas para alcançar a mesma prevalência. De forma inversa, esforços vacinais mais intensos, não trariam um ganho significativo em termos de redução do tempo. Através do gráfico da figura 18, observa-se que não há diferença significativa entre coberturas de 80 a $95 \%$, podendo-se concluir que não seria economica e logisticamente viável adotar-se uma cobertura vacinal tão intensa. As mesmas observações podem ser feitas sobre a diminuição do número de abortos, porém a queda se dá de forma mais acentuada nos

\footnotetext{
${ }^{4}$ Dados preliminares do PNCETB. Informação fornecida por Gonçalves em Brasília, em 2003.
} 
primeiros anos. Deve-se lembrar que 0 modelo considerou que a vacina protegia $100 \%$ dos animais, 0 que não justifica a adoção de coberturar menores que $100 \%$ no caso da obrigatoriedade da vacinação. 


\section{CONCLUSÕES}

A prevalência aparente de focos de brucelose (propriedades com, ao menos, uma fêmea bovina com idade superior a 24 meses soropositiva), foi calculada em 9,70\% [7,80\%; 11,60\%] no Estado de São Paulo, $10,34 \%[5,91 \% ; 16,49 \%]$ no Circuito $1,9,93 \%[5,67 \% ; 15,85 \%]$ no Circuito $2,10,13 \%[5,78 \% ; 16,17 \%]$ no Circuito $3,11,11 \%[6,61 \% ; 17,19 \%]$ no Circuito $4,7,26 \%[3,92 \% ; 12,10 \%]$ no Circuito 5, 8,22\% [4,32\%; 13,92\%] no Circuito 6 e 11,92\% [7,22\%; 18,18\%] no Circuito 7.

A prevalência aparente da brucelose, em fêmeas bovinas com idade superior a 24 meses, foi calculada em 3,81\% [0,72\%, 6,90\%] no Estado de São Paulo, 2,44\% [0,76\%; 4,12\%] no Circuito 1, 1,84\% $[0,39 \%, 3,29 \%]$ no Circuito $2,7,98 \%[0,00 \% ; 18,61 \%]$ no Circuito $3,5,52 \%[0,72 \% ; 10,32 \%]$ no Circuito 4, 1,86\% [0,45\%; 3,27\%] no Circuito 5, 1,68\% [0,48\%; 2,88\%] no Circuito 6 e 2,17\% [0,77\%; 3,56\%] no Circuito 7.

Os fatores de risco para brucelose bovina nas propriedades com atividade reprodutiva em São Paulo são: manter 87 ou mais bovinos na propriedade $(O R=2,25)$ e compra de reprodutores $(O R=1,56)$.

Não foram identificados agrupamentos de focos de brucelose no Estado de São Paulo, em relação à distribuição de controles.

0 modelo matemático proposto mostrou que a estratégia de combate à brucelose adotada atualmente deverá ser intensificada para que se possa diminuir a prevalência da doença. Mesmo assim, tais esforços só surtiriam efeitos em prazos que podem alcançar décadas. 


\section{REFERÊNCIAS}

ACHA, P. N.; SZYFRES, B. Zoonosis y enfermidades transmissibles comunes al hombre y los animales. Washington: Organización Panamericana de la Salud, 1986. p. 502-506. (Publicación científica, 503).

AMARAL, A. M. P.; ROCHA, M. B.; PEETZ, V.; MARTINS, S. S.; GHOBRIL, C. N. Estimativa da produção animal no Estado de São Paulo para 2002. Informações Econômicas, v. 33, n. 3, p. 84-98, 2003.

BAILEY, T. C.; GATRELL, A. C. Interactive spatial data analysis. Harlow: Prentice Hall, 1995. 413 p.

BEER, J. Doenças infecciosas em animais domésticos. São Paulo: Roca, 1988. 380 p.

BISHOP, G. C.; BOSMAN, P. P.; HERR, S. Bovine brucellosis. In: COETZER, J. A. N.; THOMSON, G. R.; TUSTIN, R. C. (Ed.). Infectious diseases of livestock. Austin: Texas A\&M University Press, 1994. v. 2. p. 1053-1066.

CAMERON, A. R. Survey toolbox for livestock diseases - a practical manual and software package for active surveillance in developing countries. 1999. 330 p. (ACIAR Monograph, 54).

CARPENTER, T. E. Methods to investigate spatial and temporal clustering in veterinary epidemiology. Preventive Veterinary Medicine, v. 48, n. 4. p. 303-320, 2001.

CHATFIELD, C.; COLLINS, A. J. Introduction to multivariate analysis. London: Chapman \& Hall, 1980. $246 \mathrm{p}$.

CLARK, P. J., EVANS, F. C. Distance to nearest neighbor as a measure of spatial relationships in populations. Ecology, n. 35, p. 445-453, 1954.

COCHRAN, W. G. Sampling techniques. 3. ed. New York: John Wiley \& Sons, 1997. 428 p.

CORRÊA, 0. Brucelose. In: CORRÊA, 0. Doenças infecciosas dos animais domésticos. Rio de Janeiro: Freitas Bastos, 1975. v. 1, p. 196-209. 
CRAWFORD, R. P.; HUBER, J. D.; ADAMS, B. S. Epidemiology and surveillance. In: NIELSEN, K.; DUNCAN, J. R. Animal brucellosis. Boca Raton: CRC Press, 1990. p. 131-151.

CUZICK, J., EDWARDS, R. Spatial clustering for inhomogenous populations. Journal of the Royal Statistical Society Series B, v. 52, p. 73-104, 1990.

DARWESH, M.; BENKIRANE, A. Field investigations of brucellosis in cattle and small ruminants in Syria, 19901996. Revue Scientifique et Technique Office International des Epizooties, v. 20, n. 3, p. 769-775, 2001.

DEAN, A. G. Epilnfo version 6: A word-processing, database, and statistic program for public health on IBM-compatible microcomputers. Atlanta: Center for Diseases Control and Prevention, 1994.601 p.

DIAS, J. A. Soroepidemiologia da brucelose bovina e bubalina no Estado do Paraná. 2003. $41 \mathrm{f}$. Dissertação (mestrado) - Centro de Ciências Agrárias, Universidade Estadual de Londrina, Londrina, 2003.

DONALD, A. W.; GARDNER, I. A.; WIGGINS, A. D. Cutt-off points for aggregate herd testing in the presence of disease clustering and correlation of test errors. Preventive Veterinary Medicine, v. 19, n. 3-4. p. 167 187, 1994.

ELLIOT, P.; CUZICK, J.; ENGLISH, D.; STERN, R. Geographical \& environmental epidemiology. Oxford: Oxford University Press, 1992. $382 \mathrm{p}$.

ELLIOT, P.; WAKEFIELD, J.; BEST, N.; BRIGGS, D. Spatial epidemiology. Oxford: Oxford University Press, $2000.475 \mathrm{p}$.

Epilnfo 6.04d. Atlanta: Center for Diseases Control and Prevention, 2001. Disponível em $<$ http://www.cdc.gov>. Acesso em: 10 set. 2001.

ESRI INC. ArcView GIS version 3.1. Redlands, 1996. I CD-Rom.

FARIA, J. F. Situação da brucelose no Brasil. Comunicação Científica da Faculdade de Medicina Veterinária e Zootecnia da Universidade de São Paulo, São Paulo, v. 8, n. 2, p. 161-175, 1984. 
FLETCHER, R. H.; FLETCHER, S. W.; WAGNER, E. H. Clinical epidemiology: the essentials. 2. ed. Baltimore: Williams \& Wilkins, 1998. $246 \mathrm{p}$.

FRAUENTHAL, J. C. Mathematical modeling in epidemiology. Berlin: Springer-Verlag. 1980. 118 p.

GARCIA-CARRILO, C. La brucelosis de los animales en América y su relación con la infección humana. Paris: Office International des Epizooties, 1987. 303 p.

GATRELL, A. C.; BAILEY, T. C.; DIGGLE, P. J.; ROWLINGSON, B. S. Spatial point pattern analysis and its application in geographical epidemiology. Transactions of the Institute of British Geographers, v. 21, p. 256-274, 1996.

GeoBase VB50 version 2.0. São Paulo: Base Aerofotogrametria e Projetos, 2000. I CD-Rom.

GODFROID, J. Brucellosis in wildlife. Revue Scientifique et Technique Office International des Epizooties, v. 21, n. 2, p. 277-286, 2002.

GONZÁLEZ-GUZMÁN, J.; NAULIN, R. Analysis of a model of bovine brucellosis using singular perturbations. Journal of Mathematical Biology, v. 33, p. 211-223, 1994.

GRASSO, L. M. P. S. 0 combate à brucelose bovina. 2000. 112 f. Dissertação (mestrado) - Faculdade de Medicina Veterinária e Zootecnia, Universidade de São Paulo, São Paulo, 2000.

GREGG, M. B. Field epidemiology. New York: Oxford University Press, 1996. 275 p.

Herdacc version 3. Guelph: University of Guelph, 1995. Disponível em: <http://www.vetschools.co.uk/ EpiVetNet/files/herdacc.exe>. Acesso em: 10 set. 2001.

HOSMER JR., D. W.; LEMESHOW, S. Applied logistic regression. New York: John Wiley \& Sons, 1989. 307 p.

IBGE (INSTITUTO bRASILEIRO DE GEOGRAFIA E ESTATístiCA). Censo populacional de 2000. Rio de Janeiro, 2000. 1 CD-Rom. 
IBGE (INSTITUTO BRASILEIRO DE GEOGRAFIA E ESTATÍSTICA). Malha municipal digital do Brasil: situação em 1997. Rio de Janeiro, 1999. I CD-Rom.

ITO, F. H.; VASCONCELLOS, S. A.; BERNARDI, F.; NASCIMENTO, A. A.; LABRUNA, M. B.; ARANTES, I. G. Evidência sorológica e brucelose e leptospirose e parasitismo por ixodídeos em animais silvestres do Pantanal sulmatogrossense. Ars Veterinária, Jaboticabal, v. 14, n. 3, p. 302-310, 1998.

JACQUEZ, G. M. Guidelines and procedures for investigating disease clusters. In: Procedings of a Short Course, BioMedware. Univ. of British Columbia, Ann Arbour, 1994.

JORDAN, D. Aggregate testing for the evaluation of Johne's disease herd status. Australian Veterinary Journal, v. 73, n. 1, p. 16-19, 1996.

KISH, L. Survey sampling. New York: Wiley and Sons, 1965. p. 664

LYRA, T. M. P. Epidemiologia da brucelose. Comunicação Científica da Faculdade de Medicina Veterinária e Zootecnia da Universidade de São Paulo, São Paulo, v. 8, n. 2, p. 177-186, 1984.

MARTIN, S. W.; SHOUKRI, M.; THORBURN, M. A. Evaluating the health status of herds based on tests applied to individuals. Preventive Veterinary Medicine, v. 14, p. 33-43, 1992.

MASSAD, E.; MENEZES, R. X.; SILVEIRA, P. S. P.; ORTEGA, N. R. Métodos quantitativos em medicina. Barueri: Manole, 2004. $561 \mathrm{p}$.

Mathcad 2001 Professional. Cambridge: Mathsoft Engeneering and Education Inc., 2001. 1 CD-Rom.

MAPA (MINISTÉRIO DA AGRICULTURA, PECUÁRIA E ABASTECIMENTO). Boletim de defesa sanitária animal. Brasília. v. 30. 2000a.

MAPA (MINISTÉRIO DA AGRICULTURA, PECUÁRIA E ABASTECIMENTO). Programa nacional de controle e erradicação da brucelose e tuberculose. Brasília, 2001b. Disponível em: <http://www.agricultura.gov.br/sda/dda/inicial.htm>. Acesso em: 10 set. 2001.

MAPA (MINISTÉRIO DA AGRICULTURA, PECUÁRIA E ABASTECIMENTO). Proposal or the enlargement of the foot-and-mouth disease free zone, where vaccination is practiced. Brasília, 2000c. $156 \mathrm{p}$. 
Minitab Release 14. State College: Minitab Inc., 2003. I CD-Rom.

MORAN, P. A. P. Notes on continuous stochastic phenomena. Biometrika, n. 37, p. 17-23, 1950.

NICOLETTI, P. A short history of brucellosis. Veterinary Microbiology, v. 90, p. 5-9, 2002.

NOORDHUIZEN, J. P. T. M.; FRANKENA, K.; VAN DER HOOFD, C. M.; GRAAT, E. A. M. Application of quantitative methods in veterinary epidemiology. Wageningen: Wageningen Press, 1997. $445 \mathrm{p}$.

OFFICE INTERNATIONAL DES EPIZO0TIES. Brucelosis bovina, ovina y caprina. Série técnica, n. 6, 1987, 282 p.

OFFICE INTERNATIONAL DES EPIZOOTIES. Terrestrial animal health code, 2003. 11 ed. Disponível em: <http://www.oie.int/eng/normes/MCode/A_summry.htm>. Acesso em: 27 fev. 2004.

OMER, M. K.; SKJERVE, E.; WOLDEHIWET, Z.; HOLSTAD, G. Risk factors for Brucella spp. Infetion in dairy cattle farms in Asmara, State of Eritrea. Preventive Veterinary Medicine, v. 46, n. 4. p. 257-265, 2000.

PAULIN, L. M.; FERREIRA NETO, J. S. 0 combate à brucelose bovina: situação brasileira. Jaboticabal: Funep, 2003. $154 \mathrm{p}$.

POESTER, F. P.; GONÇALVES, V. S. P.; LAGE, A. P. Brucellosis in Brazil. Veterinary Microbiology, v. 90, n. 14. p. 55-62, 2002.

$\mathbf{R}$ precompiled binary distribution version R-1.9.0. Vienna: $\mathbf{R}$ Development Core Team, 2004. Disponivel em: <http://gauss.est.ufpr.br/ CRAN/bin/windows/base/rw1090.exe>

RUSSEL, A. D.; YARNICH, V. S.; KOULIKOVSKII, A. V. Guidelines on disinfection in animal husbandry for prevention and control of zoonotic diseases. Genève: WHO, 1984.61 p.

SALMAN, M. D.; MEYER, M. E.; HIRD, D. W. Epidemiology of bovine brucellosis in the Mexicali Valley, Mexico: data gathering and survey results. American Journal of Veterinary Research, v. 45, n. 8, p. 15611566, 1984. 
SIKUSAWA, S. Prevalência e caracterização epidemiológica da brucelose bovina no Estado de Santa Catarina. 2004. $107 \mathrm{f}$. Dissertaçã̃o (Mestrado em Epidemiologia Experimental e Aplicada às Zoonoses) - Faculdade de Medicina Veterinária e Zootecnia, Universidade de São Paulo, São Paulo, 2004.

SILVA, I.; DANGOLLA, A.; KULACHELVY, K. Seroepidemiology of Brucella abortus infection in bovids in Sri Lanka. Preventive Veterinary Medicine, v. 46, n. 1. p. 51-59, 2000.

SIMES, R. J. An improved Bonferroni procedure for multiple tests of significance. Biometrika, n. 73, p. 751$754,1986$.

SPSS INC. Spss base 9.0 user's guide. Chicago: SPSS Inc., 1999a. 740 p.

SPSS INC. SPSS base 9.0. Chicago, 1999b. I CD-Rom.

THRUSFIELD, M. Veterinary epidemiology. 2. ed. Cambridge: Blackwell Science, 1995. 479 p.

TIMONEY, J. F.; GILLESPIE, J. H.; SCOTT, F. W.; BARLOUGH, J. E. The genus Brucella. In: TIMONEY, J. F.; GILLESPIE, J. H.; SCOTT, F. W.; BARLOUGH, J. E. Hagan and Bruner's microbiology and infectious diseases of domestic animals. London: Comstock Publishing Associates, p. 135-152, 1988. 912 p.

VASCONCELLOS, S. A.; ITO, F. H.; CÔRTES, J. A. Bases para a prevenção da brucelose animal. Comunicação Científica da Faculdade de Medicina Veterinária e Zootecnia da Universidade de São Paulo, São Paulo, v. 11, n. 1, p. 25-36, 1987.

VERONEZI, R. Doenças infecciosas e parasitárias. 6. ed. Rio de Janeiro: Guanabara-Koogan, 1976. 421 p.

WARD, M. P; CARPENTER, T. E. Techniques for analysis of disease clustering in space and in time in veterinary epidemiology. Preventive Veterinary Medicine, v. 45, n. 3-4. p. 257-284, 2000.

ZAR, J. H. Biostatistical analysis. 3. ed. New Jersey: Prentice-Hall, 1996. 662 p. 


\section{ANEXO A - QUESTIONÁRIO EPIDEMIOLÓGICO APLICADO NAS PROPRIEDADES AMOSTRADAS}

\begin{tabular}{|c|c|}
\hline \multicolumn{2}{|c|}{$\begin{array}{c}\text { BRUCELOSE BOVINA E BUBALINA } \\
\text { Cstudo soroepidemiológico }\end{array}$} \\
\hline 01-Identificaşão: & $02-$ Data da visita e colheita \\
\hline $\begin{array}{l}\text { Município: } \_ \text {REGIÃO: } \_ \text {UF: } \\
\text { Proprietário: }\end{array}$ & \begin{tabular}{|c|} 
\\
$03-$ Código do rebanho no estudo (9 digitos)
\end{tabular} \\
\hline $\begin{array}{l}\text { Propriedade: } \\
\text { Código de cadastro no serviço de defesa: }\end{array}$ & 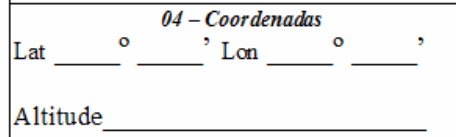 \\
\hline
\end{tabular}

05- Tipo da Exploração: $\quad \square$ corte $\quad \square$ leite $\quad \square$ mista

06- Tipo de Criação: $\square$ confinado $\square$ semi-confinado $\square$ extensivo

07- $\mathbf{N}^{0}$ de Ordenhas por dia: $\square 1$ ordenha $\square 2$ ou 3 ordenhas $\square$ Não ordenha

08- Tipo de Ordenha: $\square$ manual $\square$ mecânica ao pé $\square$ mecânica em sala de ordenha $\square$ Não ordenha 09- Produção de leite: a) $\mathrm{N}^{\circ}$ de vacas em lactação:

b) Produção diária de leite na fazenda: ___ litros

10- Usa inseminação artificial? $\square$ não $\square$ usa inseminação artificial e touro $\square$ usa só inseminação artificial

11- Raça predominante - Bovinos: $\quad \square$ zebu $\quad \square$ europeu de leite $\quad \square$ europeu de corte $\quad \square$ mestiço $\quad \square$ outras raças - Bubalinos: $\quad \square$ murrah $\quad \square$ mediterrâneo $\quad \square$ carabao $\square$ jaffarabadi $\square$ outras raças

\begin{tabular}{|c|c|c|c|c|c|c|c|c|c|c|c|c|c|c|c|}
\hline \multicolumn{7}{|c|}{ 12(a)- Bovinos eristentes } & \multicolumn{9}{|c|}{ 12(b)- Bubalinos existentes } \\
\hline \multirow{2}{*}{$\begin{array}{c}\text { Marhes } \\
\text { Castrades }\end{array}$} & \multicolumn{4}{|c|}{ Machos inteiros (neses) } & \multicolumn{2}{|c|}{ Fêneas (neses) } & \multirow{2}{*}{$\begin{array}{c}\text { Marhes } \\
\text { Castrades }\end{array}$} & \multicolumn{4}{|c|}{ Machos inteiros (neses) } & \multicolumn{4}{|c|}{ Fêneas (neses) } \\
\hline & 0.6 & 6-12 & 12-24 & $>24$ & 6-12 & $12-24>24$ & & 06 & 6-12 & 12-24 & $>24$ & $0-6$ & 6-12 & 12-24 & $>24$ \\
\hline & & & & & & & & & & & & & & & \\
\hline
\end{tabular}

13- Outras espécies na propriedade: $\square$ ovinos/caprinos $\quad \square$ equídeos $\quad \square$ suínos $\quad \square$ aves $\quad \square$ cão $\quad \square$ gato 14- Espécies silvestres em vida livre na propriedade: $\square$ não tem $\quad \square$ cervídeos $\square$ capivaras $\square$ outras:.

15- Alguma vaca/búfala abortou nos últimos 12 meses? $\square$ não $\quad \square$ sim $\quad \square$ não sabe

16- O que faz com o feto abortado e a placenta? $\square$ enterra/joga em fossa/queima $\square$ alimenta porco/cão $\square$ não faz nada 17- Faz testes para diagnóstico de brucelose? $\quad \square$ não $\quad \square$ sim

Regularidade dos testes: $\quad \square$ uma vez ao ano $\quad \square$ duas vezes ao ano $\quad \square$ quando compra animais

$\square$ quando há casos de aborto na fazenda $\square$ quando exigido para trânsito/eventos/crédito

18- Compra fêmeas ou machos com finalidade de reprodução? $\square$ não $\quad \square$ sim

Onde/de quem: $\square$ em exposição $\square$ em leilão/feira $\square$ de comerciante de gado $\square$ diretamente de outras fazendas 19- Vende fêm eas ou machos para reprodução? $\square$ não $\square$ sim

A quem/onde: $\square$ em exposição $\quad \square$ em leilão/feira $\quad \square$ a comerciante de gado $\quad \square$ diretamente a outras fazendas 20- Vacina contra brucelose? $\square$ não $\square$ sim, apenas fêmeas até 8 meses de idade $\square$ sim, fêmeas de qualquer idade

21- Local de abate das fêmeas e machos adultos no fim da vida reprodutiva:

$\square$ na própria fazenda $\square$ em estabelecimento sem inspeção veterinária

$\square$ em estabelecimento de abate com inspeção veterinária $\square$ não abate

22- Aluga pastos em alguma época do ano? $\square$ não $\square$ sim

23- Tem pastos em comum com outras propriedades? $\square$ não $\square$ sim

24- Existem na propriedade áreas alagadiças às quais o gado tem acesso? $\square$ não $\quad \square$ sim

25- Tem piquete separado para fêmeas na fase de parto e/ou pós-parto? $\square$ não $\square$ sim

26- A quem entrega leite? $\square$ cooperativa $\square$ laticínio $\square$ direto ao consumidor $\square$ não entrega

27- Resfriamento do leite: $\square$ não faz $\square$ faz Como: $\square$ em resfriador ou tanque de expansão próprio

28- A entrega do leite é feita a granel? $\square$ não $\square$ sim

$\square$ em resfriador ou tanque de expansão coletivo

29- Produz queijo e/ou manteiga na propriedade? $\square$ não $\square$ sim Finalidade: $\square$ p/ consumo próprio $\square$ p/venda 30- Consome leite cru? $\square$ não $\square$ sim

31-Tem assistência veterinária? $\square$ não $\square$ sim De que tipo? $\square$ veterinário da cooperativa $\square$ veterinário particular 
continuação

\begin{tabular}{|c|c|c|c|c|c|c|c|c|c|c|c|c|c|}
\hline \multicolumn{10}{|c|}{ 32-INFORMAÇÕES SOBRE AS AMOSTRAS COLHIDAS } & \multicolumn{4}{|c|}{ 33 - RESULTADOS LABORATORLAIS (3) } \\
\hline$r^{\circ}$ & $\begin{array}{c}\text { NÚ ME RO DO FRASCO } \\
\text { Cód. do estud o }+\mathrm{N}^{\circ} \text { sequên cial } \\
(11 \mathrm{~d} \text { igitos })\end{array}$ & $\begin{array}{c}\text { Espécie } \\
\text { (1) }\end{array}$ & $\begin{array}{l}\text { Idade } \\
\text { (anos) }\end{array}$ & $\begin{array}{c}\mathrm{N}^{\circ} \mathrm{de} \\
\text { pariçōes }\end{array}$ & $\begin{array}{c}\text { Já } \\
\text { Abortou? } \\
\text { SIMI NÂOO }\end{array}$ & BRU. & $\begin{array}{l}\text { VACI } \\
\text { LEP. }\end{array}$ & $\begin{array}{r}\text { TAS (2) } \\
\text { IBR }\end{array}$ & BVD & $\underset{(-) \text { ou }(+)}{\text { AAT }}$ & $\begin{array}{l}\text { SAL } \\
\text { (Título) }\end{array}$ & $\begin{array}{l}\text { 2-MF } \\
\text { (Titulo) }\end{array}$ & $\begin{array}{c}\text { Resultado Final } \\
\text { (NEG) (INC) (POS) }\end{array}$ \\
\hline 1 & & & & & & & & & & & & & \\
\hline 2 & & & & & & & & & & & & & \\
\hline 3 & & & & & & & & & & & & & \\
\hline 4 & & & & & & & & & & & & & \\
\hline 5 & & & & & & & & & & & & & \\
\hline 6 & & & & & & & & & & & & & \\
\hline 7 & & & & & & & & & & & & & \\
\hline 8 & & & & & & & & & & & & & \\
\hline 9 & & & & & & & & & & & & & \\
\hline .0 & & & & & & & & & & & & & \\
\hline 11 & & & & & & & & & & & & & \\
\hline .2 & & & & & & & & & & & & & \\
\hline .3 & & & & & & & & & & & & & \\
\hline 4 & & & & & & & & & & & & & \\
\hline$[.6$ & & & & & & & & & & & & & \\
\hline
\end{tabular}

Colliges e indrocies pan preendinento lede tabeh

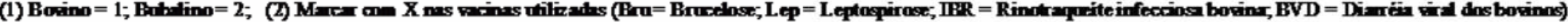

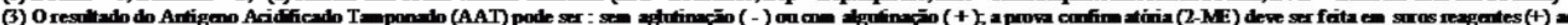

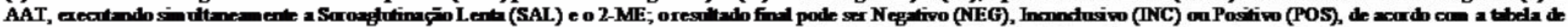

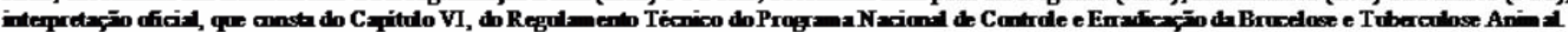

34 - RESULTADO FINAL - CLASSIFICAÇĀO DA PROPRIEDAD:

口NEGATIVA

口INOONCLUSIVA

$\square$ POSITIVA 